

\title{
Smart Sustainable Cities Assessment
}

\author{
Supervised by: \\ Professor Dr. Pedro da Costa Brito Cabral \\ NOVA Information Management School (NOVA IMS) \\ Universidade Nova de Lisboa \\ Lisboa, Portugal
}

Co-supervised by:

Professor Dr. Sven Casteleyn

Geospatial Technologies Laboratory

Universitat Jaume I

Castellon, Spain

Professor Dr. Edzer Pebesma

Institute of Geoinformatics

Westfälische Wilhelms-Universität

Munster, Germany

2019 
Copyright $(C)$ by

Adeoluwa Stephen Akande

All rights reserved 


\begin{abstract}
There has been an exponential growth of cities in the last decade. Rural to urban migration are occurring at an unprecedented level. This is partly because cities serve as hubs of innovation offering numerous economic opportunities. However, this growth comes with its unique challenges some of which include strained mobility, pollution, growth of slums etc. The "smart cities" concept aims to address this with increased efficiency using a unique combination of data and technology in every aspect of the city. Even though it is believed that the smart cities concept inherently incorporates sustainability or ultimately leads to a more sustainable city, not all smart city concepts are aligned with sustainability targets. In this research, we provide a more holistic view studying the relationship between a "smart city" and a "sustainable city". We conceptualised a framework to measure the connection between technology and environmental sustainability and categorised European cities based on this relationship. We provide a concise and clearer understanding of the drivers of the use of technology through the sharing economy to foster sustainability in cities by citizens. Using a weighting and meta-analysis of adoption theories, we laid the foundation for additional hypothesises which researchers can evaluate in future smart sustainable cities assessment studies and provided interesting insights for city councils and governments pushing for a citizen adoption of sustainable practices within their administrative boundaries. Lastly, we rank European capital cities based on how smart and sustainable they are using a composite index based on publicly available data. We also carried out a sensitivity analysis and validation study of our results.
\end{abstract}


Keywords: Smart Cities, Sustainable Cities, Clustering, Sharing economy, Environmental sustainability. 


\section{Original Contributions}

\section{$\underline{\text { Journal articles }}$}

- Akande, A., Cabral, P. and Casteleyn, S. (2019) 'Assessing the Gap between Technology and the Environmental Sustainability of European Cities', Information Systems Frontiers. doi: 10.1007/s10796-019-09903-3.

- Akande, A. et al. (2019) 'The Lisbon ranking for smart sustainable cities in Europe', Sustainable Cities and Society, 44, pp. 475-487. doi: https://doi.org/10.1016/j.scs.2018.10.009.

- Akande, A., Cabral, P. and Casteleyn, S. 'Understanding the sharing economy and its implication on sustainability in smart cities'. (Submitted to a top journal in the area of information systems).

\section{Conference papers}

- Akande, A. (2018). Smart Sustainable Cities assessment framework. In S. Vinkor, P. Porycek, N. Edelmann, \& O. Glassey (Eds.), Proceedings of the international Conference EGOV-CeDEM-ePart 2018 (pp. 287-294). Krems: Edition Donau-Universitat Krems. Retrieved from https://books.google.pt/books/about/Proceedings_of_the_International_Confere.htm I?id=NzVxDwAAQBAJ\&redir_esc $=y$

\section{Lead editor of Journal Special Issue}

- Akande, A. et al. (Eds.) (2018). Open Data for Open Cities (OD4OC): Reuse of open data through spatial analysis [Special issue]. Information, XX (4). https://www.mdpi.com/journal/information/special_issues/Open_Data_2018 


\section{Acknowledgements}

To God almighty, who kept the space-time continuum stable for long enough to have my PhD work completed.

To my lovely family, Temitayo, my wife, and Lucian, my little child, you are both my world.

To my parents and parent-in-laws, for their kind words, encouragement and frequent calls.

To Prof. Pedro Cabral, the main supervisor of this thesis, for all the guidance and mentorship.

To Prof. Sven Casteleyn, a co-supervisor of this thesis, for all the good advice to improve the quality of the articles that were published and help during my external semester in Castellon, Spain.

To all my colleagues who were kind enough to share their experience and skills with me: Fernando, Mijail, Marek, Sara and Albert.

To all of my friends who gave meaning to life outside work: Brian, Dami, Don, Jide, Yomi and others.

To the European Commission, for the financial support of the "Geoinformatics: Enabling Open Cities (GEO-C)" project within the Marie Skłodowska-Curie Actions, International Training Networks (ITN), and European Joint Doctorates (EJD). Grant Agreement number 642332 - GEO-C - H2020-MSCA-ITN-2014.

To all my sincere thanks. 


\section{Table of Contents}

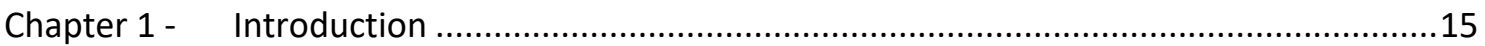

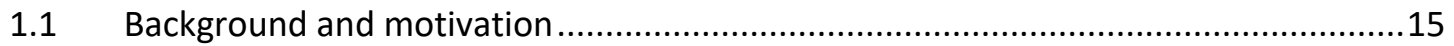

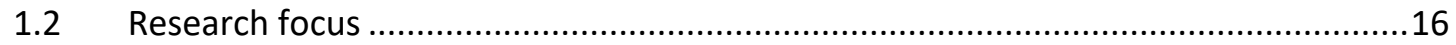

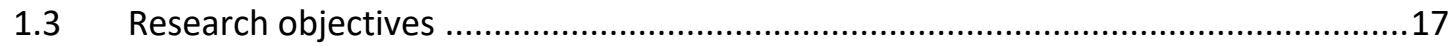

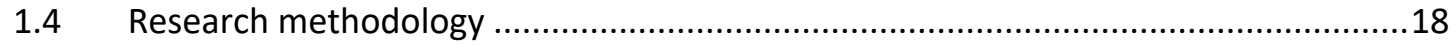

1.5 Study relevance and potential contributions .........................................................19

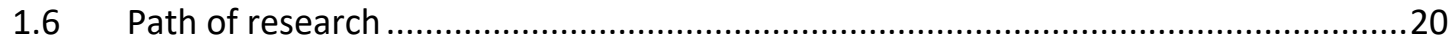

Chapter 2 - Assessing the gap between Technology and the Environmental Sustainability of

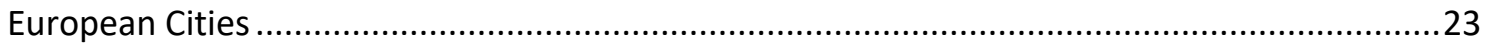

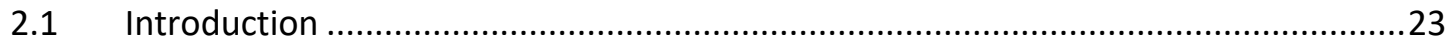

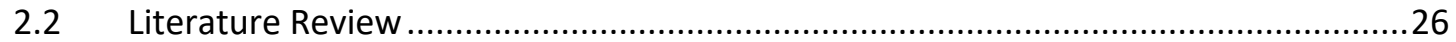

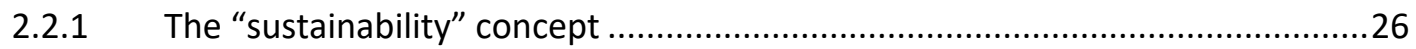

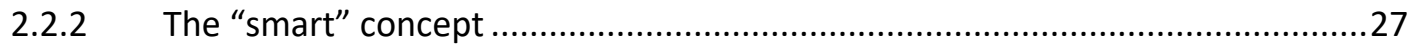

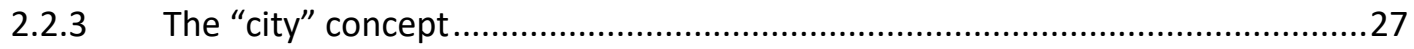

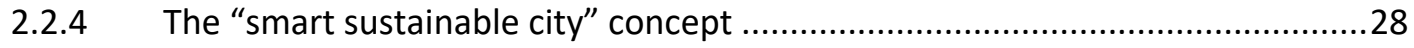

2.2.5 The link between ICT and environmental sustainability .................................28

2.3 Measuring the connection between ICT and environmental sustainability. ...............31

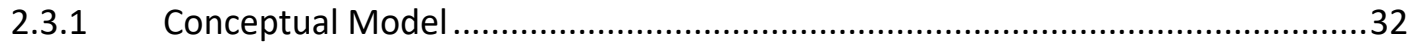

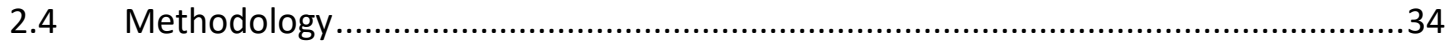

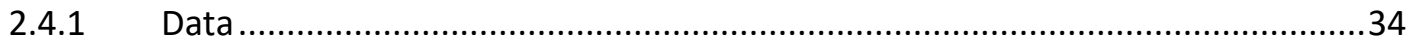

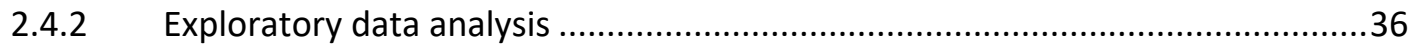

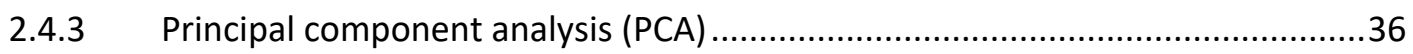

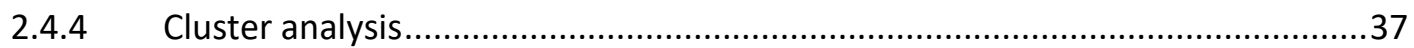

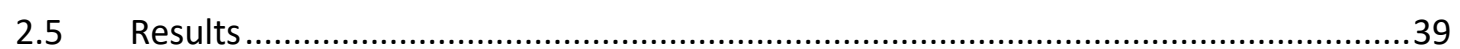

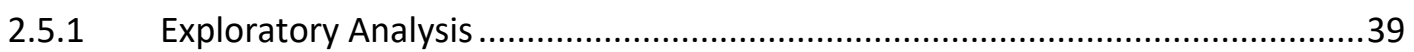

2.5.2 Principal Component Analysis ......................................................................

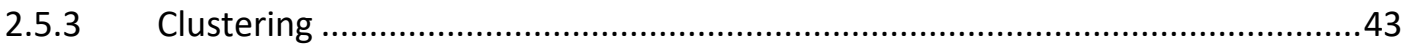

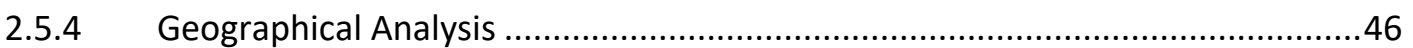

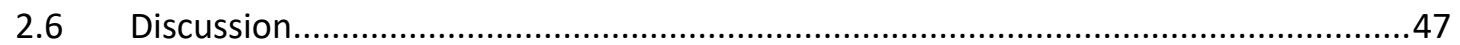

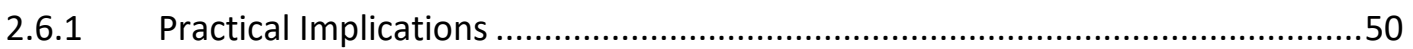

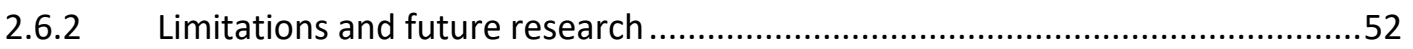

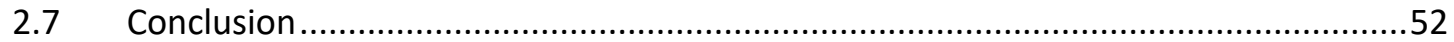


Chapter 3 - Understanding the sharing economy and its implication on sustainability in smart cities 54

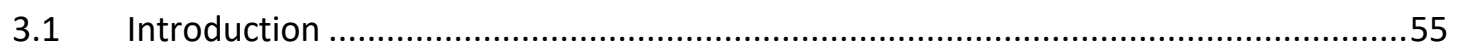

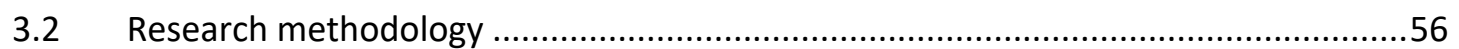

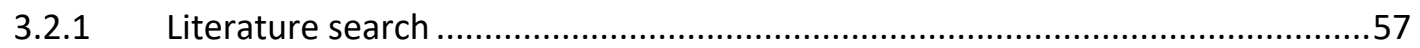

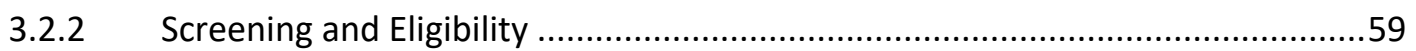

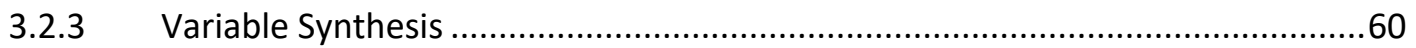

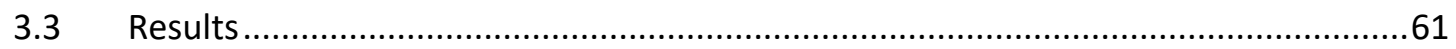

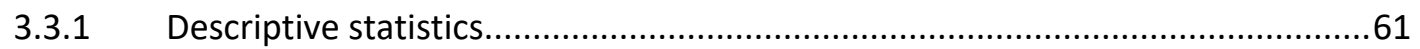

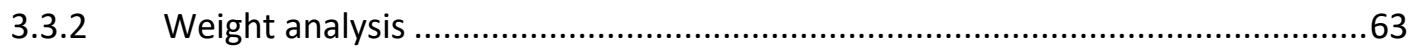

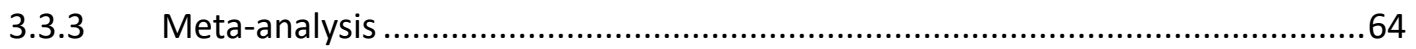

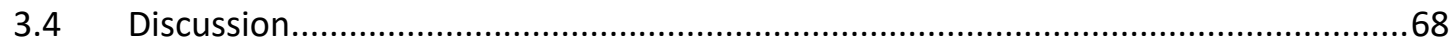

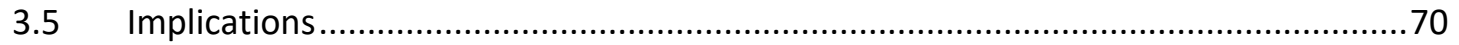

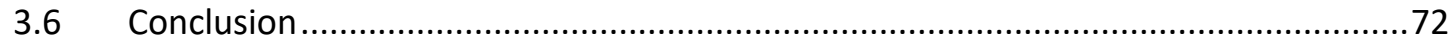

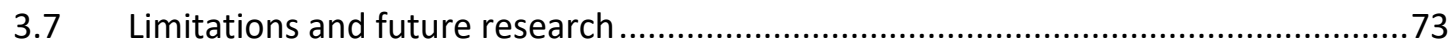

Chapter 4 - The Lisbon Ranking for Smart Sustainable Cities in Europe .................................74

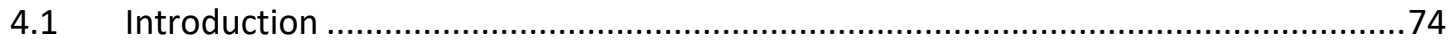

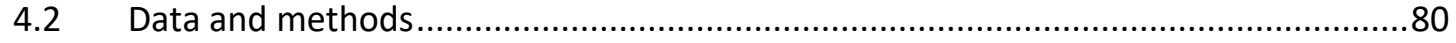

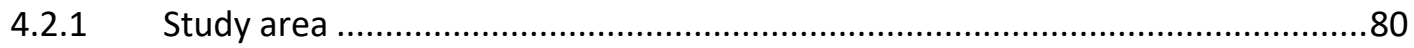

4.2.2 Data

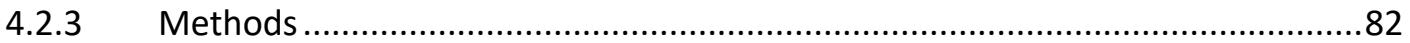

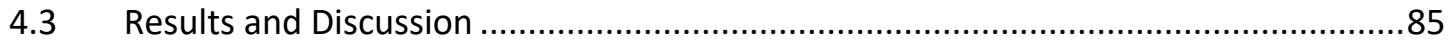

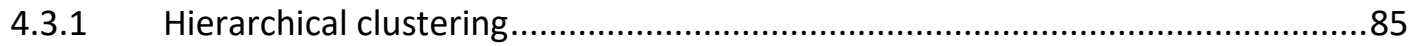

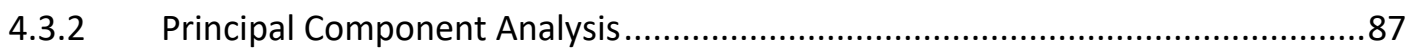

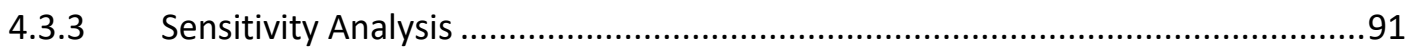

4.3.4 Rank score comparison with Gross Domestic Product (GDP) ............................93

4.3.5 Rank score comparison with geographical location.........................................94

4.3.6 Rank score comparison with size and population .............................................95

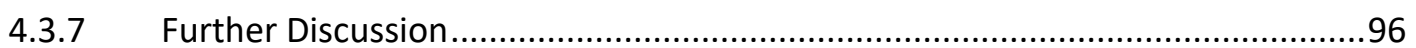

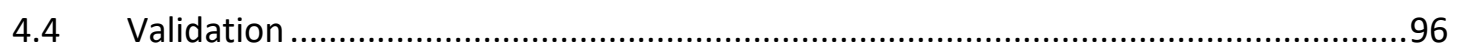

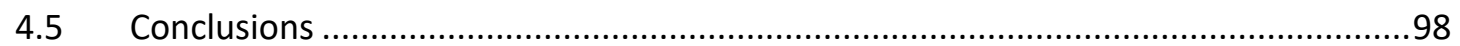

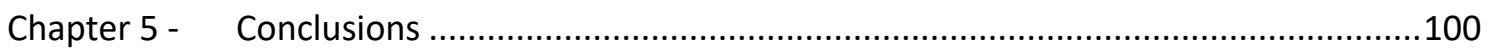

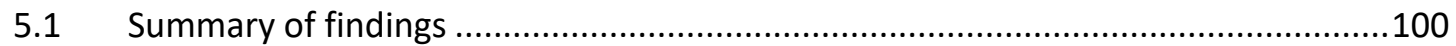

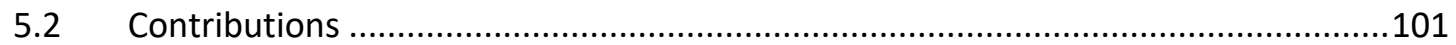

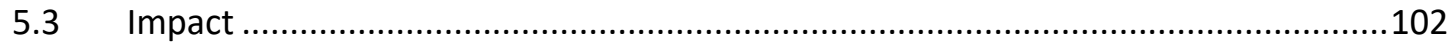




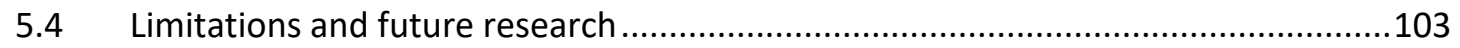

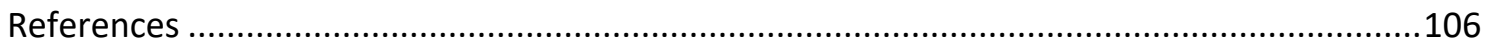

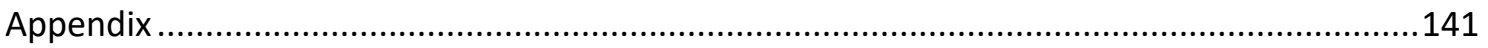

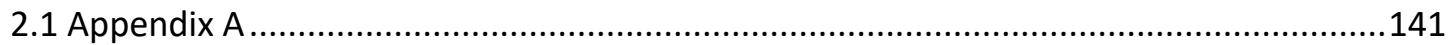

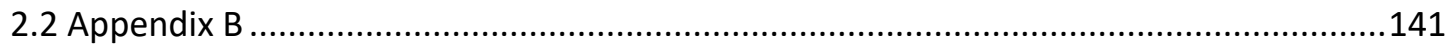

2.3 APPENDIX C

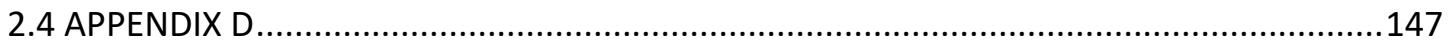

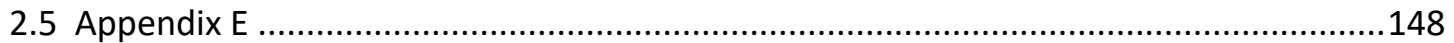

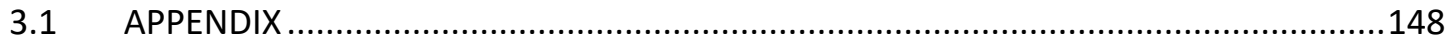

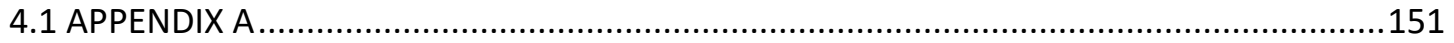

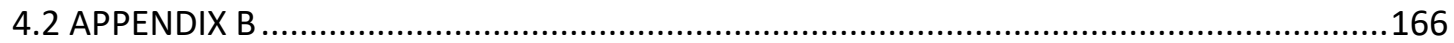




\section{List of Tables}

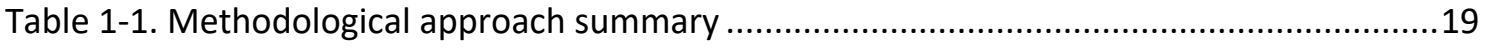

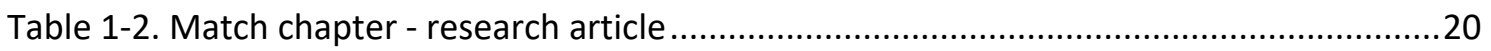

Table 2-1: Acronyms, descriptions, year and literature support of variables .............................35

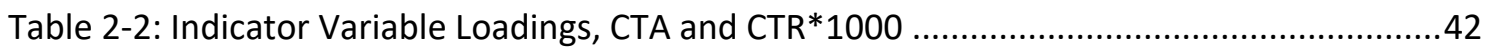

Table 3-1: Categories of keywords used to search literature database......................................58

Table 3-2: List of literature used for meta-analysis (ordered by publication year, author)........60

Table 3-3: Summary of independent - dependent variable weight analysis results (ordered by

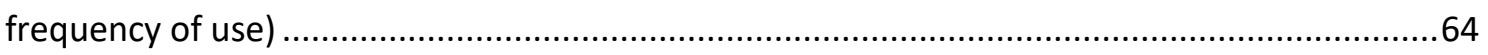

Table 3-4: Meta-analysis results (ordered by frequency) …........................................................65

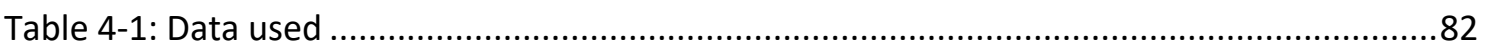

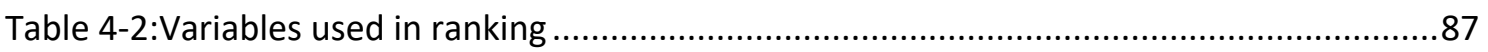

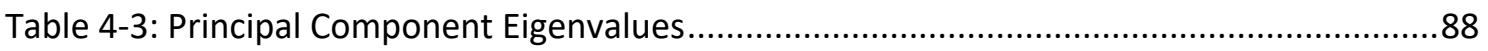

Table 4-4:Indicator Variable Loadings*1000, CTA, CTR*1000 and factor score*1000 ..............89

Table 4-5: Smart Sustainable City ranking and top three indicators that affects ranking ..........92

Table 4-6: Top 10 cities in four European ranking systems and their correlation with Smart

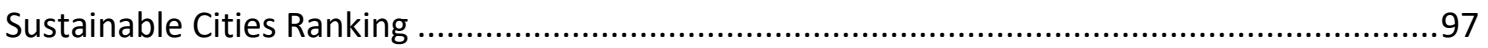

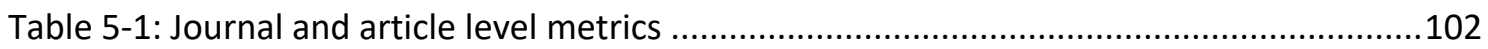




\section{List of Figures}

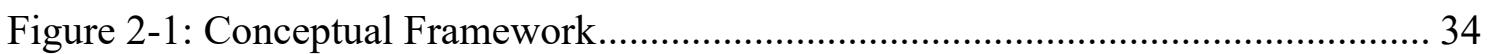

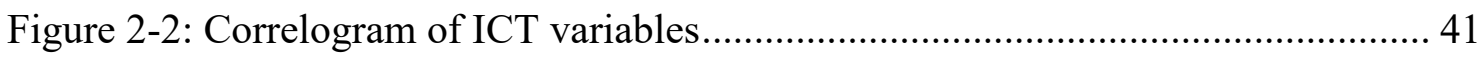

Figure 2-3: Cities ICT development coordinates on principal components ................... 43

Figure 2-4: Comparison of the r-squared values of the hierarchical methods................ 44

Figure 2-5: Average value of ICT development and $\mathrm{CO}_{2}$ emission in each cluster....... 45

Figure 2-6: European Map of its cities in terms of ICT and environmental sustainability

Figure 3-1: PRISMA data flow diagram for the systematic literature review (\# means 'number')

Figure 3-2: Number of respondents in the 22 withheld articles (by year)...................... 62

Figure 3-3: Spatial distribution of 8502 respondents in the 22 withheld articles........... 63

Figure 3-4: Forest plot of meta-analysis ordered by sample size ................................. 67

Figure 3-5: Model of drivers for the sharing economy resulting from weight analysis

and meta-analysis; $* * \mathrm{p}<0.05$

Figure 4-1: Visual representation of the UNECE-ITU Smart Sustainable Cities

Framework

Figure 4-2: Map showing EU 28 with their respective capital cities ........................... 81

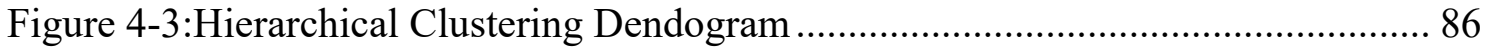

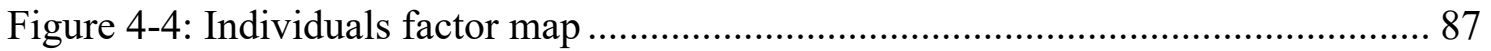

Figure 4-5: Bar chart showing rank scores of European capital cities .......................... 90

Figure 4-6: Smart Sustainable ranking of European capital cities ................................ 91

Figure 4-7:Scatterplot of the rank score and GDP of EU-28 capital cities .................... 95 


\section{List of abbreviations and acronyms}
Al
Artificial Intelligence
CRM
Customer Relation Management
CTA
Absolute Contribution
CTR
Relative Contribution
DT
Diffusion Theory
EU
European Union
EVF
Extended Valence Framework
EW
Equal Weighting
GDP
Gross Domestic Product
GHG
Green House Gases
ICT
Information Communication Technology
IPCC
Intergovernmental Panel on Climate Change
ISO
International Standards Organization
IT
Information Technology
ITU
International Telecommunication Union
KMO
Kaiser-Meyer-Olkin
NAM
Norm Activation Model
NOVA IMS
Nova Information Management School
PCA
Principal Component Analysis
PLS
Partial Least Squares
PRISMA
Preferred Reporting Items for Systematic Reviews and Meta-Analysis
RES
Renewable Energy Sources
SAS
Statistical Analysis System
SERVQUAL Service Quality
SMS
Short Message Service
SSC
Smart Sustainable City
TAC
Theory of Access-based Consumption
TAM
Technology Acceptance Model
TEA
Theory of Emerging Adulthood 
TPB

TRA

UNECE

VBNT

WPIIS

Theory of Planned Behaviour

Theory of Reasoned Action

United Nations Economic Commission for Europe

Values-Belief-Norms Theory

Working Party on Indicators for the Information Society 


\section{Chapter 1 - Introduction ${ }^{1}$}

\subsection{Background and motivation}

Cities are the bedrock of human civilization driving the industrial development of the world. They uniquely provide the density required for effective interaction and networking to generate wealth and improve living standards (Wolfe \& Bramwell, 2016). However, in recent times, many urban centres are seeing an exponential growth in population, creating a pattern of rapid urbanization (UN-HABITAT, 2011). It is projected that a huge percentage of the world's population will live in cities by 2030 (United Nations, 2014). This rapid growth of cities will create unusual sustainability challenges both on infrastructures, citizens and the environment (David, 2017). These in turn will affect the quality of life of residents of the city as well as the efficiency of its operations (Degbelo, Granell Granell, et al., 2016). Some of these challenges are already being addressed through the development of intelligent technologies (Castán, Martínez, Menchaca, \& Berrones, 2016). However, a lot of these smart solutions are not aligned with sustainability targets. For example, the explosive use of some of these intelligent technologies to improve liveability in cities will, among other things, lead to more energy demand which has an inevitable impact on climate (Chourabi et al., 2011). This problem is connected with the "Jevons Paradox", which states that "in the long term, an increase in efficiency in resource use will generate an increase in resource consumption rather than a decrease" (Giampietro \& Mayumi, 2018). Consequently, the concept of smart sustainable cities (SSC) was created (Ahvenniemi, Huovila, Pinto-Seppa, \& Airaksinen, 2017).

"A smart sustainable city is an innovative city that uses information and communication technologies (ICTs) and other means to improve quality of life, efficiency of urban operation and services, and competitiveness, while ensuring that it meets the needs of present and future generations with respect to economic, social, environmental as well as cultural aspects" (UNECE,

\footnotetext{
${ }^{1}$ Parts of the text of this chapter has been published as Akande, A. (2018). Smart Sustainable Cities assessment framework. In S. Vinkor, P. Porycek, N. Edelmann, \& O. Glassey (Eds.), Proceedings of the international Conference EGOV-CeDEM-ePart 2018 (pp. 287-294). Krems: Edition Donau-Universitat Krems. Retrieved from https://www.donau-uni.ac.at/imperia/md/content/bibliothek/folder/cedem2018.pdf\#page=301
} 
2015a). The term "Smart Sustainable Cities" only became popular around 2010 as a result of an effort to balance the "smart cities" rave of the moment with long term sustainability targets (AlNasrawi, Adams, \& El-Zaart, 2015). Bibri \& Krogstie (2017b) also appropriately describes this term as "a city that is supported by a pervasive presence and use of advanced ICT, which, in connection with various urban domains and systems and how these intricately interrelate, enables cities to become more sustainable and to provide citizens with a better quality of life". Smart sustainable cities as a concept exists at the intersection of the two broad concepts - smart cities and sustainable cities - and other concepts such as urban analytics, urbanization and urban growth, urban ICT and environmental sustainability (Höjer \& Wangel, 2015). It describes the holistic application of ICT and other smart technologies to provide mainstream solutions that provide a conducive environment for the increasing population in urban areas while guaranteeing the sustainability of the various dimensions of the urban domain. An example of when the "smart sustainable cities" concept is at work is when ICT is used to accumulate and analyse data on various urban systems and domains, and thereafter used to provide strategic insights for policy makers to make sustainable decisions to improve liveability in cities. From a synthesis of several definitions, the ITU defines a smart sustainable city as one that "uses ICT and other means to improve quality of life, efficiency of urban operation and services, and competitiveness, while ensuring it meets the needs of present and future generations with respect to economic, social and environmental aspects" (ITU, 2014).

\subsection{Research focus}

Various governments have set ambitious targets to transition their cities to being smart and sustainable using various initiatives and it is crucial that the performance of these ventures is measurable. One of the ways to go about this is to develop a framework that facilitates the tracking of the advancement of cities towards their smart-sustainable goals. The development of this framework demands an understanding of the various connecting factors linking a smart city model and a sustainable city and the relationship between them. In this research, using data at city level, we assess smart sustainable city performance by studying the link between smart city performance and sustainable city performance, evaluating drivers of the use of technology to promote the sustainable use of resources and ranking cities based on their joint smartness and sustainability performance. Specifically, we answer the following research questions: 
- What is the relationship between smart cities performance and sustainable cities performance?

There is an assumption among city managers that a drive in pushing the smartness of cities will ultimately lead to an improvement in sustainability and vice versa even though there is currently a large gap between smart city and sustainable city frameworks (Ahvenniemi et al., 2017; D’Auria, Tregua, \& Vallejo-Martos, 2018). We seek to clarify this using empirical data.

- What drives the adoption of the sharing economy to optimise the use of resources within cities?

Cities are huge inefficient engines consuming $75 \%$ of all natural resources while accounting for $50 \%$ of global waste even though they account for just 3\% of global land area and 55\% of global population (Neves, Krajewski, Jung, \& Bockemuehl, 2012). The sharing economy seeks to address this by using technology to address human needs and fairly distribute resources to reduce waste (Barnes \& Mattsson, 2017). There is still a need to understand what drives the individual adoption of the sharing economy.

- How well do cities in Europe perform in terms of their smartness and sustainability?

There is a growing demand for city assessment studies because cities are now seen as a leverage point in the quest for global sustainability due to the agglomeration of population in them. However, most city assessment studies are plagued by some methodological gaps, which we address in this dissertation and we rank cities based on how smart and sustainable they are.

\subsection{Research objectives}

The main goal of our research is to assess cities based on how smart and sustainable they are. However, to achieve that main goal, we divided our research in three different objectives, with each objective corresponding to a separate study presented as individual chapters in this dissertation.

\section{List of objectives:}

1. To evaluate the relationship between smart city performance and sustainable city performance in Europe. 
2. To identify the drivers, trends and synthesize the findings from existing research of the adoption of the sharing economy in fostering sustainability within cities.

3. To rank the performance of capital cities within Europe based on how smart and sustainable they are and explore the effect of psychological empowerment on the intention to use and recommend e-participation.

\subsection{Research methodology}

In order to address our research objectives, this dissertation is composed of three studies. The first and third study makes use of various multivariate data analytic technique, such as cluster analysis and Principal Component Analysis (PCA) (Akande, Cabral, \& Casteleyn, 2019; Akande, Cabral, Gomes, \& Casteleyn, 2019). The second study is a literature review that follows a quantitative approach to develop a weight and meta-analysis of the existing cross-sectional studies on the sharing economy.

We made used of city level secondary data on various indices for this research. The data were obtained from various authorities such as Eurostat, the International Telecommunication Union (ITU) and the Organization of Economic Cooperation and Development (OECD). This research was focused on European cities. The European Union (EU) supports the evolution of its cities to being smart and sustainable. This is exemplified by its conscious efforts to invest in various smart city initiatives. On the Market Place of the European Innovation Partnership on Smart Cities and Communities website, there are $34 \mathrm{EU}$ projects in different cities focused on the various sector components of smart cities ${ }^{2}$ (European Commission, 2016c). But beyond these smart city initiatives, the EU is also concerned with alleviating the various pressures that come along with urbanization as well as the sustainable development of its cities (European Commission, 2017).

Multivariate descriptive statistical analysis is well known for its ability to describe and analyse large data matrices. They are also known for their effectiveness in summarizing and reducing the dimensionality of a dataset (Husson, Lê, \& Pagès, 2010a). This makes them

\footnotetext{
${ }^{2}$ https://eu-smartcities.eu/eu-projects
} 
particularly suited for our research questions because of the large number of dimensions required to characterise cities and the need to synthesize our analysis for easy interpretation. Table 1.1 summarizes the research methods used for each study in this dissertation.

Table 1-1. Methodological approach summary

\begin{tabular}{lcccc}
\hline Objective & Method & Sample size & Focus & Instrument \\
\hline $\begin{array}{l}\text { Explore the relationship between smart } \\
\text { city and sustainable city performance }\end{array}$ & $\begin{array}{c}\text { Cluster } \\
\text { Analysis }\end{array}$ & 129 & Europe & Secondary data \\
\hline $\begin{array}{l}\text { Identify the drivers, trends and synthesize } \\
\text { the findings from existing literature }\end{array}$ & $\begin{array}{c}\text { Quantitative } \\
\text { literature } \\
\text { review }\end{array}$ & N/A & N/A & Existing literature \\
\hline $\begin{array}{l}\text { Ranks cities based on how smart and } \\
\text { sustainable they are }\end{array}$ & PCA & 28 & Europe & Secondary data \\
\hline
\end{tabular}

\subsection{Study relevance and potential contributions}

Although the concept of smart sustainable cities is rapidly gaining traction among urban planners and policy makers, academic literature on this concept is still scanty because the field is still in its infancy. However, a number of good articles on this subject has been published in reputable journals (Bibri \& Krogstie, 2017a; A Kramers et al., 2016; M Börjesson Rivera, Eriksson, \& Wangel, 2015). In contrast, there are quite a lot of academic articles on related concepts, such as smart cities and sustainable cities. Smart sustainable cities is a field of study that has evolved from viewing individual concepts such as smart cities and sustainable cities from a different perspective and an attempt to fuse and synthesize both concepts. This has sometimes led to the interchangeable use of the term "smart cities" and "sustainable cities" in conversations. In fact, Höjer \& Wangel (2015) argued that 'the smart city is the smart sustainable city and that the word "sustainable" can be left out without further ado'. However, when the term "smart city" is used in this context, sustainability is only assumed to be a by-product and we agree that it holds some potential for sustainability. There is need to develop robust indices to evaluate cities striving for both smart and sustainable urban development (Höjer \& Wangel, 2015). This is important because according to Bibri \& Krogstie (2017b), "without evaluative approaches and practices, smart sustainable cities risk becoming no more than labels, just like some sustainable urban forms becoming fallacies - without validated urban content or only for urban labelling". Developing 
these assessment methods will not only require a fundamental understanding of the conections between ICT and environmental sustainability in cities, but also an understanding of the drivers that operationalise these connections (Bibri \& Krogstie, 2017a). Existing literature on smart sustainable cities presents several research gaps to which this dissertation contibutes. First, there is still a knowledge gap on the joint interaction between smart city performance and sustainable city performance using a evaluative approach. Instead, the body of research focuses individually on either smart city performance or sustainable city performance. Second, there is still a lack of comparative study analysing how intelligent technology through adoption of the sharing economy can be used to optimise resource consumption and foster material sustainability in cities. Thirdly, there is still a lack of rankings of cities based on how smart and sustainable they are. Existing rankings like the European Smart Cities ranking (Giffinger et al., 2007), the European Green Capital Award (Gudmundsson, 2015), the European Green City Index (Siemens, 2009), the European Green Leaf Award (European Commission, 2016a), European Soot-free City Ranking (Reh, Fellermann, \& Duprez, 2013), Europe Quality of Life Index (Numbeo, 2016) and Urban Ecosystem Europe (Berrini \& Bono, 2007) are plagued by some methodlogical gaps which we address in this dissertation.

\subsection{Path of research}

This dissertation is made up of a collection of three research articles with each article corresponding to one of the chapters from 2 to 4 . Two of the three articles were peer-reviewed and are already published in top-tier journals (Akande, Cabral, \& Casteleyn, 2019; Akande, Cabral, Gomes, et al., 2019). The third article is still undergoing a peer-review process in a top-tier journal. It is important to state that the peer-review process significantly improved the quality of the research articles in this dissertation. These articles focus on exploring the relationship between the sustainability and smartness of cities, evaluating the drivers of the adoption of the sharing economy within a smart sustainable city and ranking of cities based on how smart and sustainable they are. Table 1.2 lists the articles and the corresponding chapter in the dissertation.

Table 1-2. Match chapter - research article 


\begin{tabular}{|c|c|c|c|c|c|c|}
\hline Chapter & Publication & Authors & $\begin{array}{c}\text { Contribution of each } \\
\text { author }\end{array}$ & Status & $\begin{array}{c}\text { Journal } \\
\text { Rank }\end{array}$ & Year \\
\hline 2 & $\begin{array}{l}\text { Assessing the gap } \\
\text { between Technology } \\
\text { and the } \\
\text { Environmental } \\
\text { Sustainability of } \\
\text { European Cities }\end{array}$ & \multirow{2}{*}{$\begin{array}{l}\text { Akande, A. } \\
\text { (AA), } \\
\text { Cabral, P. (PC), } \\
\text { Casteleyn, S. } \\
\text { (SC) }\end{array}$} & $\begin{array}{l}\text { Conceptualization, AA, PC; } \\
\text { Data curation, AA; } \\
\text { Investigation, AA; } \\
\text { Methodology, AA; Formal } \\
\text { analysis, AA, Visualization, } \\
\text { AA, PC; Writing - original } \\
\text { draft, AA; Writing - review } \\
\text { and editing, AA, PC, SC. }\end{array}$ & $\begin{array}{l}\text { Published in } \\
\text { Information } \\
\text { Systems } \\
\text { Frontiers }\end{array}$ & $\begin{array}{c}\text { Scopus - Q1 } \\
\text { ABS - } 3\end{array}$ & 2019 \\
\hline 3 & $\begin{array}{l}\text { Understanding the } \\
\text { sharing economy and } \\
\text { its implication on } \\
\text { sustainability in smart } \\
\text { cities }\end{array}$ & & $\begin{array}{l}\text { Conceptualization, AA, PC; } \\
\text { Data curation, AA; Merging } \\
\text { analysis, AA; Meta-analysis, } \\
\text { AA; Weight-analysis, AA; } \\
\text { Visualization, AA, PC, Writing } \\
\text { - original draft, AA; Writing - } \\
\text { review and editing, AA, PC, } \\
\text { SC. }\end{array}$ & $\begin{array}{l}\text { Under } \\
\text { review }\end{array}$ & $\mathrm{N} / \mathrm{A}$ & $\mathrm{N} / \mathrm{A}$ \\
\hline 4 & $\begin{array}{l}\text { The Lisbon Ranking } \\
\text { for Smart Sustainable } \\
\text { Cities in Europe }\end{array}$ & $\begin{array}{c}\text { Akande, A. } \\
\text { (AA), } \\
\text { Cabral, P. (PC), } \\
\text { Casteleyn, S. } \\
\text { (SC), Gomes, P } \\
\text { (PG) }\end{array}$ & $\begin{array}{l}\text { Conceptualization, AA, PC; } \\
\text { Data curation, AA; } \\
\text { Investigation, AA; } \\
\text { Methodology, AA; Formal } \\
\text { analysis, AA, Visualization, } \\
\text { AA, PC; Writing - original } \\
\text { draft, AA; Writing - review } \\
\text { and editing, AA, PC, SC, PG. }\end{array}$ & $\begin{array}{l}\text { Published in } \\
\text { Sustainable } \\
\text { Cities and } \\
\text { Society }\end{array}$ & $\begin{array}{c}\text { Scopus - Q1 } \\
\text { ABS - N/A }\end{array}$ & 2019 \\
\hline
\end{tabular}

The current chapter serves as an introductory section, including the background and motivation, research focus and objectives, methodology, path of research as well as the outline of the document.

Several smart city assessment frameworks strongly focus on ICT development without understanding its relationship with environmental sustainability performance (Ahvenniemi et al., 2017). In chapter two, we present a literature review on the concept of smart sustainable cities and its related concepts. Using data from cities in Europe, we also present a study on the micro-level interaction of Information and Communication Technology (ICT) and environmental sustainability. The need for a common strategy for achieving integrated smart, sustainable and inclusive growth at a European level is demonstrated.

An important use case of the smart sustainable city concept is the sharing economy which is a new economic model based on the peer-to-peer "activity of obtaining, giving, or sharing access to goods and services, coordinated through community-based online services" (Hamari, Sjöklint, 
\& Ukkonen, 2016). Given that it is an emerging concept, the adoption of the sharing economy has been slow. In chapter three, we present a study that makes use of weight and meta-analysis to determine the best drivers of the individual adoption of the sharing economy. The study presents the first attempt at advancing knowledge on the sharing economy by quantitatively synthesizing findings presented in previous literature.

An aspect of smart sustainable city assessment is city benchmarking and ranking. In chapter four, we ranked European capital cities based on how smart and sustainable they are, using a selection of indicators from a framework proposed by UNECE-ITU. The ranking is meant to attract attention and induce competition amongst cities. 


\title{
Chapter 2 - Assessing the gap between Technology and the Environmental Sustainability of European Cities
}

\begin{abstract}
$^{3}$
The growth of cities' population increased the interest in the opportunities and challenges that Information and Communication Technology (ICT) have on carbon footprint reduction, which fosters their environmental sustainability. Using Principal Component Analysis (PCA), six ICTrelated variables from European Union (EU) cities were combined into a single two-dimensional ICT index. Then, through cluster analysis, cities were clustered into four groups based on the ICT index and Carbon dioxide $\left(\mathrm{CO}_{2}\right)$ emissions. Using ICT as an indicator of smartness and $\mathrm{CO}_{2}$ emissions as an indicator of sustainability, we show that it is possible for a city to be smart but not sustainable and vice versa. Results also indicate that there is a gap between cities in northern Europe, which are the top performers in both categories, and cities in south-eastern Europe, which do not perform as well. The need for a common strategy for achieving integrated smart, sustainable and inclusive growth at a European level is demonstrated.
\end{abstract}

\subsection{Introduction}

The growth and development of an economy are intrinsically tied to its investment in the development, adoption and innovative use of modern technologies (European Commission, 2010a; Gouvea, Kapelianis, \& Kassicieh, 2017). The effective deployment and use of ICT can increase the rate of innovations in societies and economies (Gouvea et al., 2017). Furthermore, ICT is the binding element of the triple-helix dimension of sustainability; economy, environment and society (Gouvea et al., 2017; UNECE, 2015b).

The EU is taking a leading role in championing the push for a digital agenda for Europe, as the successful implementation of an ICT strategy is vital to the inclusive, equitable and sustainable economic development of Europe (Gouvea et al., 2017). This vision is contained in the

\footnotetext{
${ }^{3}$ The text from this chapter has been published as Akande, A., Cabral, P. and Casteleyn, S. (2019) 'Assessing the Gap between Technology and the Environmental Sustainability of European Cities', Information Systems Frontiers. doi: 10.1007/s10796-019-09903-3
} 
EU's strategy for smart, sustainable and resilient growth which articulates the EU's plan to achieve an inclusive, sustainable Europe and sets targets for reducing Green House Gases (GHG) by 2020 (European Commission, 2010a). Some of the targets include more energy-efficient ICT products and ICT-enabled energy-efficient buildings (OECD, 2009). A pivotal component of this plan is an urban agenda which aims to make cities attractive and sustainable through an integrated and coordinated approach (European Commission, 2010b).

The role played by ICT in the development of smart and sustainable cities globally cannot be over-emphasised (European Commission, 2010a). Cities are important to climate change and environmental sustainability discourse. This notion is because cities around the globe accommodate more than $70 \%$ of the global population and are responsible for about $75 \%$ of global energy use and energy-related GHG emissions (IPCC, 2014a; UN-HABITAT, 2011). According to Gouvea et al. (2017), "it is clear that without the diffusion and dissemination of ICT; countries cannot garner the full environmental benefits and the positive externalities that are generated as a result”. It is crucial to assess the relationship between ICT and environmental sustainability within cities in Europe, considering the serious environmental problems, the world is facing, and the interest of the EU in pursuing a digital agenda to make her cities smarter.

Previous studies have sought to understand the association between ICT and environmental sustainability using regression. Wu and Raghupathi (2018) performed a country-level study to examine this relationship and found out that ICT is positively correlated with sustainability and thus has the potential to promote environmental sustainability. Furthermore, Gouvea et al. (2017) reported a positive linear relationship between environmental sustainability and ICT in countries. However, Añón Higón et al. (2017) reported a contrasting result identifying a non-linear relationship between ICT and environmental sustainability in the shape of an inverted U-curve. The findings of these studies are based on the macro-level using country data and fail to account for the variations in this relationship from one country to another. One may ask if the relationship found is the same across all countries studied or if there are exceptions.

Furthermore, there is still a knowledge gap on the micro-level interaction of ICT and environmental sustainability. By "micro-level interaction", we mean studying this interaction using city level data as opposed to the country level data (macro-level) used in previous studies. Country level data are aggregations produced by averaging measurements across different units (cities, towns and villages) within the country. This differs from city level data which are used to 
infer city-level interaction of ICT and environmental sustainability, study within country variations and perform inter-city comparisons. This paper strives to contribute to this discourse by using a different approach to study this interaction on a micro-level using city data. Thus, this research aims to answer the following research question: is there a relationship between the ICT development and environmental sustainability of cities? A follow up to this question is: what is the nature of this relationship and is it consistent or does it vary across different cities? This question is vital to understand the concept of smart cities in relation to environmental sustainability. The concept of "smart city" and "sustainable city" is often used interchangeably in literature without a proper understanding of the relationship between them (Bibri \& Krogstie, 2017b).

Furthermore, several smart city assessment frameworks strongly focus on ICT development without understanding its relationship with environmental sustainability (Ahvenniemi et al., 2017). We intend to clarify this issue empirically by using data from cities. Specifically, we used data from the year 2016 of 129 cities in 28-member states of the EU (EU28). Our research approach is as follows:

1. Propose a framework to measure the ICT development of EU cities.

2. Calculate a single measure of ICT development (an ICT development score) based on the framework developed in objective 1.

3. Determine an appropriate measure of environmental sustainability in EU cities.

4. Establish the relationship between the ICT development and environmental sustainability of EU cities.

5. Cluster all cities in Europe based on their ICT and environmental sustainability relationship.

Our work makes significant contributions to the gaps identified in the literature. We present an exploratory analysis of the relationship between the smart cities concept and environmental sustainability using data on 129 cities within the EU. In the context of this paper, the smart cities concept is viewed from the perspective of ICT development within a city and is measured using six ICT indicators, while environmental sustainability is proxied using the GHG emissions of cities. Furthermore, we contribute to understanding the role different dimensions of ICT development play in urbanisation and environmental sustainability. This study yields valuable insights for policymakers in the urban domain on the dynamics of different levels of ICT development and its relationship to environmental sustainability for different cities within the EU. 
The rest of this article is structured as follows: In Section 2, we conduct a literature review of key concepts related to this study; in Section 3, we present the framework to measure the connection between ICT and environmental sustainability; in Section 4, we present our data and methodology; Section 5 shows the results of our analysis; Section 6 discusses the results obtained presenting the implications and limitations of the paper as well as possible future work; and Section 7 presents the conclusions.

\subsection{Literature Review}

We delve into the literature to further understand and contextualise the "sustainability", "smart" and "city" concepts within the scope of our study.

\subsubsection{The "sustainability" concept}

Sustainability is often used in literature with reference to development to connote the act of balancing the pace of development with the number of resources required to achieve such a pace. Environmental sustainability can be traced back to the $18^{\text {th }}$ century when Carl von Clausewitz postulated that we should not be cutting down trees at a rate higher than that at which they are replaced (von Clausewitz, 2009). This postulation is the underlying principle of environmental sustainability: using the earth's resources faster than it is being replenished. This unsustainable use of the earth's resources to meet man's immediate needs has resulted in, among other things, an increase in the amount of $\mathrm{CO}_{2}$ in the atmosphere. An increase in atmospheric $\mathrm{CO}_{2}$ will, in turn, lead to the warming of our planet precipitating the risk of flooding, drought and an increase in natural disasters among other things (IPCC, 2018).

The concept of sustainability was first introduced to the urban domain in the early 1990s (Wheeler $\&$ Timothy, 2014). It was born out of a realisation of the risks that urban development poses to the environment which may lead to a perilous future (Bibri \& Krogstie, 2017b). According to Bibri and Krogstie (2017a), urban sustainability is "a desired state in which urban society strives for achieving a balance between environmental protection and integration, economic development and regeneration, and social equity and justice within cities as long-term goals through the strategic process of sustainable urban development as a desired trajectory". This definition is supported in 
the various literature which hinges sustainable development on three components; economy, environment and society (Jenks \& Jones, 2008; UNECE, 2015a).

\subsubsection{The "smart" concept}

The word "smart" has been used in several contexts in literature. However, it has been most used to refer to the application of ICT in the creation and management of products, services and systems (Nasrawi, Adams, \& El-Zaart, 2016). Its use in the urban domain can be traced back to the 1960s when the term "cybernetically planned cities" was used to refer to the use of ICT to plan urban environments (Gabrys, 2014). Since then, the word "smart" has been more uniformly used when referring to the use of ICT in the urban domain (Mustafa \& Kar, 2017). This practice ranges from understanding how cities function to improve their management, to offering services that improve the quality of life of citizens (Bibri \& Krogstie, 2017b; Rana et al., 2018). It has also improved other aspects of society connected to the urban domain such as education, communication, financial services and commerce (Cruz-Jesus, Oliveira, Bacao, \& Irani, 2017).

\subsubsection{The "city" concept}

According to Nasrawi et al. (2016), a city "is a place where people live that is larger or more important than a town". Its importance is due to the size of its population and the concentration of economic opportunities in them. From being smaller in size, they have rapidly grown because of urbanisation, and this has profound consequences on global sustainability. This research views cities as an object to which the "smart" concept and "sustainability" concept can be linked. In literature, there are two research strands related to cities and sustainability. One focuses on the impact of urbanisation and cities on sustainable development and the other focuses on how we can make cities more sustainable. One of the ways to make cities more sustainable is through the proper deployment of ICT in its various forms to monitor, understand, probe and plan cities. This approach has come to be known as the "smart sustainable city concept" by academia and the international community (Bibri \& Krogstie, 2017b). 


\subsubsection{The "smart sustainable city" concept}

Smart sustainable cities is a concept that fuses environmental sustainability, urbanisation and technological development (Höjer \& Wangel, 2015). It is a term that combines smart city and sustainable city, used to describe the use of ICT to enable cities to become more sustainable and to improve the quality of life of citizens (Akande, Cabral, Gomes, et al., 2019; Al-Nasrawi et al., 2015; Bibri \& Krogstie, 2017a; Höjer \& Wangel, 2015; A Kramers et al., 2016). The use of ICT in urban systems and domains includes but is not limited to "sensing, collecting, storing, coordinating, integrating, processing, analysing, synthesising, manipulating, modelling, simulating, managing, exchanging, and sharing data for the purpose of monitoring, understanding, probing and planning modern cities to achieve particular goals" (Bibri \& Krogstie, 2017b). The emerging field of smart sustainable cities is gradually developing into two main research strands; one that focuses on the effects and implication of ICT use and infrastructure on urban sustainability (Anna Kramers et al. 2014; Nasrawi et al. 2016) and another that deals with the development of integrated frameworks to measure the combined smartness and sustainability of cities (Ahvenniemi et al. 2017). This research is line with the first strand, focusing on the relationship between ICT and environmental sustainability in cities.

\subsubsection{The link between ICT and environmental sustainability}

It is worthy to note that, despite the obvious link between ICT and environmental outcome, there are no statistical indicators that directly measure this link (OECD, 2009). Research exploring the impact of ICT and the information society on environmental sustainability only began appearing in literature in the year 2000 (Ospina \& Heeks, 2010). A survey of this literature reveals three interrelated research strands: sustainable development, mitigation and adaptation.

The first strand of research in this field explores a global perspective to link sustainable development and the information society. These researches discussed the potential effect the rapid expansion of ICT could have on the achievement of the Millennium Development Goals and environmental sustainability. Slob and van Lieshout (2002) studied the trends of ICT development and their implication on sustainability. Although they found that ICT has stimulated economic growth, they were not certain of the effect the rapid developments in ICT will cause on the environment and called for more research into technology-environment interactions. Furthermore, 
(Willard \& Halder, 2003) considered the implication of Information Society on sustainable development, highlighting the consequences environmental information systems, e-commerce and e-participation will have on sustainability from a broad perspective.

The second research strand of literature found focuses on the role ICT applications play in the reduction of $\mathrm{CO}_{2}$ emission. Here, the International Telecommunications Union plays a prominent role identifying the direct, indirect and systematic effects of ICT on $\mathrm{CO}_{2}$ emission and recommending policies and activities aimed at reducing the adverse effects and promoting the positive effects (ITU, 2008). It focuses on how the use of ICT can affect the environment in developed countries. For example, how the use of video conferencing instead of travelling can reduce the carbon footprint of the user or the use of e-mails instead of sending a postal mail in paper form (S. J. Wu \& Raghupathi, 2018). Literature here focuses on the opportunities posed by ICT to reduce $\mathrm{CO}_{2}$ emission generated by energy consumption (ITU, 2009), travel and mobility (Sustainable Development Commission, 2010) and industries (Mingay \& Pamlin, 2008).

The third strand of research explores how ICT can play a role in climate change adaptation issues in developing regions because these are most vulnerable to the effect of increased $\mathrm{CO}_{2}$ emission. This research strand examines how ICT can be used as a tool to foster innovation and involve all stakeholders in climate change strategies (Ospina \& Heeks, 2010). This is exemplified by researches on poverty reduction and environmental protection in Kenya (Mungai, 2005) and the use of SMS to report air pollution in the Philippines (Dongtotsang \& Sagun, 2006).

Of these three strands, our research falls within the second as we explore how to exploit this relationship and apply it within the context of cities and urbanisation (Yi \& Thomas, 2007).

ICT products and services are playing an essential role in improving the sustainability and liveability of cities. These products and services range from the new wave of computing such as big data analytics, Internet of Things (IoT) and Artificial Intelligence (AI) to ICT-enabled applications such as eCommerce, eBanking, eHealth, eLearning, and e-mail (Bibri \& Krogstie, 2017b; Cruz-Jesus et al., 2017; Pappas, Mikalef, Giannakos, \& Krogstie, 2018). They enable new sustainable ways of doing business and providing services in what is known as "Digital Transformation" (Pappas et al., 2018; A. Venkatesh, 2008). Furthermore, when combined with egovernment, these e-services can facilitate the transition of society into "digital nations" (A. Kar et al., 2017). Most importantly, they promote dematerialisation which has implications for the environment. Big data generated from various IoT technology gives businesses an insight into how 
their products and services are affecting the environment providing them with an opportunity to help decarbonise the global economy (Mikalef, Pappas, Krogstie, \& Giannakos, 2017). Furthermore, ICT gives businesses a competitive advantage via eCommerce (Gorla, Chiravuri, \& Chinta, 2017; Guo \& Gao, 2017), provides a cost- effective and flexible way to learn via eLearning (Joseph, Kar, \& Ilavarasan, 2017; Teo, Kim, \& Jiang, 2018), improves communication between medical personnel and their patients via eHealth (Maresova \& Klimova, 2017; Serrano, GarciaGuzman, Xydopoulos, \& Tarhini, 2018), increases the speed and flexibility of financial transaction via eBanking (Garín-Muñoz, López, Pérez-Amaral, Herguera, \& Valarezo, 2018) and reduces the cost of communication via e-mail (Gouvea et al., 2017). Overall, the ICT services highlighted above have reduced the need to commute and are inherently connected with environmental sustainability.

There are various studies on the connection between ICT, urbanisation and sustainability. Using ideas proposed by Giffinger et al. (2007), Bifulco et al. (2016) studied the roles of ICT in improving sustainability within smart cities. Using the Network Readiness Index of the World Economic Forum as a proxy for ICT and the Environmental Performance Index as a proxy for environmental sustainability, Gouvea et al. (2017) studied this link at a country level. This link was studied using ordinary least squares regression with ICT as the predictor variable. They found a positive and significant linear relationship between ICT and environmental sustainability. Their work was in line with Wu and Raghupathi (2018), who did an exploratory study on the strategic association between ICT and sustainability at country level using data from the World Bank Group. Wu and Raghupathi (2018) studied this relationship using multiple linear regression with five ICT factors derived from averaging various ICT measurements as explanatory variables. They found that ICT factors are positively associated with sustainability. However, Añón Higón et al. (2017) using ordinary least squares regression, discovered that the relationship between ICT and $\mathrm{CO}_{2}$ emission is not linear but rather an "inverted U-shaped" at country-level. Watson et al. (2010) also discussed the role of ICT in improving energy efficiency and fostering changes that reduce the environmental impact of cities.

Despite the wealth of literature in analysing the relationship between ICT development and environmental sustainability across different countries from a broad perspective, this relationship is not yet fully understood at a micro-level. Hence, there is a need to take a comprehensive approach to understand the relationship between ICT solutions and environmental sustainability 
(Bibri \& Krogstie, 2017a, 2017b). Although Kramers et al. (2016) argue that it is difficult to determine the role of ICT in environmental sustainability because of the larger socio-technical system which encapsulates ICT, we believe that this complex relationship can be broken down by operationalising theoretical constructs and studying specific aspects of this relationship. A foundational step in deciphering this relationship is understanding how this relationship varies different cities at a micro-level.

\subsection{Measuring the connection between ICT and environmental sustainability.}

Measuring the link between ICT and environmental sustainability requires the use of indicators. The Organization for Economic Co-operation and Development (OECD) Working Party on Indicators for the Information Society (WPIIS) is the international body charged with the responsibility for setting international standards for ICT indicators, which it has been doing since 1997. Although there are existing information society / ICT indices which we could have made use of, these indices exist only at macro (national) level. Some of these indices include the IDC's Information Society Index (Karvalics, 2005), ICT development Index (ITU, 2005, 2017a) the International Telecommunications Union's (ITU) Digital Access Index and Digital Opportunity Index (ITU, 2005), the World Bank's Digital Adoption Index (World Bank Group, 2016), the United Nations Development Program's Technology Achievement Index and the Infostate Index (Huyer, Hafkin, Ertl, \& Dryburgh, 2005). These macro-level indices represent a country with a single index and fail to consider the individual differences within the cities in the country. For example, in line with Oni and Papazafeiropoulou's (2014) idea, we would expect that the characteristic of a capital city is different from other cities within the same country.

Furthermore, some of these existing ICT indices are opaque on their derivation methods, while others incorporate several indicators that are not relevant for our study (Taylor, 2016). This inconsistency implies that the methodological characteristics of existing ICT indices cannot be fully evaluated. The indicators included in these ICT indices reflect the purpose for which they were developed, which is not aligned with ours. Hence, we build our own index by analysing technologies which are relevant to the scope of our study, as opposed to making use of a generic index. The challenge with this approach is the unavailability of consistent data, relevant for this study, for all cities. We need to make a compromise between the number of variables to include in 
our study and the number of cities for which these data are consistently available. Cruz-Jesus et al. (2017) described this as making "a trade-off between the depth and the width of the analysis". If more variables are used, and fewer cities are included in our study, our findings may be narrow and limited to only the cities we have included, making it impossible to generalise our conclusions to other contexts. Conversely, if we include more cities and make use of fewer variables, our analysis may not fully capture the various dimensions of ICT development, and hence, we may arrive at misleading conclusions.

Lastly, the process of associating a weight to each variable used to build the ICT index can lead to unreliable results if subjectively done (Bruno, Esposito, Genovese, \& Gwebu, 2010). Some of the subjective approaches used in previous studies include the Equal Weighting approach (World Bank Group, 2016) and the participatory approach. The Equal Weighting approach assumes that all variable contributes equally to the index (OECD, 2008). However, this is not interesting because there is no empirical basis for this assumption. The participatory approach involves the use of principal stakeholders to assign weights based on their experience. Both approaches create indices without taking cognisance of the interrelationship between indicators. Having fully understood the opportunities and obstacles of building an ICT index from variables, we opted for the use of multivariate statistics to explore the suitability, underlying nature and structure of our data and used that information to assign weights and build an index. This approach takes care of the redundant variables included in our analysis as a result of the subjective selection of indicators. Furthermore, it provides an empirical basis for weighting by determining how the different indicators change in relation to each other and across European cities. Several authors have used this method in the past (Cruz-Jesus et al. 2012; Cuervo and Menéndez 2006; Vicente and López 2011).

\subsubsection{Conceptual Model}

We turn to the literature to build on previous theoretical work to help us develop a conceptual model and select appropriate indicators for analysis. The conceptual framework proposed by OECD for measuring the information society consists of the following interconnected modules: ICT supply, ICT Infrastructure, ICT demand, ICT products, information and electronic content and ICT in a broader context (OECD, 2005). Several researchers have adapted modules from this 
framework and used it to study the ICT impact relationship in different contexts such as economic development (Cruz-Jesus et al., 2017) and sustainable development (Azadnia, Zahedi, \& Pourabedy, 2017). Furthermore, building on the framework proposed by Berkhout and Hertin (2001) to study the demand side (users and uses) of ICT and its effect on the environmental sustainability, we sought to explore this link by including indicators that measure the infrastructure and pervasiveness of ICT in our study.

ICT demand entails the use of ICT goods or services by various groups and industries to carry out their activities efficiently. The European Commission's Digital Agenda for Europe clearly outlines the role of eservices and their importance to service delivery in connection with improving the quality of life of citizens (European Commission, 2014a). Specifically, eBanking, eLearning, e-mail and eHealth were listed as being "some of the most innovative and advanced online services" (European Commission, 2014a). The use of these services has been included as variables to outline the use of ICT by individuals within cities. Furthermore, we included the percentage of enterprises selling online to take cognisance of the pervasiveness of ICT among business units. This variable is an important indicator of dematerialisation and electronic commerce (Cruz-Jesus et al., 2012; OECD, 2009).

ICT infrastructure is the services on which the information society relies on for its proliferation (Rossy de Brito et al., 2018). We decided to include Broadband Internet per 100000 persons because of the importance of a broadband connection to access the Internet. Broadband Internet is increasingly becoming important because of the recent explosion of bandwidth-intensive applications such as online gaming, audio and video streaming (D. J. Kim \& Hwang, 2012). Broadband Internet per 100000 persons has been used by many authors to measure ICT development (Cruz-Jesus et al., 2017; OECD, 2009; Vicente \& López, 2011) Data on this variable are widely available with relatively long-time series. There are standardised methodologies and collection procedures of this data (OECD, 2009). This variable is included to measure the level of connectivity with regard to ICT infrastructure within cities (Cruz-Jesus et al., 2012).

In the domain of environmental sustainability, several authors have discussed the strong connection between environmental sustainability and GHG emission in cities (Owusu \& AsumaduSarkodie, 2016; Privitera, Palermo, Martinico, Fichera, \& Rosa, 2018). Although GHG comprises $\mathrm{CO}_{2}$, methane gas, nitrous oxide and fluorinated gases, $\mathrm{CO}_{2}$ is the primary pollutant accounting for about $80 \%$ of emissions (World Bank, 2007). $\mathrm{CO}_{2}$ emission originates from anthropogenic sources such as power generation, fossil fuel generation and use, construction and heating. Hence, 
we will be making use of $\mathrm{CO}_{2}$ as our leading indicator of environmental sustainability. As such, our conceptual framework is schematised in Figure 2-1. It is made up of two pillars (perspectives): technological development, measured by ICT development, and environmental sustainability, measured by GHG emission. The technological development pillar is divided into two dimensions: ICT demand, which measures the pervasiveness of ICT by characterizing its various users and uses, and ICT infrastructure, which measures the connectivity of the information society using broadband Internet. The environmental sustainability pillar is assessed as the environmental impact of $\mathrm{GHG}$ emission as measured by $\mathrm{CO}_{2}$ emissions.

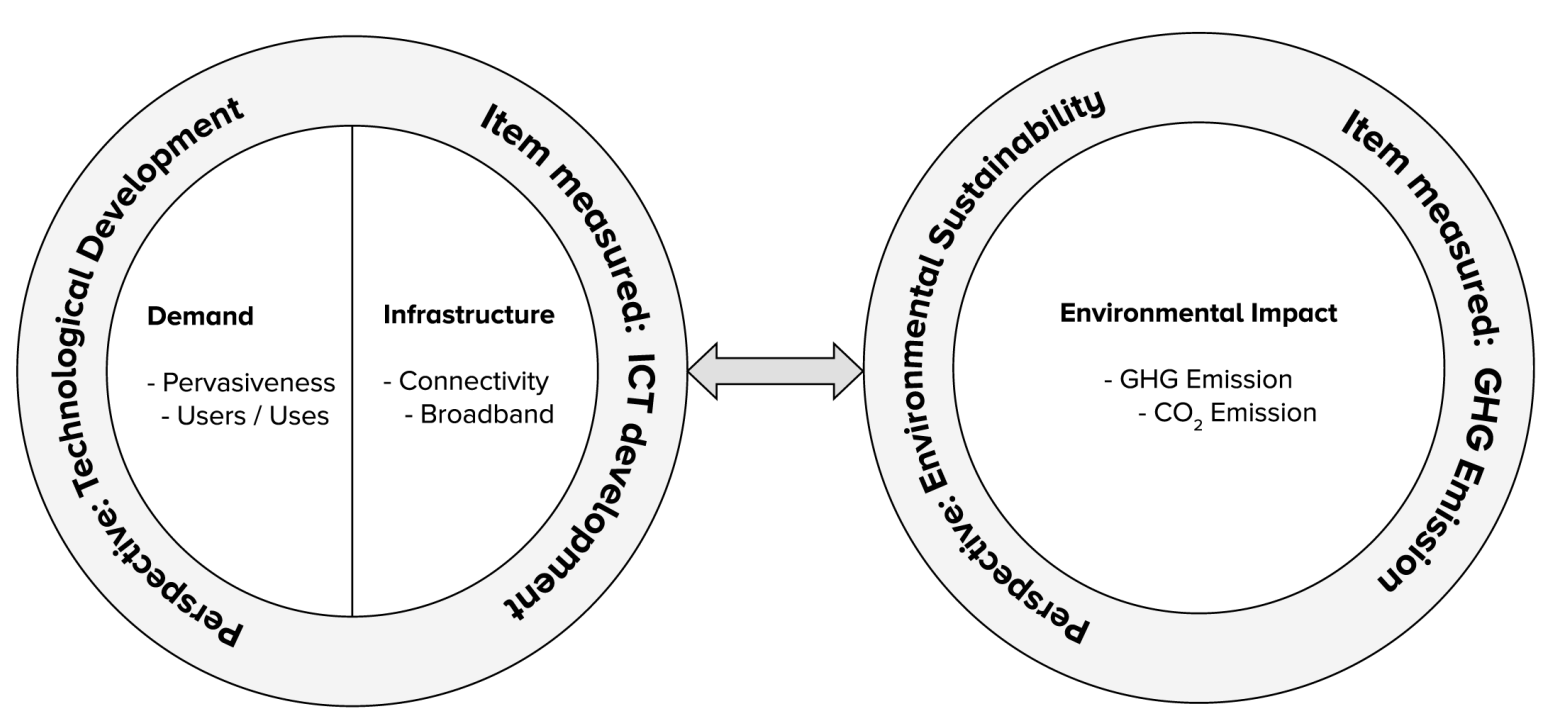

Figure 2-1: Conceptual Framework

\subsection{Methodology}

\subsubsection{Data}

Based on our theoretical framework as outlined in section 3.1, we have selected six variables to characterise the ICT development of cities and one variable to characterise the environmental sustainability of cities in Europe. These variables are listed in Table 2-1. The selected variables are in line 
with recommendations from the OECD, the European Commission and the Intergovernmental Panel on Climate Change (IPCC) (European Commission 2010a; OECD 2009). These indicators were selected based on literature and recommendations from the ITU, OECD, IPCC and the European Commission

$\mathrm{CO}_{2}$ emissions are a key indicator of contribution to climate change by cities. The parameter has been used in the past as a core indicator or environmental sustainability and climate change by the IPCC (IPCC, 2014b).

It is important to note that the variables listed in Table 2-1 are not all-inclusive of every factor that contributes to the ICT development and digital sustainability of a city. However, we believe they are adequate within the bounds of data availability limits to measure the ICT development and environmental sustainability within cities in Europe. Data for variables were sourced from the ITU, OECD and Eurostat as compiled by 2 thinknow City Benchmarking ${ }^{4}$. These secondary data sources were primarily chosen because of the following reasons:

- They are the most authoritative source of data about the availability of ICTs in households and usage of ICTs by individuals (Eurostat, 2016; ITU, 2017b).

- They ensure the quality and integrity of their data are not compromised by following an encompassing quality management approach (European Commission, 2017). Hence their data is suitable for research purposes.

- Their data have been used for previous similar researches including accessing the pattern between economic and digital development of countries (Cruz-Jesus et al., 2017), accessing the digital divide in Europe (Cruz-Jesus et al., 2012) and accessing factors driving GHG emission in Europe (Andrés \& Padilla, 2018).

Table 2-1: Acronyms, descriptions, year and literature support of variables

\begin{tabular}{|l|l|l|l|}
\hline Code & Variable & Year & Support \\
\hline BroIt & $\begin{array}{l}\text { Broadband Internet per 100000 } \\
\text { persons }\end{array}$ & 2017 & $\begin{array}{l}\text { (Cruz-Jesus et al., 2017; OECD, 2009; } \\
\text { Vicente \& López, 2011) }\end{array}$ \\
\hline eBank & $\begin{array}{l}\text { Percentage of population using } \\
\text { eBanking services }\end{array}$ & 2016 & $\begin{array}{l}\text { (Cruz-Jesus et al., 2012; European } \\
\text { Commission, 2014a) }\end{array}$ \\
\hline eLearn & $\begin{array}{l}\text { Percentage of population using } \\
\text { eLearning services }\end{array}$ & 2017 & (Çilan et al., 2009; Cruz-Jesus et al., 2012) \\
\hline
\end{tabular}

\footnotetext{
4 www.citybenchmarkingdata.com
} 


\begin{tabular}{|l|l|l|l|}
\hline e-mail & $\begin{array}{l}\text { Percentage of population using e- } \\
\text { mail }\end{array}$ & 2017 & $\begin{array}{l}\text { (Billón, Ezcurra, \& Lera-López, 2008; Bunz, } \\
\text { Curry, \& Voon, 2007; Cruz-Jesus et al., 2012; } \\
\text { Ferro, Helbig, \& Gil-Garcia, 2011) }\end{array}$ \\
\hline eHealth & $\begin{array}{l}\text { Percentage of population using the } \\
\text { Internet to seek health information }\end{array}$ & 2017 & $\begin{array}{l}\text { (Cruz-Jesus et al., 2012)(European } \\
\text { Commission, 2014a) }\end{array}$ \\
\hline eCom & $\begin{array}{l}\text { Percentage of enterprises selling } \\
\text { online }\end{array}$ & 2017 & $\begin{array}{l}\text { (Cruz-Jesus et al., 2012; Cuervo \& Menéndez, } \\
\text { 2006) }\end{array}$ \\
\hline $\mathrm{CO}_{2}$ & $\begin{array}{l}\mathrm{CO}_{2} \text { emission (Tonnes) } \\
\text { (Añón Higón et al., 2017; OECD, 2009; } \\
\text { UNECE, 2015b) }\end{array}$ \\
\hline
\end{tabular}

\subsubsection{Exploratory data analysis}

An exploratory analysis was done using numerical techniques that are statistically robust to understand the structure of our data. Summary statistics were calculated for each variable with the coefficient of asymmetry (skewness) and histograms used to check for the presence of outliers. Although, all variables under consideration are numerical, the range of values of eBank. eLearn, e-mail, eHealth and eCom differ from that of Brolt. While eBank, eLearn, e-mail, eHealth and eCom are expressed as percentages with a range of 100 , Brolt is expressed as a count with a range of 100000 . Hence, if used in their raw form, variables with higher numerical values will be assigned higher weights which would undermine the contribution of other variables in our analysis (A. Oliveira et al., 2017). We, therefore, normalised all explanatory variables using the minimum and maximum values of each respective variable transforming them to a scale between 0 and 1 before performing our hierarchical clustering tests (Akande, Costa, Mateu, \& Henriques, 2017). Furthermore, because PCA depends on the correlation structure of our data, Pearson's linear correlation coefficient was calculated to assess the existence of a linear relationship between our explanatory variables. The presence of a correlation between our explanatory variables will help us get meaningful results (Cruz-Jesus et al., 2017).

\subsubsection{Principal component analysis (PCA)}

PCA was used to transform our data from high dimensional space into a low-dimensional space (Spicer, 2005). However, before performing PCA, we checked the suitability of our dataset to be analysed by testing for certain PCA assumptions. Firstly, we tested the linear relationship between all variables using Pearson correlation coefficients. Secondly, we tested for the sampling adequacy of our dataset using the Kaiser-Meyer-Olkin (KMO) measure of sampling adequacy. Thirdly, we tested our data's suitability for reduction using Barlett's test of Sphericity (Cruz-Jesus et al., 2017). After that, we performed PCA on the 
six ICT variables to derive a single measure each of ICT development. PCA describes the variation in our data by a set of uncorrelated variables known as the principal components. The ICT variables produced six principal components. We then investigated if the first few components account for most of the variation in our original dataset to retain them and discard the remaining components. Selecting the number of principal components to retain is a fundamental decision, as choosing fewer principal components than required will produce an incomplete representation of results and selecting more principal components than necessary will result in the inclusion of noise in the results (Friesen, Seliske, \& Papadopoulos, 2016). Kaiser's criterion was used to determine the number of principal components to retain (Cruz-Jesus et al., 2017).

Variable eigenvectors were investigated to determine which variables contributed the most to each dimension to aid the interpretation of our PCA results. We made use of the contribution of each variable to the inertia explained by each axis (CTA) and the part of variance associated with each variable explained by each axis (CTR) (Koch, 2013) to determine the contributing variables to each axis. We made use of CTA and CTR because they can be used in interpreting our results statistically and geometrically (Abdi \& Williams, 2010).

Cronbach's Alpha was used to measure the internal consistency of each component (Cruz-Jesus et al., 2017). Finally, each component selected was weighted based on its variance in proportion to the total variance of all selected components. Variable loadings were multiplied by each selected principal component's weight and summed up to obtain a factor score. From the normalised table, we then calculated the coordinate of each city in relation to this factor score, multiplying the coordinate of vectors representing these cities by their respective factor score and summing them together (Friesen et al., 2016). This is more fully explained in Appendix B.

\subsubsection{Cluster analysis}

Cluster analysis was used as a robust method for identifying homogeneous groups of objects (in this case, cities) called "clusters" sharing similar ICT development / environmental sustainability characteristics in such a way that these groups "can achieve maximum internal homogeneity (within the cluster) and maximum external heterogeneity (between clusters)" (Brian Everitt, Landau, Leese, \& Stah, 2011; A. Oliveira et al., 2017). After developing a quantitative index to measure the ICT development of cities in Europe using PCA, we made use of cluster analysis to create homogenous groups of cities based on this 
index and the amount of $\mathrm{CO}_{2}$ emission in each city. We made use of a hybrid clustering approach, combining both hierarchical clustering method and partitioning method (Kumar et al., 2014). Hierarchical clustering was done to determine the number of clusters to extract since we had no prior information about the number of clusters to group the cities (Balcan \& Gupta, 2014). In hierarchical clustering, the structure of our data determines the number of clusters at each hierarchy. We also made use of the centroids of the selected clusters in the hierarchical clustering as seeds for the partitioning clustering method. The basic algorithms for hierarchical clustering can be described as follows:

1. There are $\mathrm{N}$ objects to group

2. We find the closest two points and merge them into a new point

3. We compute the similarity (distance) between this new point and the remaining points.

4. Iterate through steps 2 and 3 until there is only one point remaining.

The hierarchical algorithm and distance measurement used determines the quality of clusters obtained (Leisch, 2006). We made a comparison of the cluster solutions obtained by using different hierarchical clustering algorithms. These include centroid, Ward's method, average-linkage, single-linkage and complete-linkage method. Each of these methods was evaluated using its RSquared $\left(\mathrm{R}^{2}\right)$ value and the method with the highest $\mathrm{R}^{2}$ value was selected. The $\mathrm{R}$-squared value is a measure of the proportion of the total variance that is retained in each solution (see Appendix A). The selected hierarchical algorithm was thereafter tested using different distance measurement including Euclidean distance, squared Euclidean distance, Minkowsky and city-block distance (Brian Everitt et al., 2011). Each of these distance measures gave similar results. The result of the best hierarchical clustering algorithm was visualised using a dendrogram (also known as a binary tree) which provides a visual depiction of the formation path of the clusters (Salah, Turki, \& AlOthman, 2012).

$\mathrm{K}$-means clustering algorithm requires that the number of clusters, $\mathrm{K}$, be specified before applying the algorithm. To determine the number of clusters to use from the hierarchical clustering, we made a visual comparison of the number of clusters and the distance value at which individuals agglomerate to form a group (Cabral, Sousa, Mendes, \& de Carvalho, 2017). The dendrogram was thereafter "cut" at the appropriate number of clusters level. The centroids of each cluster were used to generate initial seeds for the partitioning clustering methods (k-means). The k-means algorithm is also implemented in four steps:

1. Partition objects into k non-empty subsets 
2. Calculate initial seeds as the centroid of the cluster of the current partition.

3. Assign each object to the cluster that has the closest centroid

4. Iterate through steps 2 and 3 until the centroid no longer moves.

This two-step approach is guaranteed to generate reliable results (Brian Everitt et al., 2011). The mean of the ICT index and $\mathrm{CO}_{2}$ emission (previously normalised) were computed within each final cluster to profile each city, allowing us to formulate a hypothesis about the distribution of the association between ICT and $\mathrm{CO}_{2}$ among cities in Europe.

Furthermore, we sought to find out if the relationship between ICT development and environmental sustainability and the geographical location of each city is correlated using Global Moran's I spatial autocorrelation (Gutiérrez, García-Palomares, Romanillos, \& Salas-Olmedo, 2017).

Choropleth maps to visualise our results were designed in ArcMap, and all other statistical analyses were carried out in R (B. Everitt \& Hothorn, 2006) and SAS (Der \& Everitt, 2010).

\subsection{Results}

\subsubsection{Exploratory Analysis}

A total of 129 European cities for which we were able to obtain data were analysed for all variables under consideration. The average percentage of the population using eBanking, eHealth, e-mail and eCommerce services are less than the median of each variable. Hence, the asymmetry of the distribution of each of these variables can be inferred as being negatively skewed. Conversely, the mean percentage of the population using eLearning services, the mean number of broadband Internet per 100000 persons and mean amount of $\mathrm{CO}_{2}$ emission is more than the average of each variable making the asymmetry of the distribution of each variable positively skewed. Further exploration of the coefficient of asymmetry and histogram of each variable showed that the variables had an absolute skewness value close to zero and did not need to be transformed (Aesaert, Voogt, Kuiper, \& van Braak, 2017). It is interesting to note that while only 5\% of the population uses eBanking service, and $42 \%$ of the population uses e-mail in Timisoara (Romania), being the lowest among the cities under consideration, Copenhagen (Denmark) has the highest values in both categories with $93 \%$ of its population using eBanking service and 97\% using e-mail. 
Timisoara (Romania) also has the lowest percentage of people using the Internet for eCommerce related activities with a value of $7 \%$. The highest percentage of a city's population using the Internet for health-related and learning activities was in London with a value of $80 \%$ and $20 \%$ respectively. Although Dubrovnik (Croatia) had the lowest amount of $\mathrm{CO}_{2}$ emission, it also had the lowest percentage of people using the Internet for learning activities. Paris (France) had the highest amount of $\mathrm{CO}_{2}$ emission among all cities under consideration. Even though these results give us an idea of the relationship between ICT and environmental sustainability among cities in Europe, simple univariate statistics is not sufficient in clearly assessing this relationship because we are dealing with multiple variables. Hence, we make use of multivariate statistical techniques to analyse all seven variables.

The Correlogram of the explanatory ICT variables shown in Figure 2-2 shows that each variable has, at least, one statistically significant $(0.01)$ correlation coefficient of 0.55 with another variable. This illustration shows the presence of a linear relationship between all variables. Of particular interest is the relationship between the percentage of people using the Internet for Banking services and the number of people using e-mail which has a correlation value of 0.9 showing that they are extremely correlated. Conversely, the broadband Internet penetration has a low correlation value of 0.25 with the number of people using the Internet to seek health-related information. 


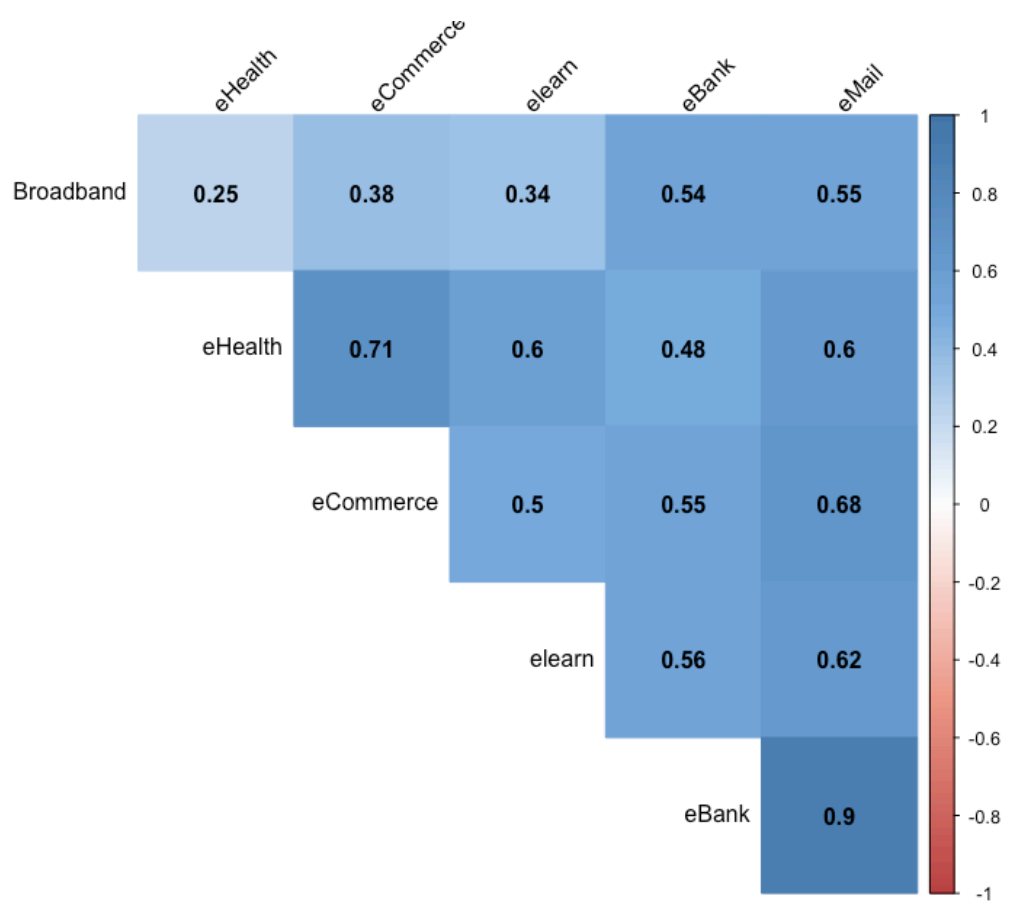

Figure 2-2: Correlogram of ICT variables

* Correlation is significant at 0.01 (pairwise two-sided)

\subsubsection{Principal Component Analysis}

We performed the KMO test to confirm the sampling adequacy of our data for PCA. The KMO for the overall dataset gave 0.77 , which means that our PCA will produce reliable results. We also executed Bartlett's test of sphericity to test the suitability of our data for reduction. This test gave us a chi-square value of 370.2 with a p-value less than 0.01 making it significant. Hence, we have adequate correlations between our variables for it to be reduced to a smaller number of components.

We carried out a PCA to reduce the complexity of the ICT variables. As indicated in our methodology, selecting the number of principal components to retain is an important decision. Following the Kaiser criterion, we selected the first two principal component which has a cumulative variance of $77 \%$ to represent our data (Table 2-2).

The first principal axis (PC1) has a variance of $60 \%$. Variables with CTA and CTR values higher than the average in an axis are considered to contribute significantly to that axis. These 
CTA and CTR values and their corresponding variables have been highlighted in green in Table 2-2. eBank, eHealth, e-mail, eCommerce and eLearn all contribute significantly to the inertia attributable to this axis (91.7\%). Furthermore, the second axis (PC2), which represents an additional $17 \%$ of the total variance, only has broadband contributing significantly to it $(50.2 \%)$. Overall, all explainable variables under consideration are very well represented on the two selected components. We obtained a Cronbach's Alpha value of 0.91 for the first component and 0.80 for the second component indicating an acceptable reliability of our results (Dunn, Baguley, \& Brunsden, 2014).

Table 2-2: Indicator Variable Loadings, CTA and CTR*1000

\begin{tabular}{|l|l|l|l|l|l|l|l|}
\hline Variables & PC1 & CTA & CTR & PC2 & CTA & CTR & Factor Score \\
\hline eBank & 0.85 & 19.88 & 717 & 0.28 & 7.80 & 077 & 0.72 \\
\hline eHealth & 0.75 & 15.44 & 557 & -0.52 & 27.33 & 270 & 0.47 \\
\hline e-mail & 0.93 & 23.93 & 863 & 0.16 & 2.45 & 024 & 0.76 \\
\hline eCommerce & 0.79 & 17.35 & 626 & -0.27 & 7.59 & 075 & 0.56 \\
\hline Broadband & 0.55 & 8.27 & 298 & 0.70 & 50.12 & 493 & 0.58 \\
\hline eLearn & 0.74 & 15.13 & 546 & -0.22 & 4.72 & 047 & 0.53 \\
\hline Variance (\%) & 60 & & 17 & \\
\hline Cumulative Variance (\%) & 60 & & & 77 & & \\
\hline Cronbach's $\alpha$ & & 0.91 & & & & 0.80 & \\
\hline
\end{tabular}

Figure 2-3 gives some interesting insights into the behaviour of cities in Europe with respect to their ICT development. From our analysis, their ICT development can be represented by two dimensions. The percentage of the population using the Internet to access banking services, healthrelated services, mail services, learning services and sell things online are strongly correlated with the first axis. Hence, this axis is related to the use of ICT and is therefore named ICT use. The second axis is only strongly correlated to broadband Internet access which is related to the availability of ICT infrastructure. Hence, we call the second axis ICT infrastructure. We computed the loading for each city and plotted it in Figure 2-3. An initial visual inspection of the plot reveals that except for certain capital cities, cities from the same country tend to have similar ICT infrastructure and use characteristics and are hence clustered together. Furthermore, we computed a factor score for each ICT variable as the weighted summation of the two principal loadings, multiplied it by their respective values in each city and summed it to obtain an ICT development index which can be found in Appendix C. Odense in Denmark is the best-ranked city for the two 
components together. It performs very well in terms of joint ICT use and infrastructure. Conversely, Timisoara in Romania is the least ICT developed city in the EU having a meagre ICT development score. These findings are consistent with Cruz-Jesus et al. (2012) who found Denmark to be the highest digitally developed country and Romania to be the least digitally developed country in the EU.

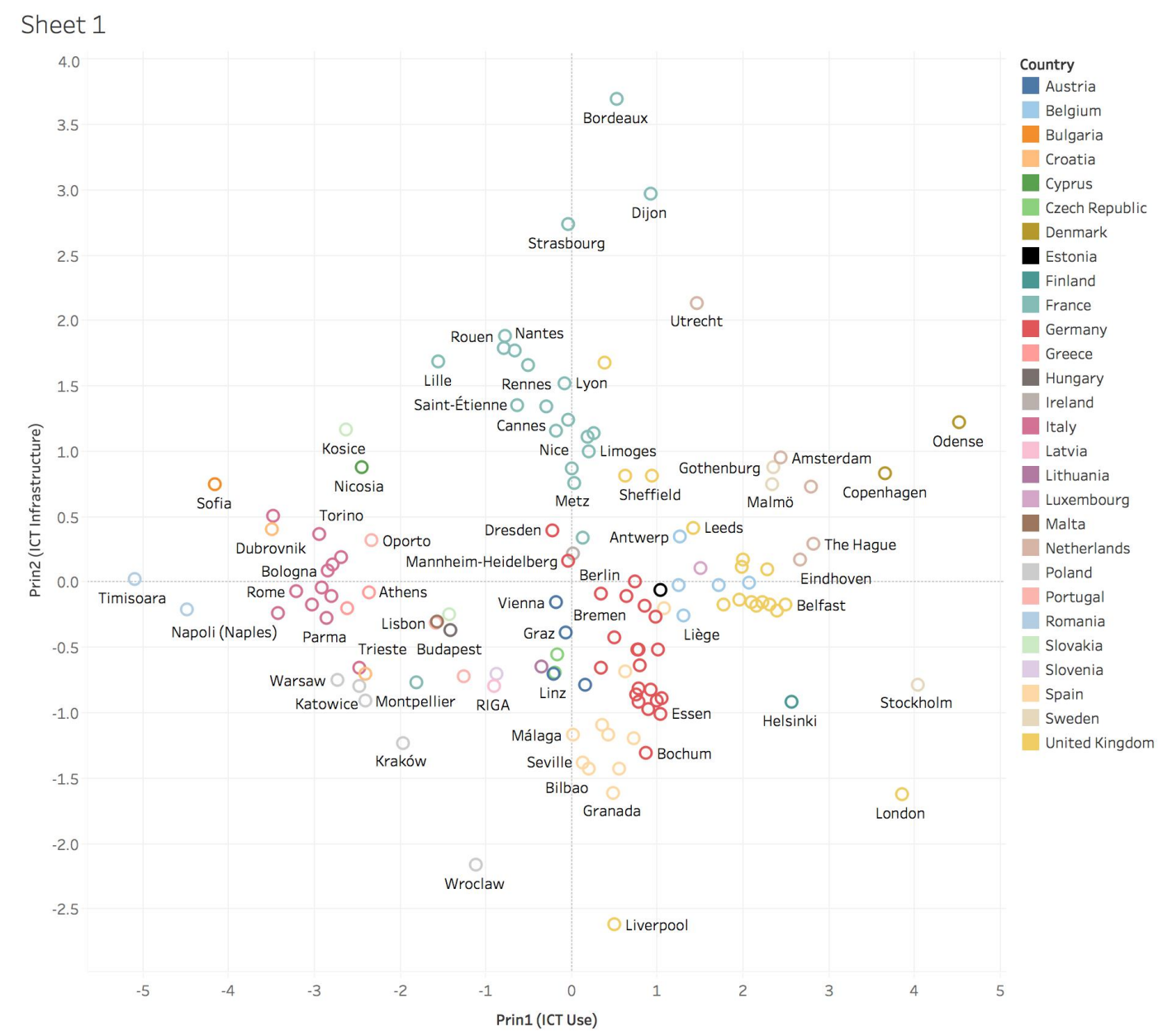

Figure 2-3: Cities ICT development coordinates on principal components

\subsubsection{Clustering}

We thereafter made a comparison of various hierarchical clustering aggregation algorithms using the ICT index and the amount of $\mathrm{CO}_{2}$ emission. The result of the comparison of the r-squared 
values of the various hierarchical methods considered is shown in Figure 2-4. Ward's aggregation criterion was chosen because it consistently had a high r-squared value which is a measure of the extent to which clusters are different from each other. Beyond this, Ward's aggregation method has been found to be the most robust of the other algorithms being able to handle noise efficiently (Balcan \& Gupta, 2014; Brian Everitt et al., 2011).

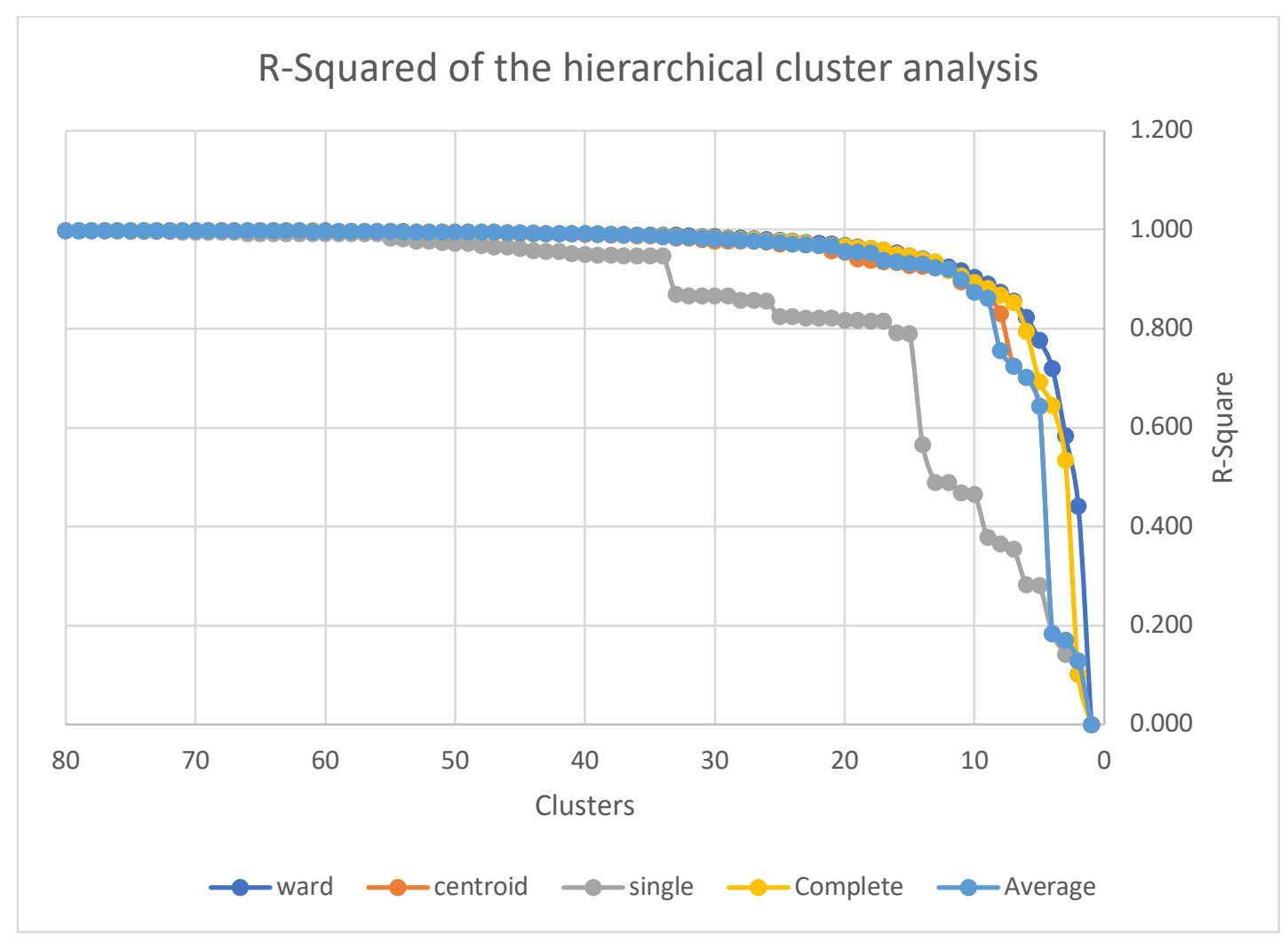

Figure 2-4: Comparison of the r-squared values of the hierarchical methods

Hierarchical clustering was thereafter done on the ICT index and $\mathrm{CO}_{2}$ emission using Ward's method. The result of this clustering is shown in the dendrogram in Appendix E, which shows the cities on the horizontal axis and the distance at which they agglomerate on the vertical axis. The dendrogram intuitively suggests the presence of four well-detached clusters. Hence, we cut our dendrogram at the four-cluster level opted for a four-cluster solution. The four clusters are shown with the red overlaid boxes representing the final clusters while the "cut" line is shown in blue. 
The centroid of the four clusters obtained from the hierarchical clustering was extracted and used as seeds to initialise the k-means clustering algorithm. We also obtained four clusters using this approach. From the analysis of the clusters, we found out that certain cities belong to a cluster with a high value of ICT index and low $\mathrm{CO}_{2}$ emission. Although this cluster is labelled cluster 3 in Figure 2-5, we call this cluster the "smart and sustainable" cluster. The average value of ICT development for cities in this cluster is 2.53 while the average $\mathrm{CO}_{2}$ emission for cities in this cluster is 6.39 Million Metric Tonnes. We also noticed that some other groups of cities have extremely low values of ICT development and a moderately low amount of $\mathrm{CO}_{2}$ emission. Hence, these cities form the "not smart but sustainable" group labelled as cluster 2 in Figure 2-5 because the average ICT development index is 0.99 while the average $\mathrm{CO}_{2}$ emission is 8.65 Million Metric Tonnes.

Furthermore, another group of cities have a moderate ICT development and extremely high $\mathrm{CO}_{2}$ emission. Hence, this group is called the "smart but not sustainable" cluster labelled as cluster 4 in Figure 2-5. Finally, we have a group of cities with small $\mathrm{CO}_{2}$ emission and an average ICT development, and hence we refer to the cities in this group as being "on the path of being smart and sustainable". It is labelled as cluster 1 in Figure 2-5. All cities under study and their respective cluster are listed in Appendix C.

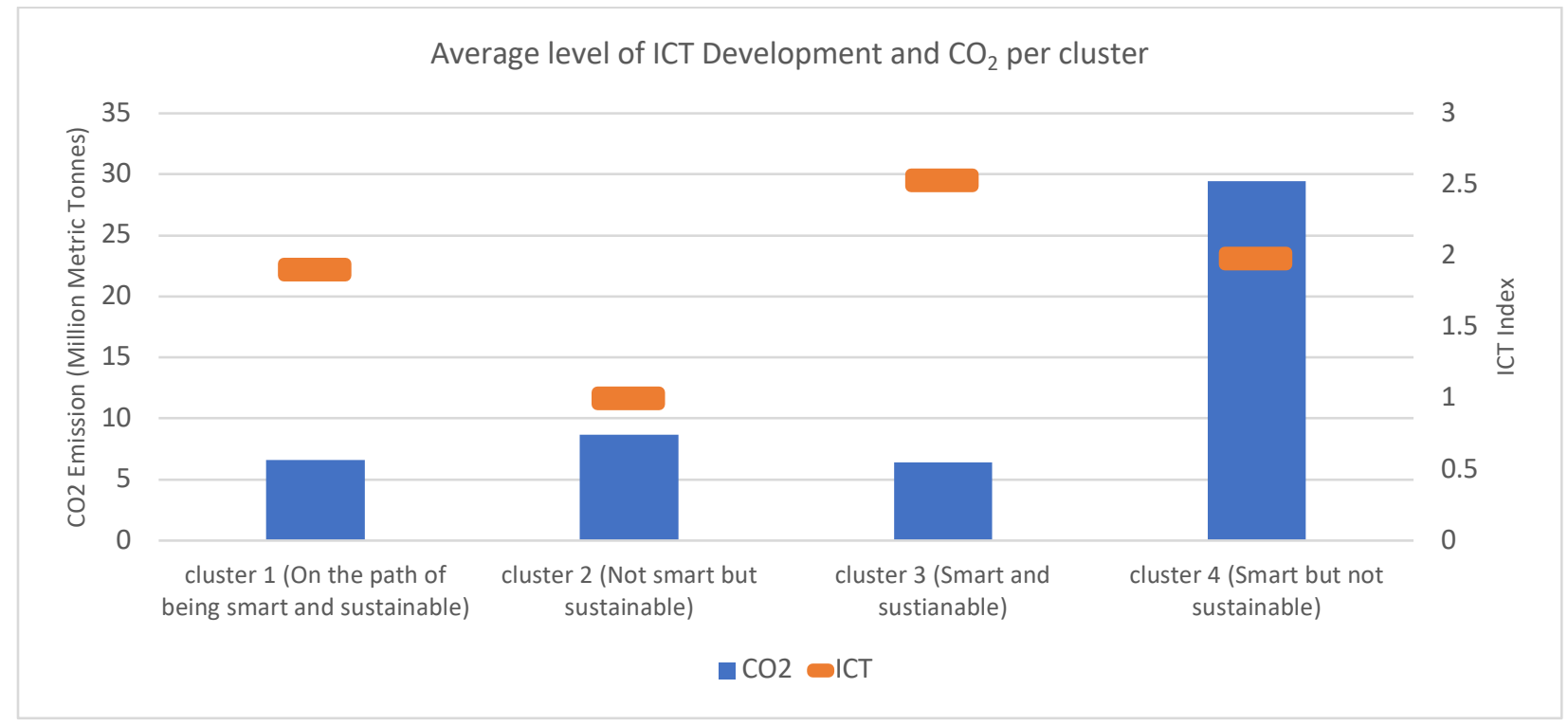

Figure 2-5: Average value of ICT development and $\mathrm{CO}_{2}$ emission in each cluster 


\subsubsection{Geographical Analysis}

The geographical distribution of the relationship between ICT development and environmental sustainability in cities was observed using maps to allow for the visual assessment of their comparative spatial distribution (Figure 2-6). Some interesting insights drawn from Figure 2-6 include:

- The geographic location of each city has a relationship with the link between ICT development and environmental sustainability. Of the 56 cities grouped as "on the path of being smart and sustainable", $48(86 \%)$ are located in central Europe while the remaining eight cities (14\%) are located in eastern and southern Europe; The 33 "not smart but sustainable" cities are predominantly found in south-eastern Europe with the exception of five cities (15\%) found in western and central Europe; all 29 "smart and sustainable" cities are found on the northern belt of Europe; and eleven "smart but not sustainable" cities are spread around central Europe.

- An obvious follow-up point is the presence of spatial autocorrelation. This factor means that cities with similar groups are clustered together in space. This clustering implies that the relationship between ICT and environmental sustainability is not randomly distributed across the EU, rather, physically adjacent cities tend to have similar characteristics and form clusters. The presence of spatial autocorrelation was tested using Moran's Index. We obtained a Moran's Index of 0.083024 with a statistically significant z-score of 4.748540 and p-value of 0.000002 indicating a tendency towards clustering with a less than $1 \%$ likelihood that our clustered pattern is a result of random chance. We have identified these clusters as "smart and sustainable", "not smart but sustainable", "smart but not sustainable" and "on the path of being smart and sustainable".

- Although we see that different cities within a country tend to have similar characteristics in terms of ICT development and environmental sustainability, we also noticed some exceptions. Of the 28 EU countries under study, five countries (Italy, France, Germany, Spain and the United Kingdom) have more than ten cities included in our study. The availability of data from a significant number of cities makes these five countries good for an intra-country comparison. Except for Italy, the capital city of each of these countries have a different group from the group of the other cities within them. 
- Finally, it did not come as a surprise that smart and sustainable cities are located in the United Kingdom, Belgium, Netherlands, Denmark, Sweden, Finland, and Luxembourg which are clustered in the North of Europe. Furthermore, the best performing cities in terms of ICT development and environmental sustainability are in Nordic countries.

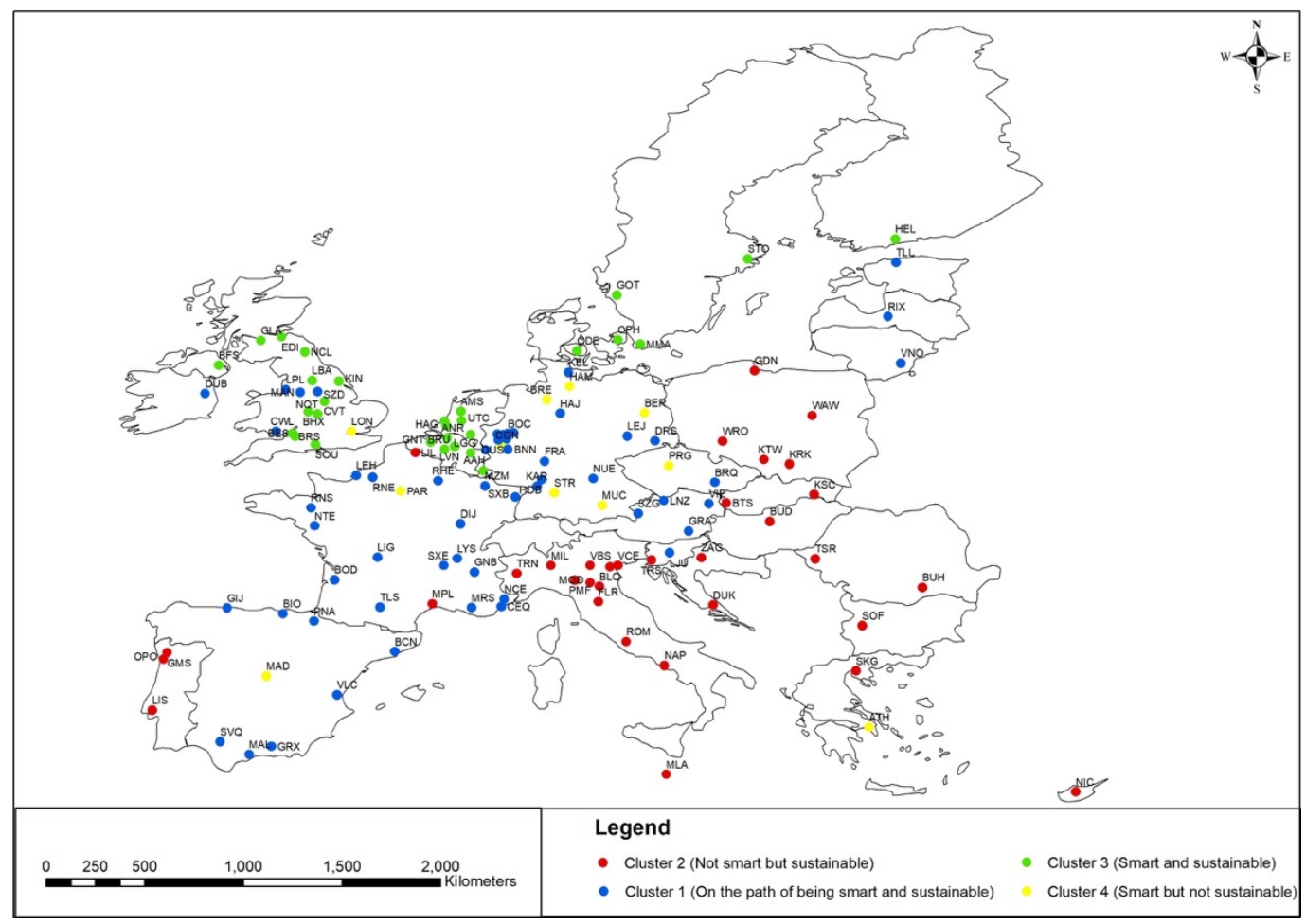

Figure 2-6: European Map of its cities in terms of ICT and environmental sustainability

\subsection{Discussion}

The exponential growth of ICT in the last decade and its application in the push for smart cities has been fundamental in addressing several urbanisation challenges ranging from energy use to quality of life of citizens. This phenomenon has led to a debate on the role of ICT in urbanisation and urban sustainability because of its growing use in urban systems and domains (Bibri \& Krogstie, 2017b). Cities are particularly important because they generate a huge chunk of global GHG due to their urban population density while consuming $70 \%$ of the world's resources (Riffat, Powell, \& Aydin, 2016). However, the relationship between ICT and environmental sustainability 
is quite complex and has not been empirically studied at sub-national (cities) level (Dedrick, 2010; Melville, 2010). Understanding this relationship is paramount in helping policymakers improve urban sustainability with the support of smart ICT.

In this study, using our proposed ICT framework, we measured the ICT development of cities in Europe using PCA, and we were able to extract and represent the two dimensions of ICT development; ICT infrastructure and ICT use. We were also able to represent the ICT development of cities in Europe using a single index and found cities in Sweden, Denmark, Netherlands and Finland to have a high level of ICT development while cities in Romania and Bulgaria have a low level of ICT development. This result corroborates previous studies which also obtained similar results at a country-level (Cruz-Jesus et al., 2017). Furthermore, we performed a cluster analysis of the ICT index and $\mathrm{CO}_{2}$ emission of cities in Europe obtaining four clusters of cities with homogenous ICT- $\mathrm{CO}_{2}$ relationships.

Regarding the relationship between ICT development and environmental sustainability across cities in the EU, we found that this relationship can be grouped into four categories; 'Not smart but sustainable', 'smart and sustainable', 'smart but not sustainable' and 'on the path of being smart and sustainable'. This finding is consistent with earlier research (Añón Higón et al., 2017), implying that the relationship between ICT and environmental sustainability is not the same for all cities but differs depending on their stage of ICT development. Hence, the possibility exists for this relationship to be positive in the case of cities categorised as "smart and sustainable" or negative as seen in cities categorised as "smart but not sustainable". At low levels of ICT development, a further increase in ICT development may result in an increase in $\mathrm{CO}_{2}$ emission in cities. However, after a certain ICT development threshold, a further increase in ICT development in cities will result in a decrease in $\mathrm{CO}_{2}$ emissions. This finding differs from conclusions in previous studies (Gouvea et al., 2017; S. J. Wu \& Raghupathi, 2018) that infer that the relationship between ICT and environmental sustainability is linearly positive and the same for all countries. On the other hand, this finding supports previous suggestions that even though ICT contributes significantly to GHG emissions, it also has the potential to reduce emissions by a fraction of five (Buttazzoni, 2008; European Commission, 2009).

Comparing the relationship of ICT development and GHG emission of cities within a country, we found that there is a tendency for the smart/sustainable profile of capital cities to differ from that of the other cities within the same country. Regarding GHG emission, our findings reveal 
that the magnitude of this difference is large as the capital city of a country has much more $\mathrm{CO}_{2}$ emission than other cities within the same country. This result is consistent with findings by (G. Chen, Wiedmann, Hadjikakou, \& Rowley, 2016) and is expected, as capital cities are usually larger, more populated and more urbanised and hence emit more $\mathrm{CO}_{2}$ when compared with other cities within the same country. In terms of ICT development, our findings reveal that the magnitude of difference in ICT development between the capital city of a country and other cities within the same country is not as significant as that of GHG emission. However, decomposing the ICT index into its principal component shows that this difference is more pronounced in principal component 2 which represents broadband connections (see Table 2). This aspect can be explained by the fact that ICT services such as eBanking, eLearning, e-mail, eHealth and eCommerce are more centrally organised and offered by the government and companies. Hence, the main barrier to the use of these services is the availability of ICT infrastructure which is higher in capital cities compared to other cities (Prieger, 2003). This finding is also in line with Ono and Zavodny (2007) who posit that differences in ICT access at an intra-national level often occur because of different characteristics. This inference could also imply that the extent to which the citizen has access to ICT infrastructure significantly influences his ability to use ICT services.

Comparing the relationship of ICT development and GHG emission of capital cities across Europe, we found Amsterdam and Copenhagen to be the best performing capital cities in terms of smartness and sustainability while Bucharest and Warsaw are the least performing capital cities. The assessment is also in line with previous studies with similar analysis at country level (Añón Higón et al., 2017). The most substantial indicator of the difference between the performance of the capital cities is the amount of $\mathrm{CO}_{2}$ emission. Best performing capital cities in Europe have found ways to utilise ICT and other means effectively to reduce their carbon footprint, however, the least performing capital cities have not been so successful in doing so. Also, our results show that the second indicator of the difference between the performance of capital cities within Europe is the level of ICT infrastructure. The wealth of countries has been identified in the literature to be a major driving factor in determining the level of ICT infrastructure (Cruz-Jesus et al., 2017). This reasoning can also be applied to cities as we observed that wealthier cities are performing better than others.

The main contribution of our study is two-fold. Firstly, we proposed a new approach to study the relationship between ICT development and $\mathrm{CO}_{2}$ emission using cities in the EU as a case 
study. We employed multivariate statistics to overcome the limitations identified in alternative approaches to create an ICT development index and created clusters of cities with similar smartness and sustainability profile. Secondly, our study sheds light on the intra-country and intercity comparisons between the role the different components of ICT development play in urbanisation and environmental sustainability on a micro-level.

\subsubsection{Practical Implications}

Understanding the relationship between technological development and the environmental sustainability of cities is critical for entities that promote smart and sustainable urban development.

The first implication can be drawn from the type of cities found in each cluster. Cities in Nordic countries and northern Europe perform best in terms of ICT development and environmental sustainability in EU. The wealth of cities has been established in literature to be a major driving factor of their performance because economic wealth is a critical prerequisite in building ICT infrastructure and adopting ICT (Billón et al., 2008; Cruz-Jesus et al., 2012). It is essential that less wealthy cities in Europe recognise the need to take advantage of the growing market of low-cost technologies to foster environmental sustainability while taking cognisance of the potential adverse effects of such. Furthermore, they also need to adopt urban policies and regulatory frameworks to foster the use of ICT in dematerialisation, travel substitution and building and energy efficiency. Finally, they need to explore environmentally-sustainable business practices and move towards a knowledge-based economy driven by ICT for an all-round "smart and sustainable" economic growth.

The second implication can be drawn from the way policymakers and the public perceive the concept of smart cities and sustainable cities. A common mistake is the assumption and misconception that all smart city concepts incorporate the goals of sustainable urban development. This misconception has been driven by previous literature which showed that the relationship between ICT development and environmental sustainability is positively linear (Gouvea et al., 2017; S. J. Wu \& Raghupathi, 2018). As a result, leading to the design of various smart city assessment frameworks that strongly focus on ICT with little attention given to environmental sustainability (Ahvenniemi et al., 2017). However, as evidenced by this research, the relationship between ICT and environmental sustainability varies among different cities. Hence, it is advisable 
that urban policymakers be intentional about explicitly including environmental sustainability in their smart city goals and leverage the use of ICT in achieving their sustainability goals.

Consequently, the concept of "smart sustainable city" should be used for emphasis when referring to the use of ICT to promote environmental sustainability by stakeholders. This shift presents a more holistic front and does not undermine the importance of either ICT or environmental sustainability in the quest for a more liveable city. Urban policymakers need a wellrounded approach when designing strategies that make use of ICT to drive environmental sustainability focusing on the built environment, living environment and resource flows.

The last practical implication is derived from the gap in ICT development and environmental sustainability between the bigger cities (capital cities) and other cities within a country. Capital cities are urbanised because of the myriad opportunities that capital cities offer as opposed to smaller cities. However, this urbanisation comes with various challenges, one of which is the emission of GHG in large quantities. People will not mind staying in smaller cities as long as they have the same level of access to services available in large cities, among other factors. ICT can help to bridge this gap by offering services such as education, health, mail, banking and commerce remotely. However, people's ability to use all these is dependent on available infrastructure. People with broadband connections will take advantage of services offered through the Internet, using more applications and for a longer time (Van Dijk, 2009). Policymakers should keep in mind that to reduce urbanisation and associated GHG emissions in large cities, they will need to broaden access to broadband Internet in smaller cities. This will reduce the pressure on the bigger cities as citizens will be able to carry out various services available through the Internet in smaller cities.

Overall, urban policymakers need a well-rounded approach when designing strategies that make use of ICT to drive environmental sustainability focusing on the built environment, living environment and resource flows. This strategy can range from the effective use of ICT to increase citizen engagement on climate change issues, to facilitating the use of applications allowed by ICT such as remote working and telecommuting. 


\subsubsection{Limitations and future research}

It is important to note that in an attempt to operationalise theoretical constructs that are not directly measurable, we have proposed observable measures based on literature. While we made an effort to perform a complete and multidimensional exploratory analysis, we had to make a compromise between the depth and width of our analysis (Cruz-Jesus et al., 2017). There is an inverse relationship between the number of cities we could have included in our analysis (width) and the number of indicators we could have used to characterise ICT development and environmental sustainability (depth). Hence, we ended up including just 129 cities in Europe and seven indicators. So, some features of ICT and environmental sustainability may not be covered as we could not include other cities and other indicators because of data constraints. Additional variables relating to teleworking incidence, changes in paper production and physical mail, patenting activity connecting ICT and the environment and research and development by the ICT sector on environmental sustainability may affect the results of this study. Including other cities in Europe and beyond may also impact our results as other cultural, political and economic factors come into play. Furthermore, this study does not infer a direct causal relationship between ICT and environmental sustainability. We simply performed a cross-sectional study to cluster a homogenous group of cities based on the relationship between ICT and environmental sustainability.

For future work, it would be interesting to expand this research and include other indicators and other cities beyond Europe to better capture the relationship between ICT and environmental sustainability on a global stage. It will also be interesting to do this analysis for historical years to characterise the long-term relationship of ICT and environmental sustainability and its evolution over the years using a longitudinal study. This work will make it possible to forecast a "smartainability" (smart and sustainable) path of global cities into the future based on past data.

\subsection{Conclusion}

Several authors have explored the relationship between ICT and environmental sustainability, but this link has not been empirically explored at a sub-national level using multivariate statistics. In 
this research, we set out to explore the link between ICT development and environmental sustainability on a micro-level, clustering 129 cities in Europe based on this relationship. We achieved this using PCA to create an ICT index for the cities under study and subsequently using cluster analysis to group and characterise each city based on its ICT and $\mathrm{CO}_{2}$ emission. We explored the two dimensions of ICT development and also carried out an intra-country and intercity comparisons of the joint ICT- $\mathrm{CO}_{2}$ characteristics of European cities. Based on our analysis, there are four groups of cities with similar ICT (smart) and $\mathrm{CO}_{2}$ (sustainable) characteristics namely; smart but not sustainable cities, not smart but sustainable cities, smart and sustainable cities and those on the path of being smart and sustainable cities.

Furthermore, we found that although cities from the same country usually have similar ICT infrastructure and use characteristics, capital cities tend to have a different profile. This difference is primarily due to the amount of GHG emission and ICT infrastructure in capital cities. Comparing the profile of capital cities across the EU, we found capital cities in northern Europe to be the best performing cities in terms of smartness and sustainability while capital cities that are "not smart but sustainable" are predominantly located in south-eastern Europe. The practical implications of this research have also been highlighted. The results of this research will help urban policymakers design appropriate strategies for achieving integrated smart, sustainable and inclusive growth at European level. 


\title{
Chapter 3 - Understanding the sharing economy and its implication on sustainability in smart cities
}

\begin{abstract}
$^{5}$
Purpose - The purpose of this article is to evaluate the main drivers of the sharing economy through an exhaustive weighting and meta-analysis of previous relevant quantitative research articles.
\end{abstract}

Design / methodology / approach - This study makes use of a systematic literature review methodology to explore the main drivers of the sharing economy. The authors analysed 22 quantitative studies from 2008 through 2019 using weighting analysis and meta-analysis.

Findings - Out of the 249 extracted relationships (independent - dependent variable), the paper identifies the "best" predictors used in theoretical models to study the sharing economy. These include; attitude on intention to share, perceived behavioral control on intention to share, subjective norm on intention to share, economic benefit on attitude and perceived risk on attitude. Geographically, Germany and the United States of America were found to be the nations with the greatest number of respondents. Temporally, we found an increasing trend in the number of articles on the sharing economy and respondents.

Research limitations / implications - The consolidation of the drivers of the sharing economy provides a solid theoretical foundation for the research community to further explore existing hypotheses and test new hypotheses in emerging contexts of the sharing economy.

Originality / value - Given the different conceptual theories that have been used to study the sharing economy and their application to different contexts, this study presents the first attempt at advancing knowledge by quantitatively synthesizing findings presented in previous literature.

Keywords Smart cities, Sustainable cities, Sharing economy, Collaborative consumption, Metaanalysis, Weight analysis

Paper type Literature review

\footnotetext{
${ }^{5}$ The text from this chapter has been submitted as "Akande, A., Cabral, P., Casteleyn, S. Understanding the sharing economy and its implication on sustainability in smart cities" to a top-tier journal.
} 


\subsection{Introduction}

The recent push for smart sustainable cities has driven the exploration of various ways technology can enable the efficient use of limited resources and "idling capacities" (underutilized physical assets), which in turn will help to reduce waste and improve the environmental sustainability of cities (Bernardi \& Diamantini, 2018). One of such approaches is the "sharing economy" concept which is a new economic model based on the peer-to-peer "activity of obtaining, giving, or sharing access to goods and services, coordinated through community-based online services" (Hamari et al., 2016). It is sometimes referred to as collaborative consumption (Belk, 2014), access-based consumption (Bardhi \& Eckhardt, 2012), peer-to-peer economy (Einav, Farronato, \& Levin, 2016) and platform economy (Langley \& Leyshon, 2017).

Sharing is a communal concept that has been practiced for many decades (Belk, 2010). Hence, it is not new. However, only recently have there been renewed conversations on sharing being a part of the broader circular economy concept in light of the unsustainable exploitation of global resources (Geissdoerfer, Savaget, Bocken, \& Hultink, 2017). Furthermore, the rapid expansion and adoption of digital platforms and other large-scale mediating technologies (Sutherland \& Jarrahi, 2018) has made sharing evolve from a simple communal concept to a large economy with various implementations. Some of these implementations involved actors, compensation schemes, participation motives and ownership transfer (Trenz, Frey, \& Veit, 2018).

The sharing economy plays an important role in enabling sustainable communities and cities, due to the fact that its main idea perfectly fits into the three dimensions of sustainable cities: economy, environment, and society (Akande, Cabral, Gomes, et al., 2019). (Frenken \& Schor, 2017) succinctly highlight the economic dimension in their definition of the sharing economy; "consumers granting each other temporary access to under-utilized physical assets ('idle capacity'), possibly for money." The sharing economy has the potential of creating new business ventures and forms of income. From an environmental viewpoint, the sharing economy helps to fight climate change by pooling resources which would otherwise duplicate climate-altering activities, e.g., car-pooling (Skjelvik, Erlandsen, \& Haavardsholm, 2017). Lastly, from a social perspective, the sharing economy facilitates the creation of new social bonds and helps in building communities (Bernardi \& Diamantini, 2018).

While the sharing economy is a core concept promoting smart sustainable cities, research in the sharing economy is still emerging. Hence, there is a need to review studies that have the 
sharing economy and its variants as their focus. Although some studies have already done reviews on the sharing economy (Cheng, 2016; Sutherland \& Jarrahi, 2018; Trenz et al., 2018), they all take a qualitative approach to such appraisals. There is still a lack of a quantitative approach to consolidate existing literature on the sharing economy. We intend to fill this gap by doing a comparative and review study on the sharing economy in order to conceptualize a theory and create a research agenda. In this paper, we will:

1. Comprehensively and rigorously evaluate literature on the sharing economy through a systematic literature review.

2. Analyze the strength of the independent - dependent variable relationships obtained from the research models in (1), through a weight and meta-analysis.

3. Propose a unified theory of sharing based on the synthesis of the outcome of (2).

Doing so, this paper makes two contributions. Firstly, it offers a first step towards a comprehensive understanding of existing trends in the use of theoretical models to understand the sharing economy. Secondly, it facilitates the path for the theoretical development of peer-to-peer sharing in cities by creating new hypotheses to motivate new studies.

This paper will be organized as follows. In section 2, we will describe the methodology used in conducting the literature review. In section 3, we will summarize the articles found using descriptive statistics, weight analysis, and meta-analysis. In section 4, we will discuss our findings and highlight their implications on theory and practice in section 5. Finally, in sections 6 and 7 , we conclude the review by highlighting limitations and future research directions.

\subsection{Research methodology}

We carried out a systematic and structured literature search, adopting the "Preferred Reporting Items for Systematic Reviews and Meta-Analysis" (PRISMA) guidelines (Moher, Liberati, Tetzlaff, Altman, \& and the PRISMA Group, 2009) to identify relevant knowledge on the sharing economy and related concepts. PRISMA, with its origins in medical science, has been extensively used in the information science field to write and appraise systematic literature reviews (Mardani et al., 2017; Naranjo Zolotov, Oliveira, \& Casteleyn, 2018; Zare et al., 2016), and is particularly suited for combining systematic reviews and meta-analyses, as in this paper. The data flow as 
recommended by PRISMA includes literature search (i.e., a systematic search, using relevant search queries over a selection of scientific databases), screening (i.e., initial decision on which studies to include for further analysis), eligibility (an in-depth analysis and decision on included studies) and included studies (i.e., final set of included studies) (Moher et al., 2009). This data flow diagram, including results from our systematic literature search, is summarized in Figure 3-1.

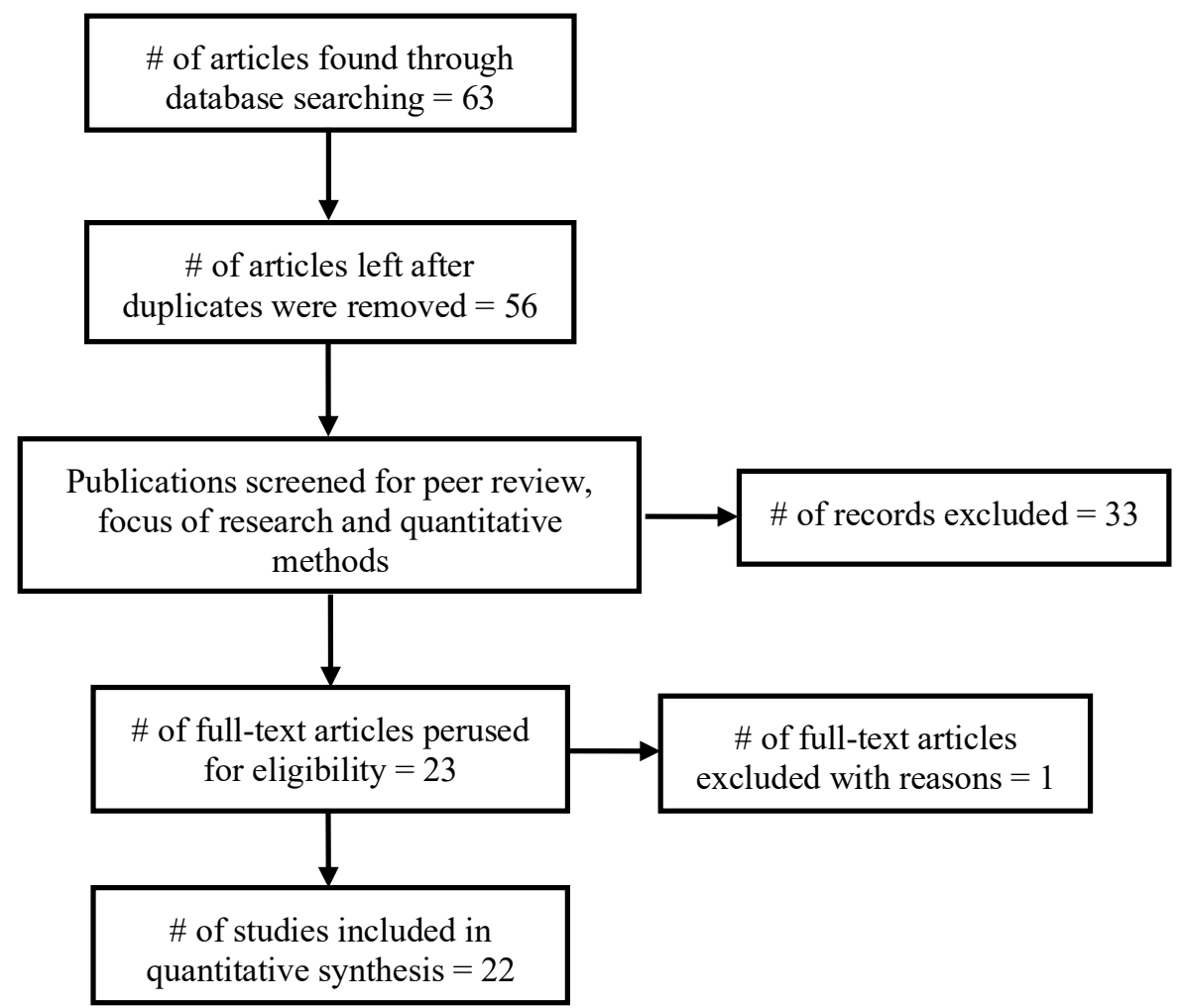

Figure 3-1: PRISMA data flow diagram for the systematic literature review (\# means 'number')

\subsubsection{Literature search}

Our literature search was conducted in two steps: an initial exploratory search and a more refined structured search. Since we are interested in analyzing the quality of relationships between drivers of peer-to-peer sharing, an initial search was done to identify critical literature and keywords relevant to our research problem. These keywords are called "entry terms" by (Bates, 1976) and serve as a foundation upon which we will build our more structured literature search and review. Next, following the approach of (Naranjo Zolotov et al., 2018), the identified keywords were categorized into three sets; theoretical model and evaluation, quantitative methods and concepts. 
The theoretical model and evaluation keywords help to identify literature where theoretical models were appraised; the quantitative methods keywords help to identify the most used statistical methods to evaluate the models; the concepts help to identify relevant literature where the concepts we are interested in were evaluated. The keywords associated with each of these categories are identified in Table 1. The concept keywords identified in Table 3-1 were also found by (Trenz et al., 2018) to be the most prominent phrases used to describe the sharing economy.

Table 3-1: Categories of keywords used to search literature database

\begin{tabular}{|c|c|c|c|}
\hline $\begin{array}{l}\text { Theoretical model } \\
\text { evaluation }\end{array}$ & and & Quantitative methods & Concepts \\
\hline model & & Structural equation modeling & sharing economy \\
\hline survey & & PLS & collaborative consumption \\
\hline \multirow[t]{4}{*}{ questionnaire } & & Regression coefficient & access-based consumption \\
\hline & & & peer-to-peer \\
\hline & & & microgrid \\
\hline & & & Platform economy \\
\hline
\end{tabular}

Using the keywords identified in Table 3-1, a more refined and structured search query was constructed using the logical operators "AND" and "OR", to obtain the following search query: ((("model" OR "survey" OR 'questionnaire") AND ("structural equation modelling" OR "PLS' OR "regression coefficient") AND ("sharing economy" OR "collaborative consumption" OR "access-based consumption" OR "peer-to-peer" OR "microgrid" OR "platform economy"))). This query was subsequently launched against the Scopus and Web of Science databases, which were selected because they form the largest abstract and indexing multidisciplinary databases (Burnham, 2006), and we thus believe they contain a representative sample of the multidisciplinary literature on the novel concept of the sharing economy and related relevant concepts (Harzing \& Alakangas, 2016).

As a result of our search, we found a total of 63 scholarly papers (see Figure 3-1 identification). The subject areas of these scholarly papers were very diverse, ranging from social sciences and decision sciences to engineering and energy. Furthermore, $79 \%$ of these scholarly papers were research articles, and $17 \%$ were from conference proceedings. It is important to note that even though we did not filter our initial search by year, we obtained results ranging from the 
year 2008 to 2019 . Out of the initial 63 scholarly papers obtained, seven papers were duplicates and hence excluded from further analysis, resulting in 56 withheld studies in the identification phase (see Figure 3-1 - identification).

\subsubsection{Screening and Eligibility}

In line with the PRISMA guidelines, all articles in the initially identified set were evaluated for their eligibility using certain inclusion and exclusion criteria. This assessment was done to ensure that each article meets certain quality standards and addresses the research topic at hand. Concretely, the inclusion criteria include: (1) publication must be in English and have been peerreviewed; (2) factors that drive the individual adoption of peer-to-peer sharing must be the central focus of research (Trenz et al., 2018); (3) the approach must be quantitative with a statistical evaluation of effect sizes that are comparable (i.e., they have a scale that ranges between 0 and 1). We focused on individual adoption because the sharing economy is an emerging concept whose theoretical development is still in its early stages. For objective temporal comparison, we excluded articles found in the year 2019 as we were in the middle of 2019 at the time of analysis for this research. Using these criteria, 33 papers were not considered relevant for further analysis (see Figure 3-1 - screening), which left us with 23 quantitative papers for further analysis. Each of these 23 papers were perused and metadata was extracted, including the year of publication, source reference, theory(ies) or framework used, independent and dependent variables, path coefficients (beta), significance of paths, method of analysis used, keywords, type of survey, findings from abstract or conclusion, focus area of study, size of population surveyed, kind of population surveyed and country of study.

Based on some of the extracted metadata, we determined that (Lang, 2018) and (Lang \& Joyner Armstrong, 2018) made use of the same dataset of respondents. Hence, as recommended by (Wood, 2008) and (Naranjo Zolotov et al., 2018), we only selected the article with the highest number of variables for inclusion in the meta-analysis, since including articles with a duplicated dataset may bias the aggregation of our results. The article selected for further analysis among the two was (Lang, 2018). 


\subsubsection{Variable Synthesis}

After performing the in-depth screening of the articles using the extracted metadata, we were left with 22 articles for further analysis. These articles and some of the extracted metadata are listed in Table 3-2. As mentioned in the previous section, we collected the dependent and independent variables of the models used in each of these articles as metadata. At the point of collation, we noticed overlaps and synonyms in the variable's names. For example, dependent variable names such as intention to use and intention are synonymous and were merged into a single variable. The results of these syntheses can be found in Appendix 1.

Table 3-2: List of literature used for meta-analysis (ordered by publication year, author)

\begin{tabular}{|c|c|c|c|c|c|}
\hline No. & Author & $\begin{array}{l}\text { Model / } \\
\text { Framework }\end{array}$ & Focus area & Size & Country \\
\hline 1. & (Toni, Renzi, \& Mattia, 2016) & ТPB & $\begin{array}{l}\text { Peer-to-peer } \\
\text { accommodation } \\
\text { sharing }\end{array}$ & 384 & Italy \\
\hline 2. & (Barnes \& Mattsson, 2017) & TRA & Car sharing & 115 & Denmark \\
\hline 3. & (Roos \& Hahn, 2017a) & TPB, VBNT & Bike sharing & $\begin{array}{l}150 \\
18\end{array}$ & $\begin{array}{l}\text { Germany } \\
\text { Switzerland }\end{array}$ \\
\hline 4. & (J. Wu, Zeng, \& Xie, 2017) & $\begin{array}{l}\text { Self- } \\
\text { developed }\end{array}$ & Room sharing & 445 & China \\
\hline 5. & $\begin{array}{l}\text { (Yang, Song, Chen, \& Xia, } \\
\text { 2017) }\end{array}$ & $\begin{array}{l}\text { Self- } \\
\text { developed }\end{array}$ & Sharing services & 440 & China \\
\hline 6. & $\begin{array}{l}\text { (Amaro, Andreu, \& Huang, } \\
\text { 2018) }\end{array}$ & TRA & Room sharing & $\begin{array}{l}98 \\
104\end{array}$ & $\begin{array}{l}\text { Germany } \\
\text { China }\end{array}$ \\
\hline 7. & $\begin{array}{l}\text { (Amirkiaee \& Evangelopoulos, } \\
\text { 2018) }\end{array}$ & $\begin{array}{l}\text { Self- } \\
\text { developed }\end{array}$ & Ride sharing & 300 & U.S.A. \\
\hline 8. & $\begin{array}{l}\text { (Barbu, Florea, Ogarcă, \& } \\
\text { Răzvan Barbu, 2018) }\end{array}$ & $\begin{array}{l}\text { Self- } \\
\text { developed }\end{array}$ & Ride sharing & 320 & Romania \\
\hline 9. & (Becker-Leifhold, 2018) & TPB, VBNT & Fashion sharing & 1009 & Germany \\
\hline 10. & $\begin{array}{l}\text { (H. K. Chen, Chou, \& Hung, } \\
\text { 2018) }\end{array}$ & TPB, TAM & Bike sharing & 287 & Taiwan \\
\hline 11. & (Hamenda, 2018) & SERVQUAL & Ride sharing & 219 & Indonesia \\
\hline 12. & $\begin{array}{l}\text { (Hawlitschek, Teubner, \& } \\
\text { Gimpel, 2018) }\end{array}$ & ТРВ & $\begin{array}{l}\text { Peer-to-peer } \\
\text { sharing }\end{array}$ & 745 & Germany \\
\hline 13. & (Huarng \& Yu, 2018) & $\begin{array}{l}\text { Self- } \\
\text { developed }\end{array}$ & Room sharing & 397 & Taiwan \\
\hline 14. & $\begin{array}{l}\text { (Y. G. Kim, Woo, \& Nam, } \\
\text { 2018) }\end{array}$ & NAM, TPB & Sharing services & 344 & $\begin{array}{l}\text { South } \\
\text { Korea }\end{array}$ \\
\hline
\end{tabular}




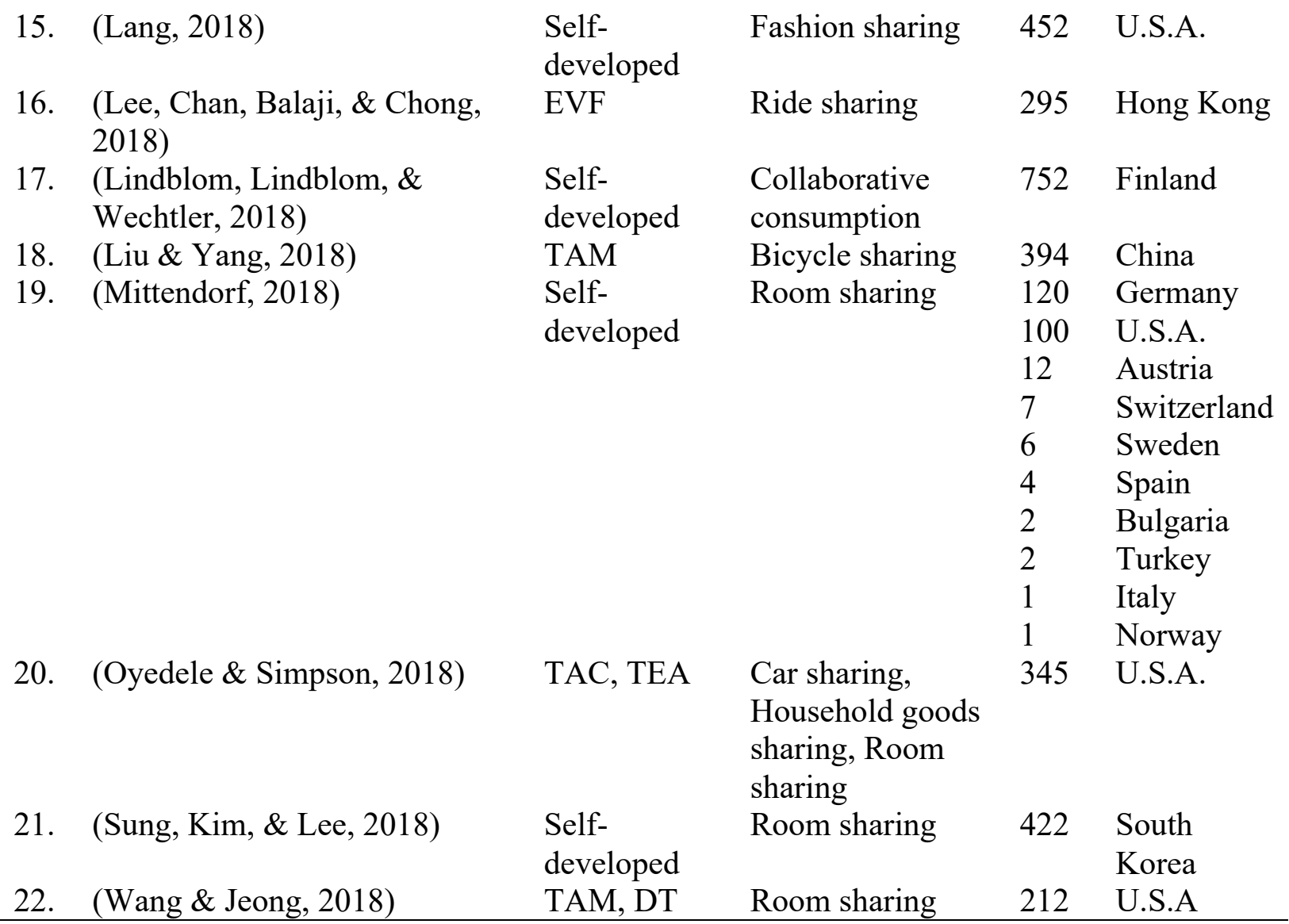

Notes: VBNT - Values-Belief-Norms Theory, TRA - Theory of Reasoned Action, TAM - Technology Acceptance Model, TPB - Theory of Planned Behavior, DT - Diffusion Theory, NAM - Norm Activation Model, SERVQUAL Service Quality, EVF - Extended Valence Framework, TAC - Theory of Access-based Consumption, TEA - Theory of Emerging Adulthood, U.S.A - United States of America

\subsection{Results}

In this section, we summarize the evolution of the sharing economy in terms of the spatiotemporal trend of respondents and weight analysis and meta-analysis of variables.

\subsubsection{Descriptive statistics}

Even though we obtained results from the year 2008 to 2019 from our initial literature search, we identified a total of 22 research articles that quantitatively evaluate the sharing economy published from 2016 through 2018 after applying the inclusion and exclusion criteria discussed in section 2.2. These 22 articles had a total of 249 relationships (independent - dependent variable) which 
were used for the weighting and meta-analysis. The 249 relationships had been tested on 8502 respondents from various countries. The type of respondents includes university students, millennials, sharing service users and the general public.

A temporal analysis of the number of respondents in Figure 3-2 shows an increasing trend with 2018 having the largest number of respondents (6950).

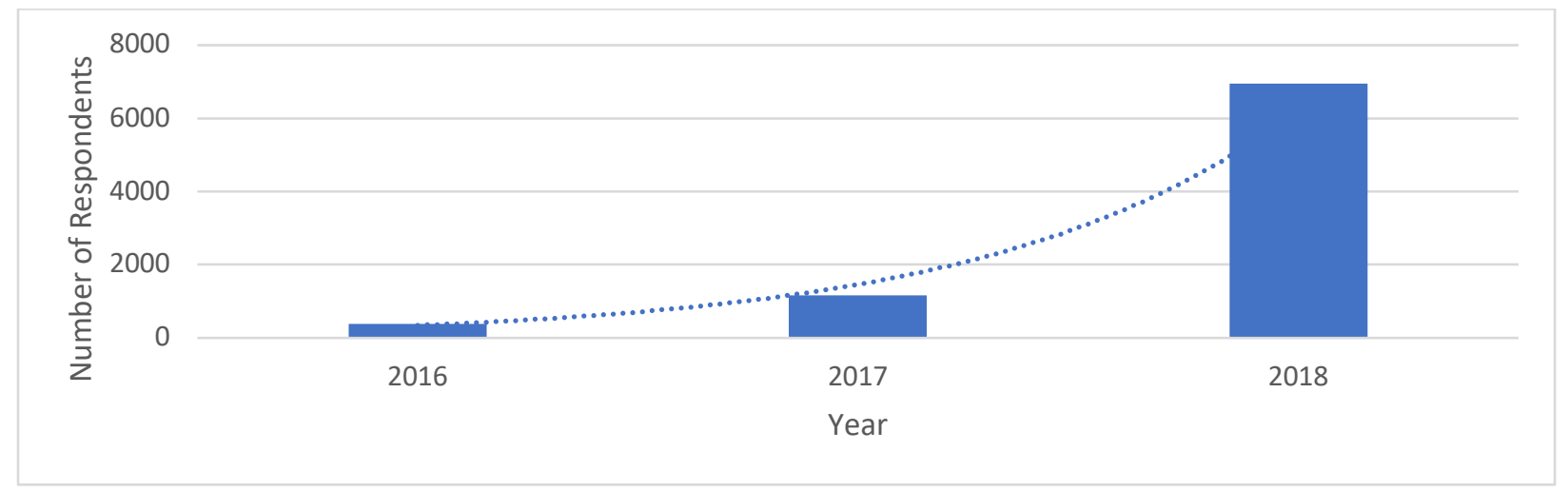

Figure 3-2: Number of respondents in the 22 withheld articles (by year)

Visualizing the number of respondents by country on a map in Figure 3-3 shows that Germany, the United States of America and China have the highest sample sizes with 2122, 1409 and 1383 respondents respectively. The results also show that no studies have been done in Africa, Central and South America, and Australia. 


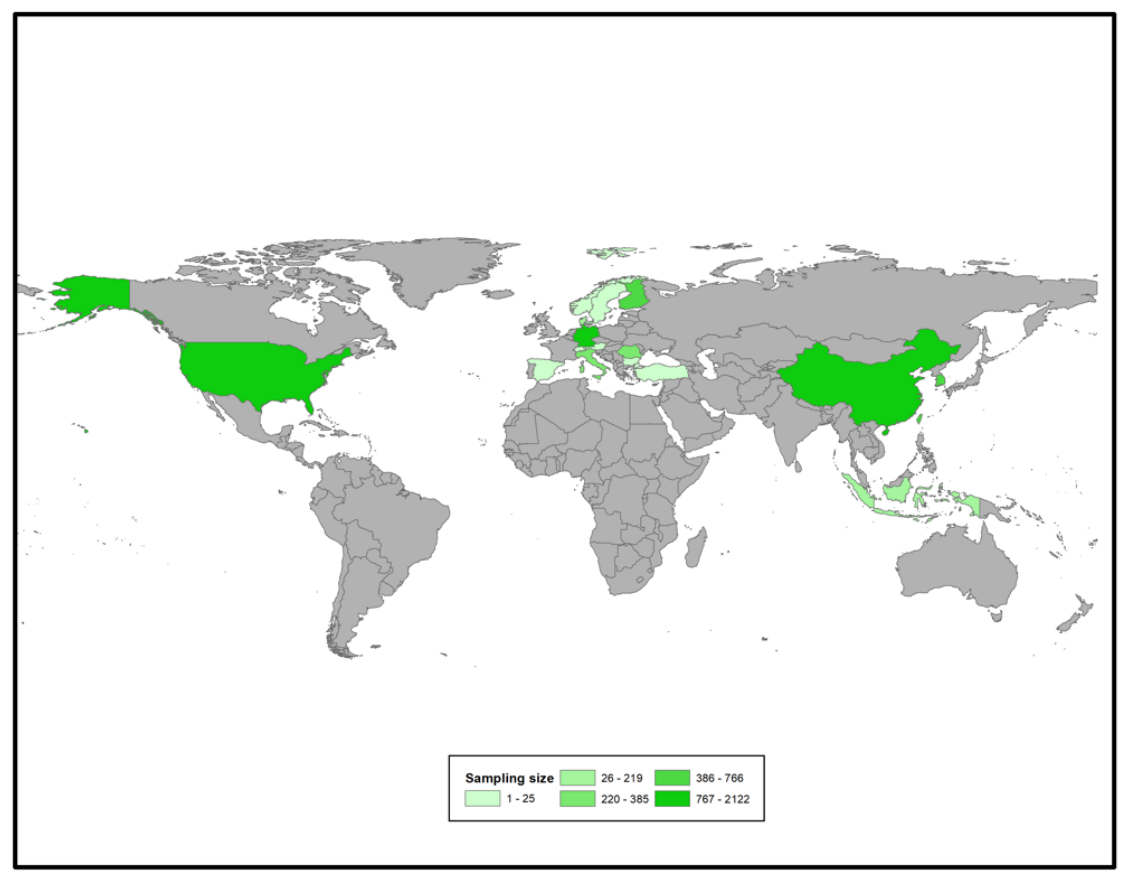

Figure 3-3: Spatial distribution of 8502 respondents in the 22 withheld articles

\subsubsection{Weight analysis}

Using variables from numerous IT adoption studies, (Jeyaraj, Rottman, \& Lacity, 2006) calculated the weight of a variable by dividing the frequency of a variable found to be significant by the total number of times such a variable was investigated. However, in this study, instead of making use of individual variables, we considered relationships (independent - dependent variable) with a frequency of 3 (three) or more for our weighting analysis (Naranjo Zolotov et al., 2018). As shown in Table 3-3, 18 (eighteen) relationships were evaluated with the resulting weights varying from 0 (zero) to 1 (one). 0 (zero) signifies that the relationship was non-significant across all studies evaluated and 1 (one) signifies that the relationship was significant across all studies.

According to (Baptista \& Oliveira, 2016) a relationship construct is considered to be a best predictor if it has been well-utilized (i.e., examined five times or more) in literature with a resultant weight that is greater than 0.80 . Furthermore, a relationship construct is considered to be a promising predictor if it has not been well-utilized but has a weight equal to 1 (one). Following this reasoning, we determined that the best predictors of sharing in the circular economy are: attitude on intention to share (1.00), perceived behavioral control on intention to share (1.00), subjective norm on intention to share $(0.83)$, economic benefit on attitude $(0.80)$ and perceived 
risk on attitude (0.80). Of the remaining relationships, the following are considered to be promising predictors of sharing; relative flexibility utility on intention to share (1.00), familiarity on intention to share (1.00) and trust on attitude (1.00). Although with potential, these relationships will still need to be further tested before they can be certified as a best predictor of sharing.

Table 3-3: Summary of independent - dependent variable weight analysis results (ordered by frequency of use)

\begin{tabular}{|c|c|c|c|c|c|c|}
\hline Independent variable & $\begin{array}{l}\text { Dependent } \\
\text { variable }\end{array}$ & $\begin{array}{l}\text { Non- } \\
\text { significant }\end{array}$ & Significant & $\begin{array}{l}\text { Frequency } \\
\text { of use }\end{array}$ & $\begin{array}{l}\text { Weight } \\
\text { Significant } \\
\text { Frequency }\end{array}$ & $\bar{l}$ \\
\hline Attitude & Intention to share & 0 & 11 & 11 & 1.00 & \\
\hline Trust & Intention to share & 4 & 4 & 8 & 0.50 & \\
\hline Subjective norm & Intention to share & 1 & 5 & 6 & 0.83 & \\
\hline $\begin{array}{l}\text { Perceived behavioral } \\
\text { control }\end{array}$ & Intention to share & 0 & 5 & 5 & 1.00 & \\
\hline Economic benefit & Attitude & 1 & 4 & 5 & 0.80 & \\
\hline Perceived risk & Attitude & 1 & 4 & 5 & 0.80 & \\
\hline Perceived risk & $\begin{array}{l}\text { Perceived } \\
\text { enjoyment }\end{array}$ & 1 & 3 & 4 & 0.75 & \\
\hline Economic benefit & Intention to share & 1 & 3 & 4 & 0.75 & \\
\hline Social benefit & Intention to share & 2 & 2 & 4 & 0.50 & \\
\hline Environmental benefit & Attitude & 2 & 2 & 4 & 0.50 & \\
\hline Social benefit & Attitude & 2 & 2 & 4 & 0.50 & \\
\hline Relative flexibility utility & Intention to share & 0 & 3 & 3 & 1.00 & \\
\hline Familiarity & Intention to share & 0 & 3 & 3 & 1.00 & \\
\hline Trust & Attitude & 0 & 3 & 3 & 1.00 & \\
\hline Perceived risk & Intention to share & 2 & 1 & 3 & 0.33 & \\
\hline Prosocial utility & Intention to share & 3 & 0 & 3 & 0.00 & \\
\hline $\begin{array}{l}\text { Relative transaction } \\
\text { utility }\end{array}$ & Intention to share & 3 & 0 & 3 & 0.00 & \\
\hline Shareaids & Intention to share & 3 & 0 & 3 & 0.00 & \\
\hline
\end{tabular}

\subsubsection{Meta-analysis}

Meta-analysis enables us to statistically synthesize the effect sizes of the relationships between constructs across previous studies (Zare et al., 2016). We used a free and open tool called MetaEssentials because of its adaptability, extensibility and robust integration with the Microsoft Excel package (Suurmond, van Rhee, \& Hak, 2017). As input, we made use of the standardized regression coefficient $(\beta)$, which shows the strength of the influence of an independent variable 
over a dependent variable, and the sample size of relationships that had a frequency of 3 or more in the articles reviewed. We had the option of either using a "fixed effect" model or a "random effect" model for the meta-analysis. The fixed effect model assumes that the variation in effect sizes between the different studies is only due to the sampling error (Hedges \& Vevea, 1998). However, this assumption does not hold in social sciences studies like ours (Naranjo Zolotov et al., 2018). Hence, our choice of the random effect model for this study. Furthermore, the random effect model has been used in similar meta-analytic studies as ours (Naranjo Zolotov et al., 2018; Talò, Mannarini, \& Rochira, 2014).

Table 3-4: Meta-analysis results (ordered by frequency)

\begin{tabular}{|c|c|c|c|c|c|c|c|c|}
\hline \multirow[t]{2}{*}{$\begin{array}{l}\text { Independent } \\
\text { variable }\end{array}$} & \multirow[t]{2}{*}{$\begin{array}{l}\text { Dependent } \\
\text { variable }\end{array}$} & \multirow[t]{2}{*}{ Frequency } & \multirow[t]{2}{*}{$\begin{array}{l}\text { Average } \\
\beta\end{array}$} & \multirow{2}{*}{$\begin{array}{l}\sum \\
\text { sample } \\
\text { size }\end{array}$} & \multirow[t]{2}{*}{$\begin{array}{l}\mathrm{p}- \\
\text { value }\end{array}$} & \multirow[t]{2}{*}{$\begin{array}{l}\text { z- } \\
\text { value }\end{array}$} & \multicolumn{2}{|c|}{$\begin{array}{l}\text { Confidence } \\
\text { interval }\end{array}$} \\
\hline & & & & & & & $\begin{array}{l}\text { Lower } \\
\text { limit }\end{array}$ & $\begin{array}{l}\text { Upper } \\
\text { limit }\end{array}$ \\
\hline Attitude & $\begin{array}{l}\text { Intention to } \\
\text { share }\end{array}$ & 11 & 0.49 & 4809 & .00 & 37.16 & 0.47 & 0.51 \\
\hline Trust & $\begin{array}{l}\text { Intention to } \\
\text { share }\end{array}$ & 8 & 0.16 & 1500 & .00 & 6.24 & 0.11 & 0.21 \\
\hline $\begin{array}{l}\text { Subjective } \\
\text { norm }\end{array}$ & $\begin{array}{l}\text { Intention to } \\
\text { share }\end{array}$ & 6 & 0.18 & 2971 & .00 & 9.91 & 0.14 & 0.21 \\
\hline $\begin{array}{l}\text { Perceived } \\
\text { behavioral } \\
\text { control }\end{array}$ & $\begin{array}{l}\text { Intention to } \\
\text { share }\end{array}$ & 5 & 0.34 & 2769 & .00 & 18.62 & 0.31 & 0.37 \\
\hline $\begin{array}{l}\text { Economic } \\
\text { benefit }\end{array}$ & Attitude & 5 & 0.14 & 2219 & .00 & 6.63 & 0.10 & 0.18 \\
\hline Perceived risk & Attitude & 5 & -0.19 & 1197 & .00 & -6.65 & -0.24 & -0.13 \\
\hline $\begin{array}{l}\text { Economic } \\
\text { benefit }\end{array}$ & $\begin{array}{l}\text { Intention to } \\
\text { share }\end{array}$ & 4 & 0.11 & 2408 & .00 & 5.42 & 0.07 & 0.15 \\
\hline Social benefit & $\begin{array}{l}\text { Intention to } \\
\text { share }\end{array}$ & 4 & 0.06 & 790 & .05 & 1.69 & -0.01 & 0.13 \\
\hline $\begin{array}{l}\text { Environmental } \\
\text { benefit }\end{array}$ & Attitude & 4 & 0.10 & 1467 & .00 & 3.84 & 0.05 & 0.15 \\
\hline Social benefit & Attitude & 4 & 0.13 & 1467 & .00 & 5.00 & 0.08 & 0.18 \\
\hline Perceived risk & $\begin{array}{l}\text { Perceived } \\
\text { enjoyment }\end{array}$ & 4 & -0.19 & 452 & .00 & -4.08 & -0.28 & -0.10 \\
\hline Perceived risk & $\begin{array}{l}\text { Intention to } \\
\text { share }\end{array}$ & 3 & -0.05 & 784 & .08 & -1.40 & -0.12 & 0.02 \\
\hline $\begin{array}{l}\text { Prosocial } \\
\text { utility }\end{array}$ & $\begin{array}{l}\text { Intention to } \\
\text { share }\end{array}$ & 3 & 0.02 & 345 & .36 & 0.37 & -0.09 & 0.13 \\
\hline
\end{tabular}




\begin{tabular}{|c|c|c|c|c|c|c|c|c|}
\hline $\begin{array}{l}\text { Relative } \\
\text { transaction } \\
\text { utility }\end{array}$ & $\begin{array}{l}\text { Intention to } \\
\text { share }\end{array}$ & 3 & 0.03 & 345 & .29 & 0.55 & -0.08 & 0.14 \\
\hline $\begin{array}{l}\text { Relative } \\
\text { flexibility } \\
\text { utility }\end{array}$ & $\begin{array}{l}\text { Intention to } \\
\text { share }\end{array}$ & 3 & 0.49 & 345 & .00 & 9.91 & 0.41 & 0.57 \\
\hline Shareaids & $\begin{array}{l}\text { Intention to } \\
\text { share }\end{array}$ & 3 & 0.07 & 345 & .10 & 1.30 & -0.04 & 0.17 \\
\hline Familiarity & $\begin{array}{l}\text { Intention to } \\
\text { share }\end{array}$ & 3 & 0.24 & 345 & .00 & 4.53 & 0.14 & 0.34 \\
\hline Trust & Attitude & 3 & 0.30 & 1257 & .00 & 10.96 & 0.25 & 0.35 \\
\hline
\end{tabular}

The result of our meta-analysis is visualized using a forest plot in Figure 3-4. The x-axis represents the "weighted average effect" $(\beta)$, which is the combined effect size from all the relationships under study. Each relationship average effect is represented by a blue dot bound by a small black line showing the lower limit and upper limit of the confidence interval at $95 \%$. If the confidence interval is entirely on the right side of the vertical line through zero, it means that relationship exhibits a significant positive effect. Conversely, if the confidence interval is entirely on the left side of the vertical line through zero, it means that the relationship exhibits a significant negative effect. However, if the confidence interval intersects the line through zero, it means such a relationship is not statistically significant. Following this line of thought, all relationships with the exception of social benefit on intention to share, perceived risk on intention to share, prosocial utility on intention to share, relative transaction utility on intention to share and shareaids on intention to share are statistically significant.

Further exploring the relationships using their p-values in Table 3-4 shows that all relationships with the exception of the relationships listed in the previous statement are statistically significant because their $p$-values are less than 0.05. Among the statistically significant relationships, attitude on intention to share with a $\beta$ values of 0.49 , relative flexibility utility on intention to share (0.49), perceived behavioral control on intention to share (0.34), trust on attitude (0.30), familiarity on intention to share (0.24), perceived risk on attitude (-0.19), subjective norm on intention to share $(0.18)$ and economic benefit on attitude $(0.14)$ were found to be strongest. This finding is in line with the weighting analysis which categorized these relationships into either "best predictors" or "promising predictors" of the sharing economy. Following the approach of (Naranjo Zolotov et al., 2018), we constructed a model of the best predictors in Figure 3-5. 
To evaluate the amount of heterogeneity in the dataset (Table 3-4) on which the model in Figure 3-5 is based, we made use of the $\mathrm{I}^{2}$ statistics as recommended by (Hak, van Rhee, \& Suurmond, 2016). The $\mathrm{I}^{2}$ statistics is a relative measure of the amount of detected variance that reflects real differences in effect sizes (Borenstein, Hedges, Higgins, \& Rothstein, 2009). We obtained an $\mathrm{I}^{2}$ statistic of $98.38 \%$ which indicates that there is a high level of heterogeneity for the variables listed in Table 3-4.

Independent variable

Attitude

Subjective norm

Perceived behavioral control

Economic benefit

Economic benefit

Trust

Environmental benefit

Social benefit

Trust

Perceived risk

Social benefit

Perceived risk

Perceived risk

Prosocial utility

Relative transaction utility

Relative flexibility utility

Shareaids

Familiarity
Dependent variable

Intention to share Intention to share

Intention to share Intention to share Attitude

Intention to share

Attitude

Attitude

Attitude

Attitude

Intention to share

Intention to share

Perceived enjoyment

Intention to share

Intention to share

Intention to share

Intention to share

Intention to share
Average
$\beta$

0.49

0.18

0.34

0.11

0.14

0.16

0.10

0.13

0.30

$-0.19$

0.06

$-0.05$

$-0.19$

0.02

0.03

0.49

0.07

0.24

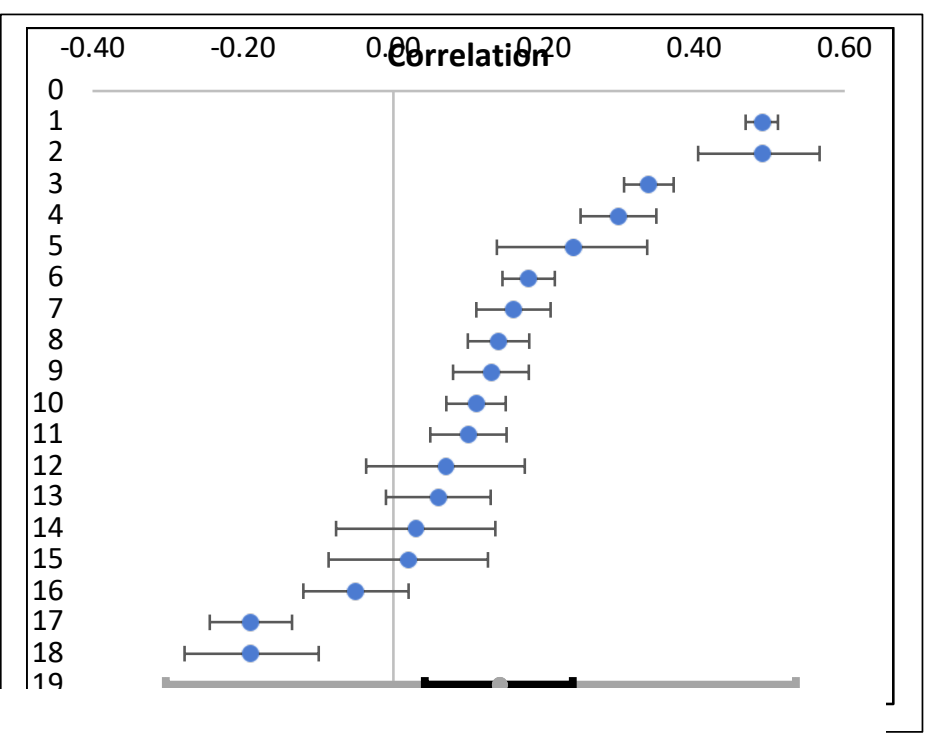

Figure 3-4: Forest plot of meta-analysis ordered by sample

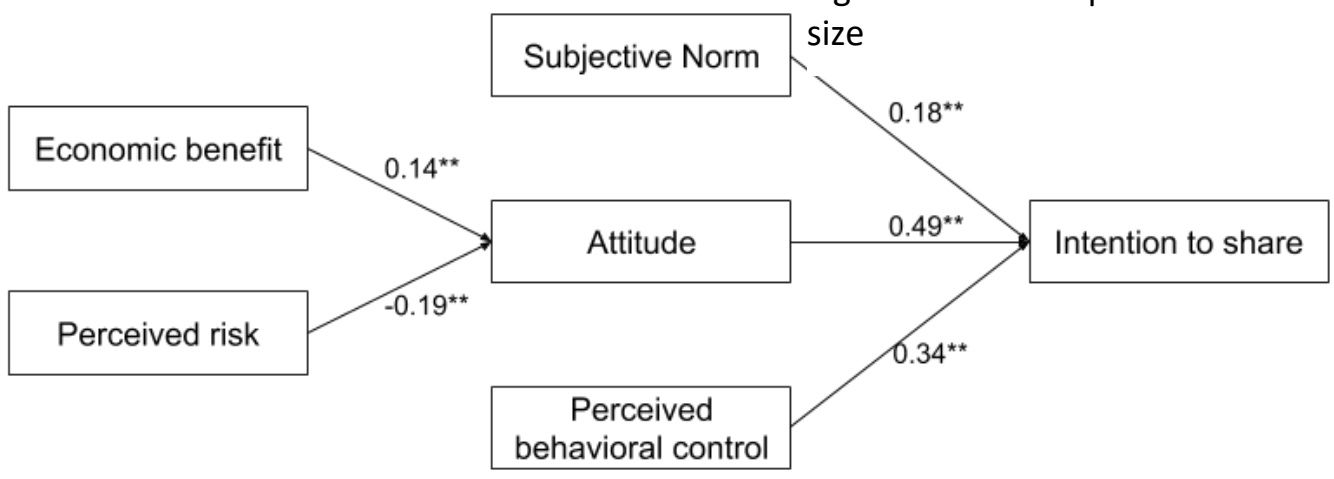

Figure 3-5: Model of drivers for the sharing economy resulting from weight analysis and meta-analysis;

$* * p<0.05$ 


\subsection{Discussion}

We evaluated seventeen (17) theoretical models and constructs in the 22 peer-reviewed literature published on the drivers of the sharing economy. Furthermore, we extracted 249 relationships (independent-dependent variable) from our literature analysis, providing a holistic picture of all constructs used for assessing the sharing economy. A weighting analysis of these relationships helped in revealing the "best" and "promising" predictors in the investigation of the sharing economy. These findings were supported by a meta-analysis which also revealed the strength of these relationships using their "weighted average effect" $(\beta)$ and confidence interval visualized in a forest plot (see Figure 3-4).

"Best" predictors include attitude, perceived behavioral control and subjective norm on intention to share, and economic benefit and perceived risk on attitude. These predictors were also established to be statistically significant by the meta-analysis. This result is in line with findings by (Baptista \& Oliveira, 2016; Naranjo Zolotov et al., 2018), who found that the higher the weight of a variable, the higher its probability to achieve significance in a meta-analysis. These predictors were used in creating new hypotheses highlighted in the model in Figure 3-5. We found the resulting model to be similar to that of the Theory of Planned Behavior (TPB) (Ajzen, 1985), but with an extension of economic benefit and perceived risk on attitude. Economic benefit on attitude was found to be a strong positive predictor for ride sharing (Amirkiaee \& Evangelopoulos, 2018), product sharing (Hawlitschek et al., 2018) and room sharing (Sung et al., 2018). The importance of "saving money" as a motivation on the attitudinal beliefs of peer-to-peer sharing was also emphasized by (Hellwig, Morhart, Girardin, \& Hauser, 2015). Furthermore, perceived risk on attitude was also found to be a strong negative predictor for product sharing (Hawlitschek et al., 2018) and fashion sharing (Lang, 2018). There is some amount of risk involved in sharing one's properties with strangers, and this negatively influences the disposition of people to engage in peer-to-peer sharing (Belk, 2014).

"Promising" predictors from the weighting analysis include relative flexibility utility and familiarity on intention to use, and trust on attitude. These predictors are considered promising because even though their weight is equal to one, they have not been tested up to 5 times (Jeyaraj 
et al., 2006). Results from the meta-analysis also show that these predictors are promising in terms of the strength of their significance and average $\beta$. This finding may suggest that consumers are more willing to participate in peer-to-peer sharing if they are familiar with the service and if there is an "absence of limitations on product use within the sharing system" (Oyedele \& Simpson, 2018). Furthermore, individuals with a higher level of trust in the mediating technology and other users show more positive attitude towards peer-to-peer sharing in various contexts such as car sharing (Mazzella, Sundararajan, Butt d'Espous, \& Mohlmann, 2016) and accommodation sharing (Hawlitschek, Teubner, \& Weinhardt, 2016). However, because these predictors have not been sufficiently tested, we cannot categorize them as best predictors of intention to share. There is still a need for more literature to test the predictors to further determine their predictive power on intention to share.

Previous quantitative research on the sharing economy have made use of TPB, TRA, its variants and self-developed models and frameworks (Table 3-2). Hence, the most evaluated constructs originate from TPB and TRA or are adapted from them. This logically explains the resulting model from our weighting and meta-analysis being very similar to the TPB with an extension of economic benefit and perceived risk on attitude (Figure 3-5). It is important to note that the TPB itself is an adaptation of TRA proposed by (Ajzen, 2011) to strengthen it by including the perceived behavioral control construct. From the derived model in Figure 3-5, attitude with a $\beta$ of 0.49 plays the most important role in determining an individual intention to participate in the sharing economy. This makes sense because the sharing economy is a relatively new concept which is different from the conventional way of consuming goods and services and will largely depend on an individual's positive or negative evaluative feeling about it to adopt it. This is in line with previous research which, using other theories, identified attitude and its variants as the most important driver of the individual adoption of various technologies such as mobile banking ( $\mathrm{T}$. Oliveira, Faria, Thomas, \& Popovič, 2014), e-commerce (Hernandez, Jimenez, \& Martín, 2009) and e-participation (Naranjo-Zolotov, Oliveira, \& Casteleyn, 2019). It is interesting to note that environmental benefit, with a $\beta$ of 0.10 , did not have a good predictive power on individual's attitude about the sharing economy. This implies that even though the environment is a major beneficiary of the sharing economy and collaborative consumption, individuals do not consider it when evaluating their feeling about various sharing services. This could be because of their non- 
awareness of the connection between fostering a sustainable environment and their use of the sharing economy. Furthermore, social benefit was neither a good predictor of attitude $(\beta=0.13)$ nor intention to share $(\beta=0.06)$. Put in the context of smart sustainable cities, which are made up of the three dimensions of the economy, environment and society, our findings show that users of the sharing economy prioritize economic benefits over environmental and social benefits (Akande, Cabral, Gomes, \& Casteleyn, 2018). This is in line with findings by (Böcker \& Meelen, 2017) who noted that users of the sharing economy are more motivated by financial benefit than by positive social reasons or positive impact on the environment.

Although perceived risk had a significant predictive power of -0.19 on perceived enjoyment in the meta-analysis, it had a weight slightly below 0.80 . We recommended further research on this construct and its connection with the intention to share to decisively ascertain its impact in the prediction of the sharing economy. Also, trust on intention to share was found to be significant with a $\beta$ of 0.16 but obtained a very low weight of 0.50 in the weight analysis. As suggested by (Naranjo Zolotov et al., 2018), this low weight may discourage the use of this construct in future studies.

\subsection{Implications}

The consolidation of the aggregate effect of an independent variable on a dependent variable using a weight analysis, and the appraisal of their predictive strength and significance using a metaanalysis, allowed us to identify attitude as the most important predictor of the intention to share. Overall, our results show that all the constructs in TPB with an extension of economic benefit and perceived risk on attitude are the best predictors of intention to share. These results suggest the continued use of economic benefit and perceived risk on attitude in subsequent research of individual level adoption of the sharing economy.

Furthermore, we have also identified patterns, trends and issues with independent-dependent variable relationships used in various models to study the sharing economy. For example, even though trust on intention to share was frequently used in previous studies and had a significant $\beta$, 
its weight was very low. These findings can serve as a foundation for researchers to accurately evaluate previously used constructs and build on existing research, incorporating new variables in their research models. In line with (Naranjo Zolotov et al., 2018), we recommend that independentdependent relationships with high use frequency, low weight and non-significant $\beta$ be excluded from further analysis while promising predictors be included in future research.

Understanding the drivers of the sharing economy is critical for entities that aim to promote smart and sustainable urban development. The weight analysis identified attitude, subjective norm and perceived behavioral control on intention to share, and economic benefit and perceived risk on attitude as being the best predictors. These results were supported by the meta-analysis as being significant. Of these results, attitude on intention to share was established as the most important predictor. This implies that city councils and governments should prioritize policies and strategies that influences citizens' positive disposition towards cleaner practices that reduce their environmental adverse impact. Some of these strategies could include supporting businesses with environmentally sustainable practices, improving public transportation and cycling infrastructures to encourage its use rather than driving and promoting waste sorting and recycling. This will help to promote an understanding of the connection between a citizen's resource consumption lifestyle and its effect on the environment, which will in turn promote a concern for the planet earth and its biosphere (Kalsoom, 2018).

Looking at the three dimensions of smart sustainable cities, the high weight and significance of economic benefit on attitude and low weight and significance of social and environmental benefit on attitude may suggest that citizens are more interested in the financial implication of sustainable practices than the societal or environmental benefit. The sharing economy has been established in literature to provide additional income for owners and providers while saving costs for users (X. Wu \& Zhi, 2016). From the perspective of urban sustainability, this result implies that city councils and governments should also emphasize the economic benefits of adopting sustainable practices to encourage their adoption, since citizens consider it more important than social and environmental benefits. Certain "green goods" such as green food (Barosh, Friel, Engelhardt, \& Chan, 2014), green building (Eichholtz, Kok, \& Quigley, 2010) and electric vehicles (Egbue \& Long, 2012a) have been established in literature as being more expensive upfront even though they 
may be cheaper in the long run. There is a need to make green solutions more competitive in terms of cost since potential financial benefit plays a major role in their adoption. Some options city councils could consider to make smart sustainable initiatives financially attractive include the use of tax incentives to (initially) subsidize costs and increased research investments in sustainable innovations (Egbue \& Long, 2012b).

\subsection{Conclusion}

We evaluated drivers of individual adoption of the sharing economy using a weight and metaanalysis of 249 relationships (independent - dependent variables) obtained from 22 quantitative studies and discuss their implication on sustainability in a smart city. This research found that quantitative research on drivers of the sharing economy only started in the year 2016 and no study has been done so far in Africa, Central and South America and Australia. This research further establishes the 'best' and 'promising' predictors of the sharing economy using criteria proposed by (Jeyaraj et al., 2006). The identified best predictors include attitude, subjective norm and perceived behavioural control on intention to share; and economic benefit and perceived risk on attitude. Attitude was identified as playing the most important role in predicting intention to share, suggesting that city councils and governments should pay particular attention to strategies that influence the positive predisposition of citizens towards planet Earth and life on it in their quest to make cities smart and sustainable. Furthermore, the best predictors were also found to be statistically significant in the meta-analysis implying that they can be used for future research on the adoption of innovative sustainable solutions within cities. The identified promising predictors include relative flexibility utility and familiarity on intention to share; and trust on attitude. Although, these constructs have a weight of 1, they have not been sufficiently tested in previous research. Hence, more research is needed on these constructs to ascertain their predictive power in the adoption of the sharing economy. Overall, this research critically consolidates existing quantitative literature on the sharing economy and serves as a solid theoretical foundation for all members of the academic community that are interested in the adoption of the sharing economy to foster the sustainability of cities. 


\subsection{Limitations and future research}

There are two limitations to this study which readers should be aware of.

Firstly, like other literature review studies, the 22 articles that were included in our analysis were constrained by the selection criteria highlighted in section 2. It is possible that there are other studies not included in our analysis because they are either qualitative, yet to be published, published in non-peer-reviewed mediums such as books or magazines, or published in languages other than English. Hence, generalizations based on our results should be done with caution.

Secondly, studies included in our analysis are assumed to be methodologically sound. This means that their data were pulled from a complete probability sample, measurements are genuine, correct and reliable and appropriate statistical analysis have been rigorously used. However, in reality this is not always verifiable. Given that the weight and meta-analysis of this study is based on the results of previous studies, the accuracy of our results is based on the accuracy of the previous research used. This should be kept in mind while interpreting our results.

This research synthesized outcomes from different use cases of the sharing economy such as room sharing, car sharing and fashion sharing. However, there may be slight variations between the individual adoption of each of these use cases. We recommend a comparative meta-analysis among the different contexts of use of the sharing economy. Furthermore, using the derived model in Figure 3-5 as a foundation, we suggest the exploration of other constructs in emerging contexts of the sharing economy. For example, exploring the individual adoption of peer-to-peer renewable energy sharing within microgrids. 


\title{
Chapter 4 - The Lisbon Ranking for Smart Sustainable Cities in Europe
}

\begin{abstract}
$^{6}$
There has recently been a conscious push for cities in Europe to be smarter and more sustainable, leading to the need to benchmark these cities' efforts using robust assessment frameworks. This paper ranks 28 European capital cities based on how smart and sustainable they are. Using hierarchical clustering and Principal Component Analysis (PCA), we synthesized 32 indicators into 4 components and computed rank scores. The ranking of European capital cities was based on this rank score. Our results show that Berlin and other Nordic capital cities lead the ranking, while Sofia and Bucharest obtained the lowest rank scores, and are thus not yet on the path of being smart and sustainable. While our city rank scores show little correlation with city size and city population, there is a significant positive correlation with the cities' GDP per inhabitant, which is an indicator for wealth. Lastly, we detect a geographical divide: 12 of the top 14 cities are Western European; 11 of the bottom 14 cities are Eastern European. These results will help cities understand where they stand vis-à-vis other cities, giving policy makers an opportunity to identify areas for improvement while leveraging areas of strength.
\end{abstract}

\subsection{Introduction}

Cities are the hubs of innovation that drive the economic development of the world (Currid, 2006). Worldwide, the cities' population is growing, and it is projected that more than $60 \%$ of the population of the world will live in cities by 2030 (United Nations, 2014). However, the uncontrolled growth of a city can have adverse effects on the environment and its citizens (Annez \& Buckley, 2008; Organisation for Economic Co-Operation and Development \& China Development Research Foundation, 2010), and the anticipated growth of cities is expected to pose unprecedented sustainability challenges, both on infrastructures and the environment (David, 2017; Estevez et al., 2016; Han et al., 2016). These in turn will affect the quality of life of citizens as well as the efficiency of a city's operations (Degbelo, Granell, et al., 2016). Some of these

\footnotetext{
${ }^{6}$ The text from this chapter has been published as Akande, A., Cabral, P., Gomes, P., \& Casteleyn, S. (2019). The Lisbon ranking for smart sustainable cities in Europe. Sustainable Cities and Society, 44, 475-487. https://doi.org/https://doi.org/10.1016/j.scs.2018.10.009
} 
challenges are already being addressed through the development of intelligent technologies (Castán et al., 2016; Degbelo, Bhattacharya, et al., 2016; Vinod Kumar \& Dahiya, 2017). However, many of these smart solutions are not aligned with sustainability targets, thereby generating the concept of smart sustainable cities (Ahvenniemi et al., 2017): A smart sustainable city is an innovative city that uses information and communication technologies (ICTs) and other means to improve quality of life, efficiency of urban operation and services, and competitiveness, while ensuring that it meets the needs of present and future generations with respect to economic, social, environmental as well as cultural aspects (UNECE, 2015a).

Given the various interventions to improve liveability in cities, there is no better time to take a holistic view of the urban space, studying its sustainability using various dimensions (McDonnell \& MacGregor-Fors, 2016; Phillis, Kouikoglou, \& Verdugo, 2017a). It is also important to be able to measure the performance of these interventions (Chourabi et al., 2011; Webb, Hawkey, \& Tingey, 2016).

The demand for city rankings and assessment studies that address sustainability issues have increased over the past decade because cities are now seen as a leverage point in the quest for global sustainability due to the agglomeration of population in them (Grant \& Chuang, 2012a). Such studies serve as planning and evaluation tools for politicians, city administrators and urban planners to compare different project / policy alternatives. City rankings helps policy makers to understand how globalization and urbanization affect our urban spaces (Grant \& Chuang, 2012a). It is an important tool to help cities understand how they performed in the different dimensions of urban sustainability compared to other cities within the same region and identify areas for improvement.

In the past decade, several studies use the indicator-based approach to access various dimensions of urban smartness and sustainability, aggregate these dimensions and benchmark global cities based on them (Phillis et al., 2017). Some of these studies include the United Nation's (UN) City Prosperity Index (UN-HABITAT, 2015), the Sustainable Cities Index (Batten, 2016), the Cities in Motion Index (Berrone, Ricart, Carraso, \& Ricart, 2016), the Global Power City Index (Ichikawa, Yamato, \& Dustan, 2017; Mori Memorial Foundation, 2016), the Mercer Quality of Living (Mercer, 2018), the Spatially Adjusted Liveability Index (The Economist Intelligence Unit, 2016), the CityCard Index (Grant \& Chuang, 2012b), the Cities of Opportunity index (PwC, 2016) and the Sustainable Assessment by Fuzzy Evaluation (SAFE) index (Phillis et al., 2017b). These 
studies attempt to benchmark several global cities using indicators ranging from 17 to 77 in number with various weighting and aggregation methods.

Other studies have ranked more specific aspects of urban sustainability, such as urban mobility (Bojković, Petrović, \& Parezanović, 2018), urban water management (van Leeuwen, Frijns, van Wezel, \& van de Ven, 2012), urban air quality (Sheng \& Tang, 2016) and urban economic development (Giffinger, Haindlmaier, \& Kramar, 2010).

The European Union (EU) supports the movement of its cities to being smart and sustainable. This is exemplified by its conscious efforts to drive this by investing in various smart city initiatives. On the Market Place of the European Innovation Partnership on Smart Cities and Communities website, there are $34 \mathrm{EU}$ projects in different cities focused on the various sector components of smart cities ${ }^{7}$ (European Commission, 2016c). But beyond these smart city initiatives, the EU is also concerned with alleviating the various pressure that come along with urbanization as well as the sustainable development of its cities (European Commission, 2017).

In the past, multiple city rankings have been developed to benchmark European cities. These include the European Smart Cities ranking (Giffinger et al., 2007), the European Green Capital Award (Gudmundsson, 2015), the European Green City Index (Siemens, 2009), the European Green Leaf Award (European Commission, 2016a), European Soot-free City Ranking (Reh et al., 2013), Europe Quality of Life Index (Numbeo, 2016) and Urban Ecosystem Europe (Berrini \& Bono, 2007). Although these studies have contributed to the developing discourse on sustainable strategies of cities within the European Union, they are still plagued by some methodological gaps (McManus, 2012; Meijering, Kern, \& Tobi, 2014), which we aim to address with our research:

1. Lack of a proper definition of a ranking theme: In a bid to fuse several concepts and ideas into a single ranking study, the previous studies fail to provide a definition of their ranking theme (Meijering et al., 2014). A proper definition of the ranking theme is important because it gives potential users of the study a clear understanding of the multidimensional phenomenon being measured. This in turn determines the design of the theoretical framework and methodological characteristics of the ranking which influences the final ranking outcome (OECD, 2008). The ranking theme for this study is "Smart Sustainable Cities" as defined by the United Nations Economic Council for Europe (UNECE, 2015a).

\footnotetext{
${ }^{7}$ https://eu-smartcities.eu/eu-projects
} 
2. Selection of Cities: Benchmarking cities involves comparing urban areas with diverse history, geography, features, population, trajectory and governance. This makes objective comparison very complex, hence requiring the need for a city selection criterion (Meijering et al., 2014). The urban benchmarking studies mentioned above have made use of either a geographic scope, population size or convenience sampling to select cities to build an index and rank. However, Aksoy et al. (2016) and KPMG (2010) recommend the use of a city typology to make benchmarking more meaningful. A city typology ensures that the cities being compared have a useful amount of homogeneity and is based on the city's population density, economic character, wealth, climate and history (KPMG, 2010b). In this research, we selected cities as defined by the territorial typologies for European cities and metropolitan areas (Eurostat, 2013). Specifically, we made use of cities categorized as "capital metro regions" within the European Union.

3. Data sourcing: The source of data for benchmarking cities determines the credibility of the index created and ranking done (Meijering et al., 2014). The urban benchmarking studies mentioned above have obtained data through various means including expert-group interviews, questionnaires and publicly available databases from national statistical offices. This can bring to question the consistency and coherence of the used data, which will inadvertently affect the results obtained. We propose to use Eurostat, which is a single open database from a credible source (Feldmann, 2008). This will ensure the consistency of the data being used and guarantee the reproducibility of our results.

4. Weighting: The creation of an index involves the appropriate weighting of variables used in its creation. While some of the urban benchmarking studies mentioned above are opaque about their weighting methodology, others make use of either an Equal Weighting (EW) approach or participatory methods. The Equal Weighting (EW) method is one where all variables are given equal weights (Debnath et al., 2014; Meijering et al., 2014). This is however not interesting because it assumes all variables contribute equally (without any empirical basis) to the phenomenon under study (Kahn, 2006; OECD, 2008). The participatory methods is one where various stakeholders are used to assign weights (Giffinger et al., 2010; Kahn, 2006; Mayer, 2008; Morse \& Fraser, 2005; OECD, 2008). Although subjective, this method works well when there is a well-defined basis for evaluating the phenomenon under study, which is difficult to obtain for international comparisons (Munda, 2004). Both methods of weighting 
create a composite index without taking cognizance of the interrelationship between indicators. This leads to the creation of an index that is "indicator rich but information poor" which often confuses and misleads urban policy makers (OECD, 2008). It will be interesting to statistically explore the suitability, underlying nature and structure of the data set and use that information for weighting. In our approach, we will be making use of variance-based statistical techniques to determine the appropriateness of the selected indicators to describe smart sustainable cities, determine how the different indicators change in relation to each other and across European cities, and use this information to weight and aggregate our data.

The aim of this research is to use a well-motivated weighting scheme to create a properly defined ranking for smart sustainable cities for a clearly defined selection of cities in Europe based on open and credible data source(s). To achieve this, we make use of indicators jointly proposed by the United Nations Economic Commission for Europe (UNECE) and the International Telecommunications Union (ITU), data from Eurostat's Urban Audit database and Principal Component Analysis (PCA) to rank European capital cities based on how smart and sustainable they are.

The indicators used were developed by UNECE-ITU after consultations with member states and various stakeholders worldwide (UNECE, 2015a). The framework proposed by UNECE-ITU uses a tripartite approach under the broad areas of economy, environment, and society (Figure 4-1). Each of these three broad areas are further broken down into six topics, with a number of indicators characterizing each topic. In a bid to operationalize the theoretical concept of "Smart Sustainable Cities", we selected 32 indicators for which publicly available data could be found from the UNECE-ITU framework. These 32 indicators have been selected as a suitable balance between the depth and width of our research (Cruz-Jesus et al., 2017) and also to include all the thematic areas in the framework. These 32 indicators are also contained in similar frameworks such as the International Standards Organization Indicators for city services and quality of life (ISO, 2014a) and the EU sustainable development strategy (European Commission, 2016b).

Data on the selected indicators were obtained from Eurostat. Eurostat is the authority on statistics for the European Union, providing statistics to enable comparison between countries, regions and cities in the EU. The data used in this study are public and can be accessed and freely downloaded 
online $^{8}$. Eurostat ensures that the quality and integrity of its data are not compromised by following an encompassing quality management approach and making its data suitable for research purposes (Angeloni, 2016; Eurostat, 2017; Jacinto \& Soares, 2008).

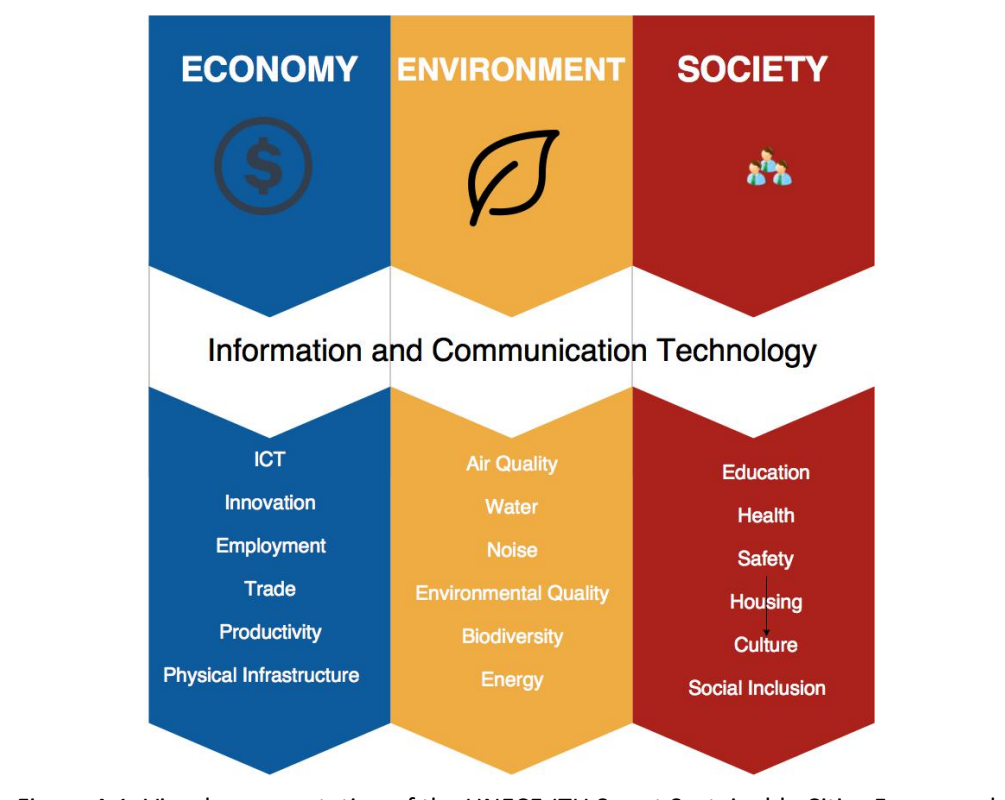

Figure 4-1: Visual representation of the UNECE-ITU Smart Sustainable Cities Framework

The data obtained was analysed using a dimension reduction algorithm called the Principal Component Analysis (PCA). PCA is a multivariate statistical procedure used to synthesize multiple variables by transforming the original variables into a new set of orthogonal variables in such a way that variation is emphasized and strong patterns become noticeable ( $\mathrm{Xiao}, \mathrm{Lu}, \& \mathrm{Xu}$, 2017). These new sets of variables are fewer than or equal to the number of original variables and have been transformed so that a small number of principal components will account for a large part of the original data variation (Vidal, Ma, \& Sastry, 2016). In doing this, PCA makes the exploration and visualization of high dimensional datasets easier.

PCA have been applied and found useful in many fields including archaeology (I.T. Jolliffe \& Cadima, 2016), atmospheric science (Hannachi, Jolliffe, Stephenson, \& Trendafilov, 2006), neuroscience (Hyvärinen, 2013), data mining (Metsalu \& Vilo, 2015; Witten, Frank, Hall, \& Pal, 2016), finance (Liao, Huang, \& Wu, 2012), taxonomy (Kucharczyk, Kucharczyk, Stanislawek, \& Fedor, 2012), medicine (Caprihan, Pearlson, \& Calhoun, 2008; Omucheni, Kaduki, Bulimo, \& Angeyo, 2014) etc. PCA has also been used in several aspects of urban studies such as local

\footnotetext{
${ }^{8}$ http://ec.europa.eu/eurostat/web/main/home
} 
economic development (Wong, 2002), urban economics (C. Chen, Ding, \& Liu, 2008), quality of residential environment (Tu \& Lin, 2008), life expectancy (Takano, Nakamura, \& Watanabe, 2002), urban heat island (Weng, Liu, Liang, \& Lu, 2008), and urban remote sensing (Li \& Yeh, 1998). PCA serves as an effective tool for synthesizing multidimensional data and creating new indices, which can be used for ranking (Marsal-Llacuna, Colomer-Llinàs, \& Meléndez-Frigola, 2015; Wei, Huang, Li, \& Xie, 2016). However, none of the studies listed above sought to rank cities using PCA based on a standardized framework.

Specifically, the objectives of this study are to:

1. Systematically reduce the number of indicators required to characterize a smart and sustainable city using open data and multivariate statistics;

2. Develop a single quantitative index to measure and rank European capital cities, based on a synthesis of the reduced set of indicators obtained in objective 1; and

3. Find the possible association of the cities' rank score with GDP and other variables.

4. Identify specific indicators which cities can leverage to significantly improve how smart and sustainable they are in relation with other European cities.

\subsection{Data and methods}

\subsubsection{Study area}

Our focus in this research is on the capital cities of the 28 member nations of the EU shown in Figure 4-2, because of the unique role they play in the EU serving as hubs of innovation, growth, and diversity (European Commission, 2016; United Nations, 2014). 


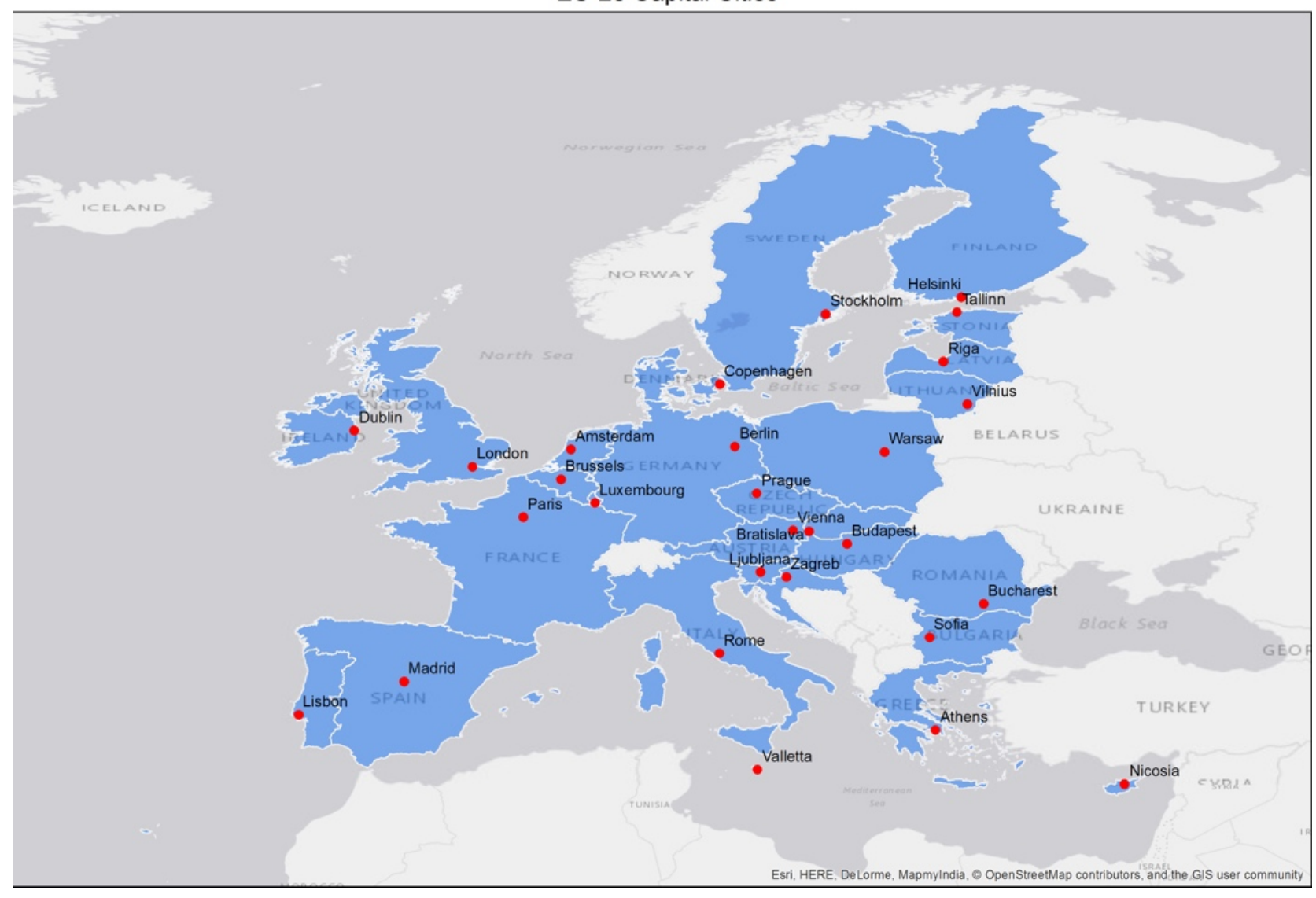

Figure 4-2: Map showing EU 28 with their respective capital cities

\subsubsection{Data}

Data for the indicators, used to define all topics under the three thematic areas of the UNECE-ITU Smart Sustainable cities indicators, were obtained for the EU-28 capital cities from Eurostat (European Comission, 2016). Data from the Eurostat's general and Urban Audit database have been used for similar studies including European Cities' green performance evaluation (Serbanica \& Constantin, 2017), urban mobility indicator creation (Bojković et al., 2018), EU sustainable development assessment (Szopik-Depczyńska et al., 2018) and European cities smart and sustainable urban regeneration modelling (García-Fuentes et al., 2017).

As shown in Table 4-1, the data used for this research are made up of $78 \%$ local data for individual cities under study, 16\% regional data, and 6\% national data. The list of 32 indicators for which data were obtained can be found in Appendix A. The inclusion of regional and national data was necessary because of the lack of local data for certain indicators needed to achieve full characterization of all topics under the three broad areas as outlined by UNECE-ITU. However, 
these data have been adequately denominated to make comparison across different sized cities adequate.

Table 4-1: Data used

\begin{tabular}{|l|l|l|}
\hline Database & Spatial Level & Number of indicators \\
\hline Urban Audit & Local - NUTS3 & 25 \\
\hline Eurostat Database & Regional - NUTS2 & 5 \\
\hline Eurostat Database & National & 2 \\
\hline Total & & 32 \\
\hline
\end{tabular}

\subsubsection{Methods}

In order to rank European capital cities, it is necessary to obtain a single measure of their smartness and sustainability. Since we are working with 32 variables, we made use of a two-pronged approach of feature selection to obtain a smaller number of variables to represent the larger group of 32 variables, and then feature extraction to build a new set of variables while reducing noise and redundancy in the process.

\section{Data Processing}

Various summary statistics including the mean, median, standard deviation, and correlation matrix of all 32 variables for the 28 selected European capital cities selected were calculated using the analysis ToolPak of Microsoft excel as one of the steps to understand the underlying structure of our data (Berk \& Carey, 2009).

City rank values are usually influenced by the presence of outliers in their variables, and these must therefore be taken care of. Variables containing outliers were identified as those having a distribution with absolute skewness greater or less than one (Aesaert et al., 2017; Groeneveld \& Meeden, 1984). Boxplots and histograms were plotted for each variable to further understand outliers. Variables identified to be skewed were transformed using the powerTransform function in R. This uses the maximum likelihood approach of Box \& Cox (1964) to select the appropriate transformation power, which was applied on the relevant variables. 
Thereafter we normalized our data, scaling down values of the indicators. Normalization is crucial in PCA because it is a variance maximizing exercise and sensitive to the relative scaling of the original variables. This step prevents one variable from dominating all others, thus enabling the data analysis method to treat the data "fairly" (Kotsiantis, Kanellopoulos, \& Pintelas, 2006). To normalize our data we made use of the minimum and maximum value of each variable. In this way, we ensured that the values of each variable range between 0 and 1 (Bannerjee, Bone, \& Finger, 2016).

\section{Feature selection}

Clustering was used as a robust method to identify homogenous group of variables called "clusters" sharing similar characteristics across all cities under study such that these clusters have "maximum internal homogeneity (withing the cluster) and maximum external heterogeneity (between clusters)" (Cruz-Jesus et al., 2017). We made use of the FactoMineR package in R to perform a hierarchical clustering on all 32 variables grouped according to the EU28 capital cities to obtain an optimal number of clusters (Husson, Lê, \& Pagès, 2010b). The basic algorithm for the hierarchical clustering as applied to our study can be described as follows:

1. There are 32 objects (points) to classify.

2. We find the closest two points and merge them into a new point.

3. We compute the similarity (distance) between this new point and the reminaing points.

4. We repeat steps 2 and 3 until there is only one point remaining

We then made use of the variance based feature reduction technique called "low variance filter" (Kouser, Lavanya, Rangarajan, \& Acharya Kshitish, 2016). Here, we calculated the variance of each variable in a cluster and removed those parameters with variance below a certain threshold. This is achieved by arranging the variance of all variables in a cluster in descending order and adding the variance of each variable (starting with the variable with the largest variance) until a specified threshold Z\% is reached. Thereafter, the remaining variables are discarded. This step ensures that we retain only variables that hold sufficient information in each cluster. 


\section{Feature Extraction}

PCA was applied to selected variables to transform the data from a high-dimensional space to a low-dimensional space. To test the suitability of our data for reduction, we made use of the Bartlett's test of sphericity. The Bartlett's measure tests for our correlation matrix being an identity matrix, which indicates that there is some relationship between our variables (Bartlett, 1937; Doyle et al., 2017). We also performed the Kaiser-Meyer-Olkin (KMO) test to measure the sampling adequacy of our data for PCA (Cruz-Jesus et al., 2017). We thereafter did a PCA using the following steps:

1. We calculated the correlation matrix of all variables obtained from the low variance filter in the previous step.

2. Using the correlation matrix, we deduced the eigenvector and eigenvalue. The eigenvector indicates the direction of our new axis and the eigenvalue indicates the magnitude of variability in the new axis.

3. We multiplied our original data with the eigenvectors to rotate our data to align with the new axis (Principal Components).

The feature selection and feature extraction was implemented in R (Husson et al., 2010b; Lê, Josse, \& Husson, 2008).

For this research the Kaiser's criterion was used to select appropriate Principal Components for further analysis (Friesen et al., 2016; Scariano, 2013). Kaiser (1960) proposed selecting principal components with eigenvalues greater than one (1) and Humphreys \& Montanelli (1975) recommended the Kaiser's criterion for large correlation matrices such as ours.

To determine contributing variables to each principal component under consideration, variable eigenvectors were investigated (Friesen et al., 2016). We made use of the contribution of each variable to the inertia explained by axis (CTA) and the part of variance of each variable explained by each axis (CTR) (Isnard \& Sautory, 1994; Koch, 2013). We made use of CTA and CTR because they can be used in interpreting our results statistically and geometrically (Abdi \& Williams, 2010).

Each component selected was weighted based on its variance in proportion to the total variance of all selected components. Variable loadings were multiplied by each selected principal component's weight and summed up to obtain a factor score. From the normalized table, we then 
calculated the coordinate of each capital city in relation to this factor score, multiplying the coordinate of vectors representing these cities by their respective factor score and summing them together (Friesen et al., 2016). This is more fully explained in Appendix B.

\subsection{Results and Discussion}

\subsubsection{Hierarchical clustering}

As a first step in reducing the dimensionality of our data, hierarchical clustering was done to identify groups of similar variables in our dataset. We explored our hierarchical cluster solution using the dendogram shown in Figure 4-3. The dendogram lists all the variables represented as numbers, which are clustered along the x-axis and the distance at which the clusters are formed at each level on the y-axis. Five clusters were selected to characterize the structure of our data (indicated using coloured boxes on the $\mathrm{x}$ axis in Figure 4-3). Taking a closer look at variables in each cluster, it can be seen that, with the exception of a few variables, each cluster tends to contain variables that belong to the same topic and area in the UNECE-ITU smart sustainable cities framework. 


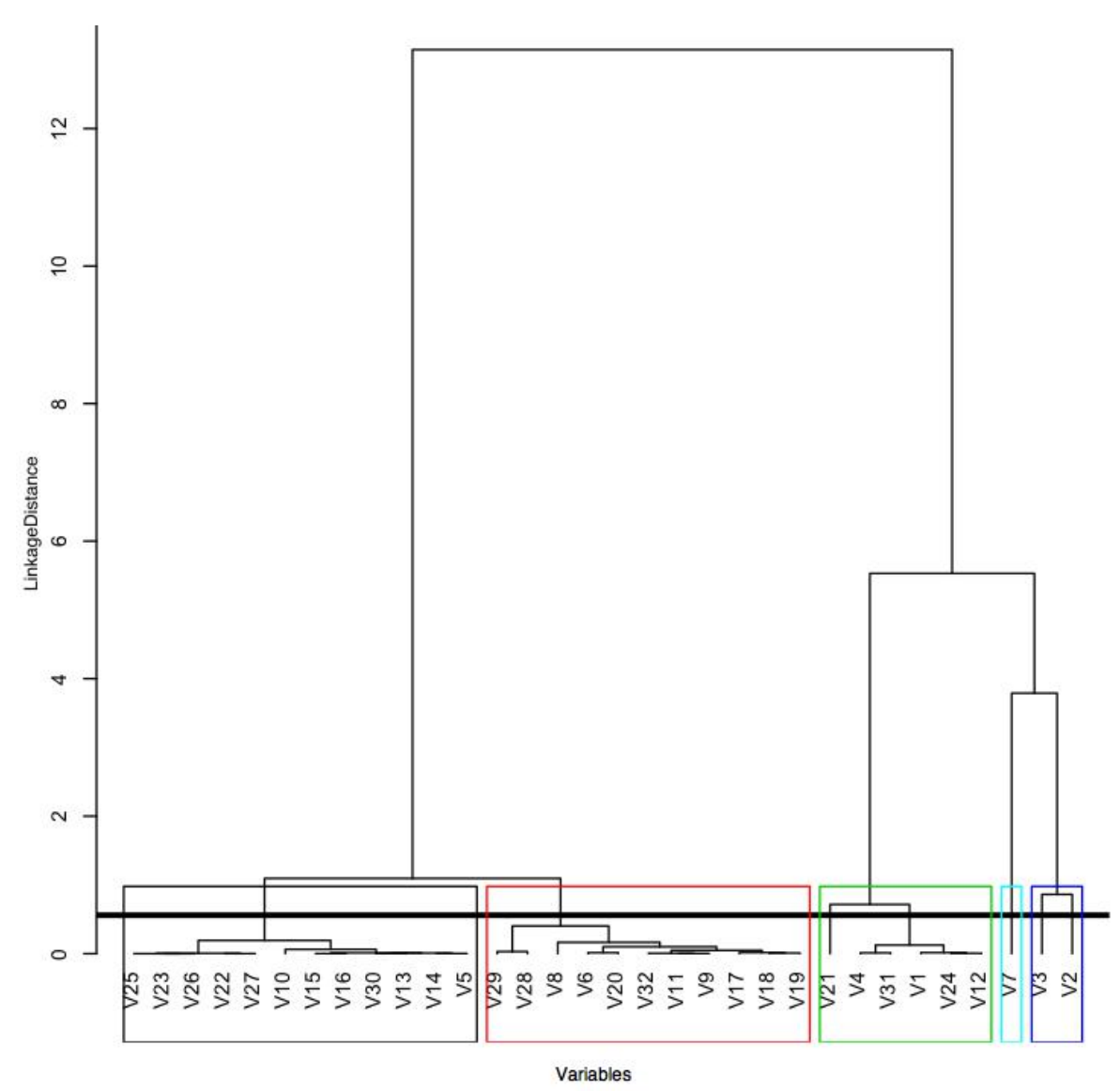

Figure 4-3:Hierarchical Clustering Dendogram

The individual factor map in Figure 4-4 is a plot of the Principal Component for variables on the first two principal components. It reveals the structural relationship between the variables, the cities, and the components. The first component accounts for $64.05 \%$ of the total variance while the second component accounts for an additional 15.63\%. Together they account for a total variance of $79.68 \%$. From it, we can see that variable 7 , which is the length of dedicated bicycle lanes, has a high score on component one, while variable 23, which is the percentage of total deaths, has a low score. The five selected clusters can also be seen on the factor map (Figure 4-4; same colour codes used as in Figure 4-3). 


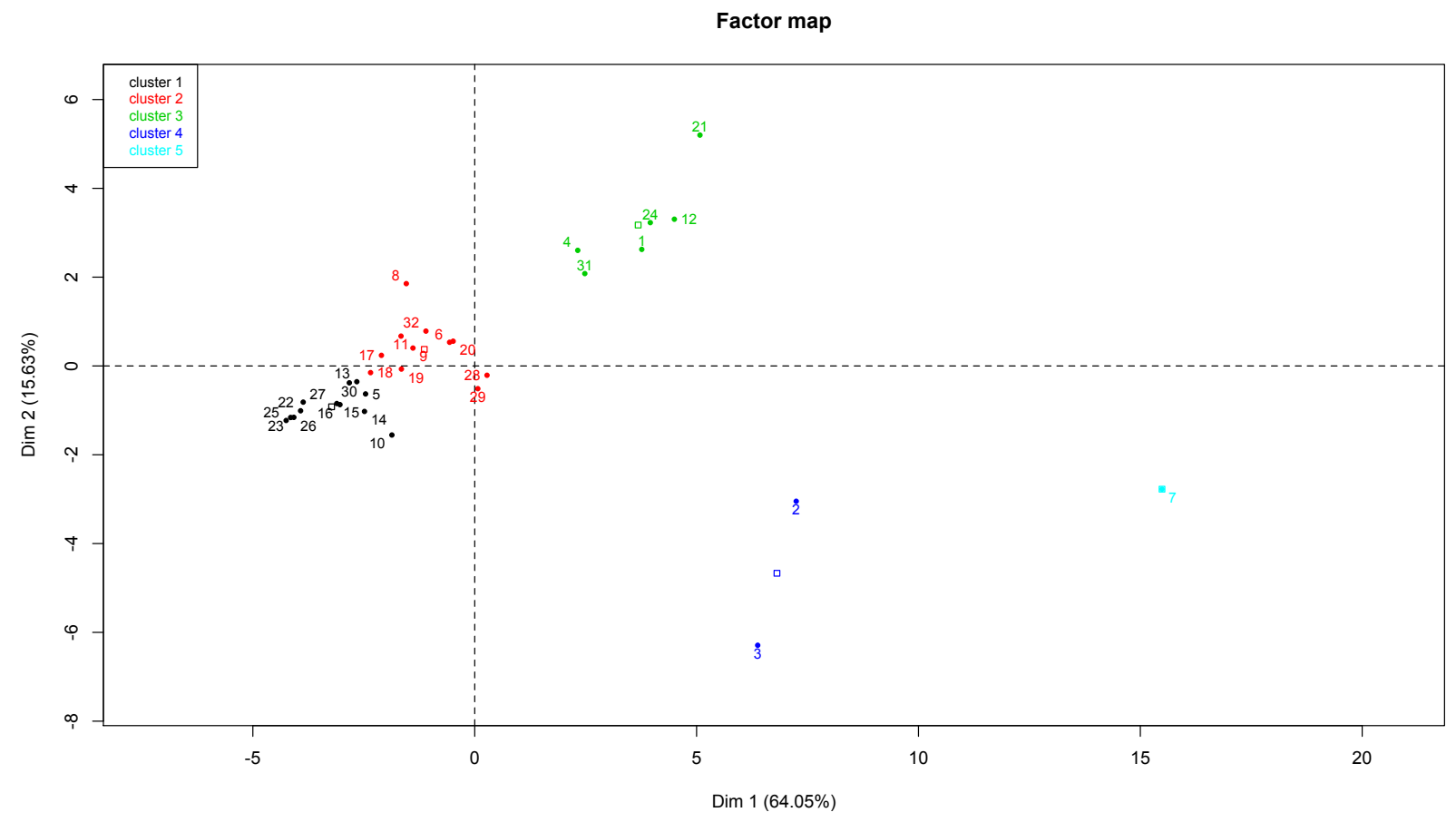

Figure 4-4: Individuals factor map

\subsubsection{Principal Component Analysis}

After reducing the number of variables using the low variance filter approach highlighted in our methodology above, 15 variables were selected as shown in Table 4-2.

Table 4-2:Variables used in ranking

\begin{tabular}{|l|l|}
\hline Patent applications to the EPO per million of active population & V3 \\
\hline Persons employed between the ages of 20 and 64 (\%) & V4 \\
\hline $\begin{array}{l}\text { E-commerce, Customer Relation Management (CRM), and } \\
\text { secure transactions (\%) }\end{array}$ & V5 \\
\hline $\begin{array}{l}\text { Length of bicycle network (dedicated cycle paths and lanes) } \\
(\mathrm{km})\end{array}$ & $\mathrm{V} 7$ \\
\hline $\begin{array}{l}\text { Number of days particulate matter PM10 concentrations } \\
\text { exceed } 50 \mu \mathrm{g} / \mathrm{m}^{3}\end{array}$ & $\mathrm{~V} 8$ \\
\hline Greenhouse gas emissions from transport (million tonnes) & V10 \\
\hline $\begin{array}{l}\text { Share of the urban waste water load (in population } \\
\text { equivalents) treated according to the applicable standard (\%) }\end{array}$ & V12 \\
\hline
\end{tabular}




\begin{tabular}{|l|c|}
\hline $\begin{array}{l}\text { Proportion of population living in households considering that } \\
\text { they suffer from noise (\%) }\end{array}$ & V13 \\
\hline Protected terrestrial area (\%) & V17 \\
\hline Electricity generated from renewable sources (\%) & V19 \\
\hline Share of total deaths per year (\%) & V23 \\
\hline Number of theatres & V29 \\
\hline Gender pay gap in unadjusted form (\%) & V30 \\
\hline Voter turnout in national and EU parliamentary elections (\%) & V31 \\
\hline Gini coefficient of equalized disposable income & V32 \\
\hline
\end{tabular}

We performed the Bartlett's measure test and obtained a p-value of $2.54 * 10^{-5}$, which is less than 0.05 and is statistically significant. Hence, we can perform a PCA on our dataset. Furthermore, the Kaiser-Meyer-Olkin (KMO) measure of sampling adequacy for our overall dataset yielded a value of 0.65 indicating a relative compactness of the patterns of the correlations in our dataset (CruzJesus et al., 2017). Our principal component analysis should therefore yield distinct and reliable results.

Performing a PCA on the variables in Table 4-2 gives a total of 15 components. In Table 4-3, the proportion of variance indicates how much of the total variance a principal component has. The first principal component explains the greatest amount of the total variance of our data. The total amount of variance explained by subsequent components decreases with their distance from PC1. However, only the first four principal components are of interest to us because their eigenvalues are greater than one (Kaiser, 1960). 69.1\% of variance can be explained by four principal components retained. All other components are ignored.

Table 4-3: Principal Component Eigenvalues

\begin{tabular}{|l|l|l|l|l|l|}
\hline Component & Eigenvalue & Difference & Proportion & Cumulative & PCw (\%) \\
\hline PC1 & 4.87 & 2.71 & 32.50 & 32.50 & 47.05 \\
\hline PC2 & 2.17 & 0.27 & 14.46 & 46.95 & 20.93 \\
\hline PC3 & 1.89 & 0.48 & 12.66 & 59.61 & 18.33 \\
\hline PC4 & 1.42 & 0.43 & 9.45 & 69.06 & 13.68 \\
\hline
\end{tabular}

The first principal component represents $32.5 \%$ of the total variance, as shown in Table 4-3. Variables with CTA values greater than the average in an axis, Table 4-4, are considered to contribute significantly to that axis. These CTA values have been highlighted in green in Table 4-4. For the vector generating axis one, this includes the number of patent applications made to 
the European Patent Office per million of active population (V3), the percentage of e-commerce, customer relation management (CRM) and secure transactions in a city (V5), the length of bicycle network (V7), the number of days particulate matter (PM10) concentrations exceed $50 \mu \mathrm{g} / \mathrm{m}^{3}$ (V8), the share of urban waste water load treated to applicable standards (V12), share of protected terrestrial area (V17), share of deaths (V23) and Gini coefficient of disposable income (V32). A further analysis of CTR values shows that the percentage of voter turnout in national and EU parliamentary elections (V31) is a variable to include in the explanation of the first axis because its CTA is quite close to the average CTA and the first axis explains the main part of the variance associated to this variable. The second principal component represents an additional $14.5 \%$ of the total variance with percentage of persons employed between the ages of 20 and 64 (V4), number of days of particulate matter concentration exceeding $50 \mu \mathrm{g} / \mathrm{m}$ (V8), number of theatres (V29), and gender pay gap (V30) contributing significantly to this component. PC3 represents $12.7 \%$ of the total variance of the greenhouse gas emissions from transport (V10), electricity generated from renewable energy (V19), and the percentage of voter turnout in national and EU parliamentary elections (V31) contribute significantly to the inertia associated with this component. PC4 represents $9.4 \%$ of the total variance and is highly influenced by the percentage of persons employed between the ages of 20 and 64 (V4), the amount of greenhouse gas emissions (V10), protected terrestrial areas (V17), and Gini coefficients of disposable income (V32). Overall, all variables contribute to the four selected components.

The factor scores are a weighted summation of the four principal loadings (Table 4-4).

Table 4-4:Indicator Variable Loadings*1000, CTA, CTR*1000 and factor score*1000

\begin{tabular}{|c|c|c|c|c|c|c|c|c|c|c|c|c|c|}
\hline Variable & $\mu 1$ & CTA & CTR & $\mu 2$ & CTA & CTR & $\mu 3$ & CTA & CTR & $\mu 4$ & CTA & CTR & $\begin{array}{l}\text { Factor } \\
\text { Score }\end{array}$ \\
\hline V3 & 0.853 & 14.9 & 728 & $\overline{-}-089$ & 0.36 & 8 & 0.034 & 0.06 & 1 & 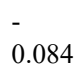 & 0.50 & 007 & 378 \\
\hline V4 & 0.207 & 0.88 & 43 & 0.716 & 23.6 & 512 & $\begin{array}{l} \\
\end{array}$ & 0.75 & 14 & 0.381 & 10.2 & 145 & 278 \\
\hline V5 & 0.829 & 14.1 & 687 & 0.070 & 0.23 & 5 & $\overline{0}-014$ & 0.01 & 0 & $\overline{0}-125$ & 1.09 & 15 & 385 \\
\hline V7 & 0.804 & 13.3 & 647 & - & 0.08 & 2 & 0.252 & 3.34 & 63 & $\begin{array}{l}- \\
0.104\end{array}$ & 0.76 & 11 & 402 \\
\hline V8 & $\overline{-}-5.587$ & 7.07 & 345 & $\overline{-}-520$ & 12.4 & 270 & $\overline{0}-037$ & 0.07 & 1 & 0.305 & 6.56 & 93 & -350 \\
\hline V10 & 0.420 & 3.62 & 176 & $\overline{0}-352$ & 5.7 & 124 & 0.636 & 21.3 & 404 & 0.356 & 8.92 & 126 & 289 \\
\hline
\end{tabular}




\begin{tabular}{|c|c|c|c|c|c|c|c|c|c|c|c|c|c|}
\hline V12 & 0.693 & 9.86 & 481 & 0.302 & 4.20 & 91 & $-\overline{0.175}$ & 1.61 & 31 & 0.184 & 2.38 & 34 & 382 \\
\hline V13 & 0.211 & 0.92 & 45 & $\overline{-}-302$ & 4.22 & 91 & $\begin{array}{l}- \\
0.346\end{array}$ & 6.30 & 120 & 0.696 & 34.2 & 484 & 068 \\
\hline V17 & $\overline{-} .699$ & 10 & 490 & $\overline{-}-129$ & 0.77 & 17 & 0.015 & 0.01 & 0 & $\overline{-} \mathbf{0 . 2 6 3}$ & 4.90 & 69 & -390 \\
\hline V19 & 0.094 & 0.18 & 9 & 0.072 & 0.24 & 5 & 0.746 & 29.3 & 556 & $\begin{array}{l}- \\
0.144\end{array}$ & 1.46 & 21 & 176 \\
\hline V23 & $\begin{array}{l}- \\
0.641\end{array}$ & 8.42 & 411 & 0.285 & 3.74 & 81 & 0.277 & 4.04 & 77 & 0.193 & 2.63 & 37 & -165 \\
\hline V29 & 0.305 & 1.91 & 93 & 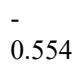 & 14.1 & 306 & 0.493 & 12.8 & 243 & 0.254 & 4.55 & 65 & 153 \\
\hline V30 & 0.267 & 1.47 & 72 & 0.694 & 22.2 & 482 & 0.252 & 3.33 & 63 & 0.188 & 2.49 & 35 & 343 \\
\hline V31 & 0.565 & 6.54 & 319 & 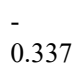 & 5.22 & 113 & 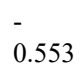 & 16.1 & 306 & 0.098 & 0.68 & 10 & 107 \\
\hline V32 & 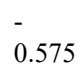 & 6.79 & 331 & 0.248 & 2.83 & 61 & 0.136 & 1.0 & 19 & 0.515 & 18.7 & 265 & -123 \\
\hline
\end{tabular}

Finally, we multiplied the factor scores of each variable by their respective normalized values of indicators for each city and summed in order to obtain a rank score. This was arranged in descending order to give a ranking of the capital cities as shown in Figure 4-5 and Figure 4-6.

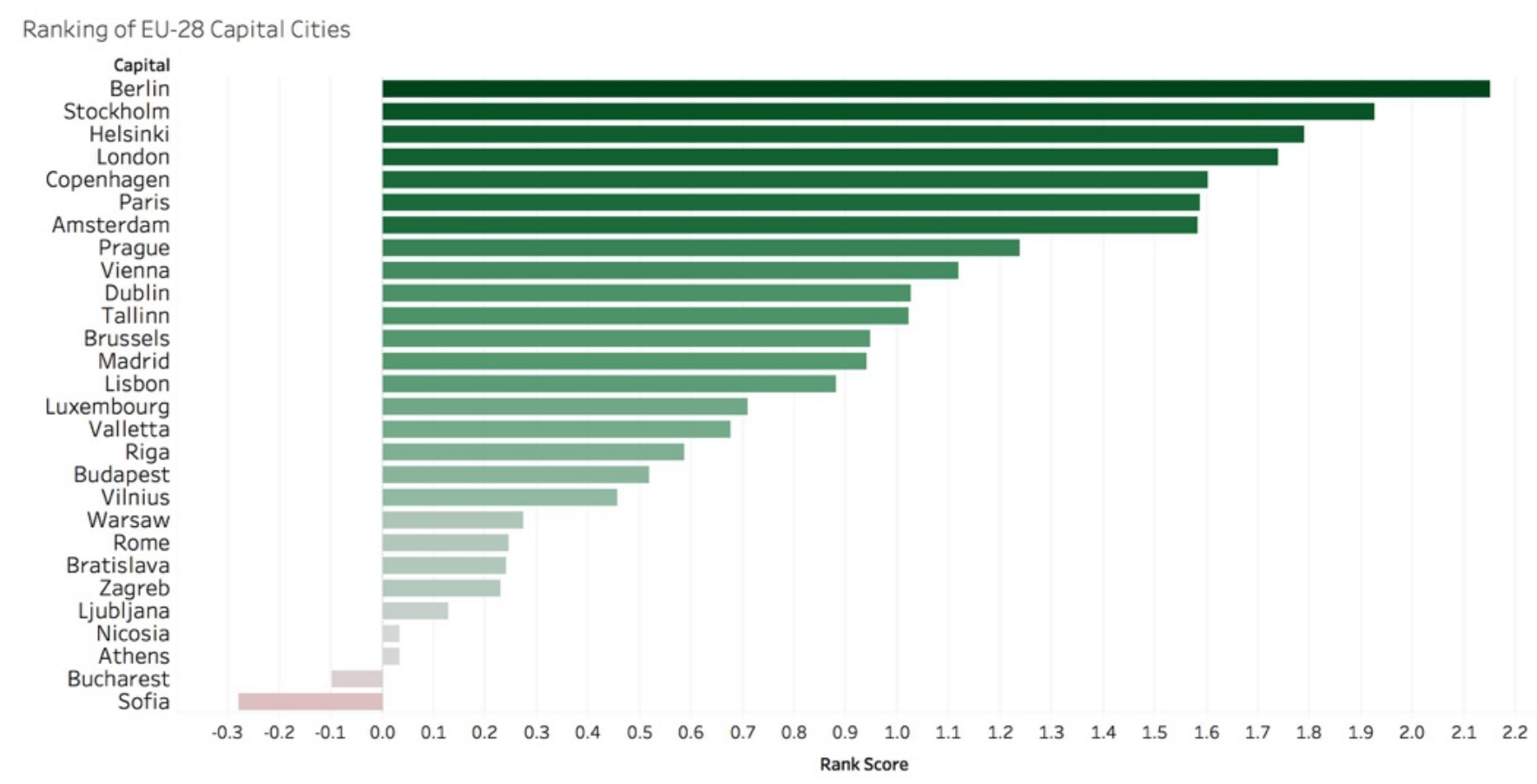

Figure 4-5: Bar chart showing rank scores of European capital cities 


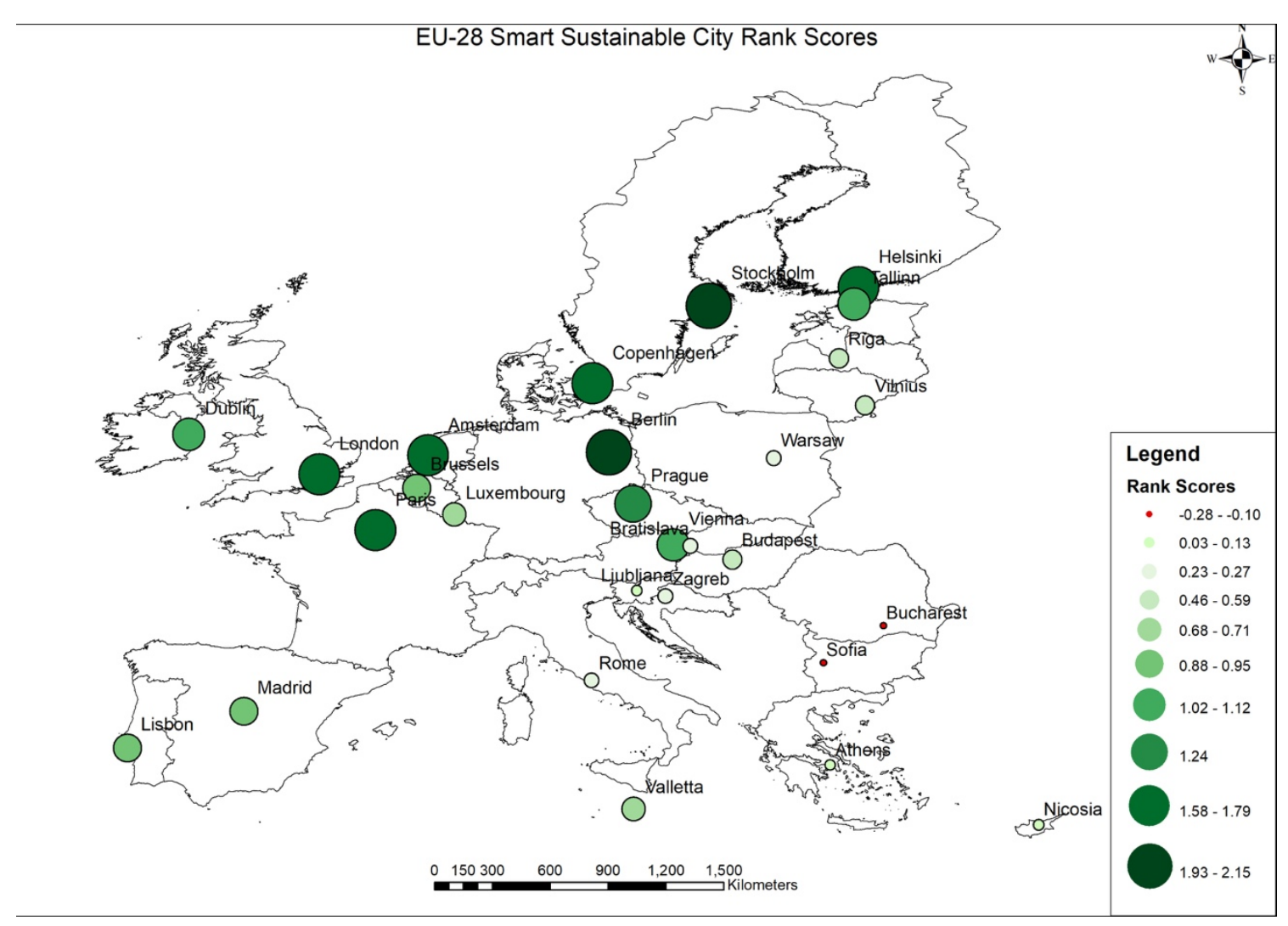

Figure 4-6: Smart Sustainable ranking of European capital cities

\subsubsection{Sensitivity Analysis}

Beyond ranking cities based on how smart and sustainable they are, this research aims to help decision makers by pinpointing those indicators that have a huge effect in determining the ranking. This was done by eliminating the factor score of each of the final variables and comparing the resulting ranking of cities with the original ranking (Saisana \& Saltelli, 2011). Table 4-5 shows the top three indicators that affects the ranking of each city. These indicators serve as leverage points which city councils and urban planners can use to either maintain or improve the overall sustainability of their city. 
Table 4-5: Smart Sustainable City ranking and top three indicators that affects ranking

\begin{tabular}{|c|c|c|}
\hline Rank & City & Top three indicators that affects ranking \\
\hline 1 & Berlin & Bicycle network, Wastewater treatment, E-commerce \\
\hline 2 & Stockholm & Wastewater treatment, Patent applications, E-commerce \\
\hline 3 & Helsinki & Wastewater treatment, Patent applications, Bicycle network \\
\hline 4 & London & Wastewater treatment, Bicycle network, E-commerce \\
\hline 5 & Copenhagen & Wastewater treatment, E-commerce, Patent applications \\
\hline 6 & Paris & Wastewater treatment, Unemployment, GHG emissions \\
\hline 7 & Amsterdam & Wastewater treatment, E-Commerce, Unemployment \\
\hline 8 & Prague & Wastewater treatment, E-Commerce, Gender inequality \\
\hline 9 & Vienna & Gender Inequality, Patent applications, E-Commerce \\
\hline 10 & Dublin & E-Commerce, Wastewater treatment, Unemployment \\
\hline 11 & Tallinn & Wastewater treatment, Gender Inequality, Unemployment \\
\hline 12 & Brussels & E-Commerce, Wastewater treatment, Patent application \\
\hline 13 & Madrid & Wastewater treatment, Protected terrestrial area, E-Commerce \\
\hline 14 & Lisbon & Wastewater treatment, Unemployment, E-Commerce \\
\hline 15 & Luxembourg & $\begin{array}{l}\text { Wastewater treatment, Protected terrestrial area, } \\
\text { Unemployment }\end{array}$ \\
\hline 16 & Valletta & Wastewater treatment, PM10 concentration, E-commerce \\
\hline 17 & Riga & Wastewater treatment, Unemployment, Gender inequality \\
\hline 18 & Budapest & $\begin{array}{l}\text { Wastewater treatment, Unemployment, Protected terrestrial } \\
\text { area }\end{array}$ \\
\hline 19 & Vilnius & Unemployment, E-commerce, Gender inequality \\
\hline 20 & Warsaw & $\begin{array}{l}\text { Wastewater treatment, PM10 concentration, Protected } \\
\text { terrestrial area }\end{array}$ \\
\hline 21 & Rome & GHG emissions, Protected terrestrial area, PM10 concentration \\
\hline 22 & Bratislava & Protected terrestrial area, Gender inequality, E-commerce \\
\hline 23 & Zagreb & Protected terrestrial area, E-commerce, Unemployment \\
\hline 24 & Ljubljana & Protected terrestrial area, E-commerce, Waste water treatment \\
\hline 25 & Nicosia & Protected terrestrial area, PM10 concentration, Unemployment \\
\hline 26 & Athens & $\begin{array}{l}\text { Protected terrestrial area, Wastewater treatment, PM10 } \\
\text { concentration }\end{array}$ \\
\hline 27 & Bucharest & $\begin{array}{l}\text { PM10 concentration, Wastewater treatment, Protected } \\
\text { terrestrial area }\end{array}$ \\
\hline 28 & Sofia & PM10 concentration, Protected terrestrial area, Unemployment \\
\hline
\end{tabular}

We discuss the ranking and its relation to cities' geographies and demographics in the following subsections. 


\subsubsection{Rank score comparison with Gross Domestic Product (GDP)}

A scatterplot of the rank score of each capital city and its Gross Domestic Product (GDP) obtained from Eurostat, shown in Figure 4-7, reveals a relationship between how smart and sustainable a city is, according to our calculated rank scores, and its wealth. Except for Berlin and Luxemburg, which are outliers, the strength of this relationship is measured using a correlation coefficient of 0.80 , which is statistically significant at $5 \%$. Wealthier cities primarily located in Western and Northern Europe tend to be ranked better than other cities. This is because initiatives and projects that drive the competitiveness of a city in terms of how smart and sustainable the city is are usually capital intensive, giving wealthier governments an advantage (Siemens, 2009). In contrast, poorer governments are usually more focused on more basic developmental issues.

A temporal analysis of GDP per capita shows that although cities in central and eastern Europe have an average yearly growth of $3.7 \%$, this growth rate is still less than $75 \%$ of the EU average. This deprives these cities of the much-needed funds needed for research and development (R\&D) to foster innovation and pivot towards a more sustainable future. R\&D is the heart of smart sustainable development and requires a lot of money (Serbanica \& Constantin, 2017).

Furthermore, being wealthier gives governments leverage in setting more ambitious policy goals for their cities compared to less wealthy governments. For example, Copenhagen has an ambitious climate plan to be the first carbon-neutral capital city by 2025 (Bodansky, 2010). Stockholm also aims to have vehicle fleets completely rid of fossil fuel by 2030. Berlin, the only capital city in Europe with its GDP per inhabitant lower than the national average, benefits from well-crafted polices in air quality, energy, and environmental governance (European Comission, 2016). The GDP of Luxemburg is extremely high because the country has an unusual financial and tax system and serves as a host to many international companies (Annaert, 2004; European Commission, 2014b). Wealth and government policies can also be thought of in a feedback loop in which money (wealth) is needed to be able to set ambitious policy goals and craft carefully designed policies, which in turn help the government to save more money. For example, using policies to drive energy efficiency in buildings and vehicles can save money and cut emissions (Hughes, Chu, \& Mason, 2018; Zhou et al., 2016). Hence, there needs to be a balance of maximizing the performance of a city with as little money as possible. 


\subsubsection{Rank score comparison with geographical location}

An important insight is gained from the spatial pattern of the ranking results. A visual inspection of Figure 4-6 reveals that similar ranking values are clustered together in the map. A test of spatial autocorrelation using Global Moran I reveals that there is a positive spatial autocorrelation (0.31) among the city ranks. We can therefore infer that the performance of each city in our ranking isn't randomly spatially distributed but each city influences its neighbours making cities with similar behaviours clustered together. This is responsible for a geographical divide between cities that are well ranked and those that are not. Twelve of the top 14 cities are in Western Europe while 11 of the bottom 14 cities are in Eastern Europe. This result corroborates findings by the European Union which identified a developmental gap between western and eastern European cities (European Commission, 2014c). It is interesting to note that Budapest, Prague, Bratislava, Warsaw, Ljubljana, Vilnius, Riga, Tallinn, Sofia and Bucharest all belonged to the former Communist Bloc until 1990 and went through several years of transitions (Roaf, Atoyan, Joshi, \& Krogulski, 2014; Serbanica \& Constantin, 2017). Although, the communist laws did not entirely neglect the environment, industries were not adequately incentivised to adopt more efficient processes and adhere to the laws (Constantin, 1999; Hirt \& Stanilov, 2009). The collapse of the communist bloc led to a change in the existing urban patterns with an increase in private car usage, a decrease in open and green spaces and a conversion of garages and ground floors of buildings into shops and offices (European Commission, 2016b; Hirt \& Stanilov, 2009). We hypothesize that joining the European Union played a role in driving cities in central and eastern Europe towards a smart and sustainable path. This is evidenced by the fact that Valletta, Riga, Budapest, Vilnius, Warsaw, Bratislava, Ljubljana are cities in countries that joined the EU in 2004 while the two least ranked cities (Sofia and Bucharest) are in countries joined the EU in 2007. Prague and Tallinn are exceptions because even though they were a part of the communist bloc, they are ranked in the top 14 cities. These two cities are located in countries categorised as "fast-track reforming states" because of their high exposure to globalization, extreme "EU-ization" influences and creative deployment of technology to foster a sustainable and inclusive society (Ian, Kaliopa, \& Natasa, 2003; Nam \& Pardo, 2011). Furthermore, 3 of the top ranked 5 cities are cities from the Scandinavian region of Northern Europe. Stockholm, Helsinki, and Copenhagen have very strong environmental policies and are focused on improving the quality of life of their citizens (Lindström \& Eriksson, 1993). 


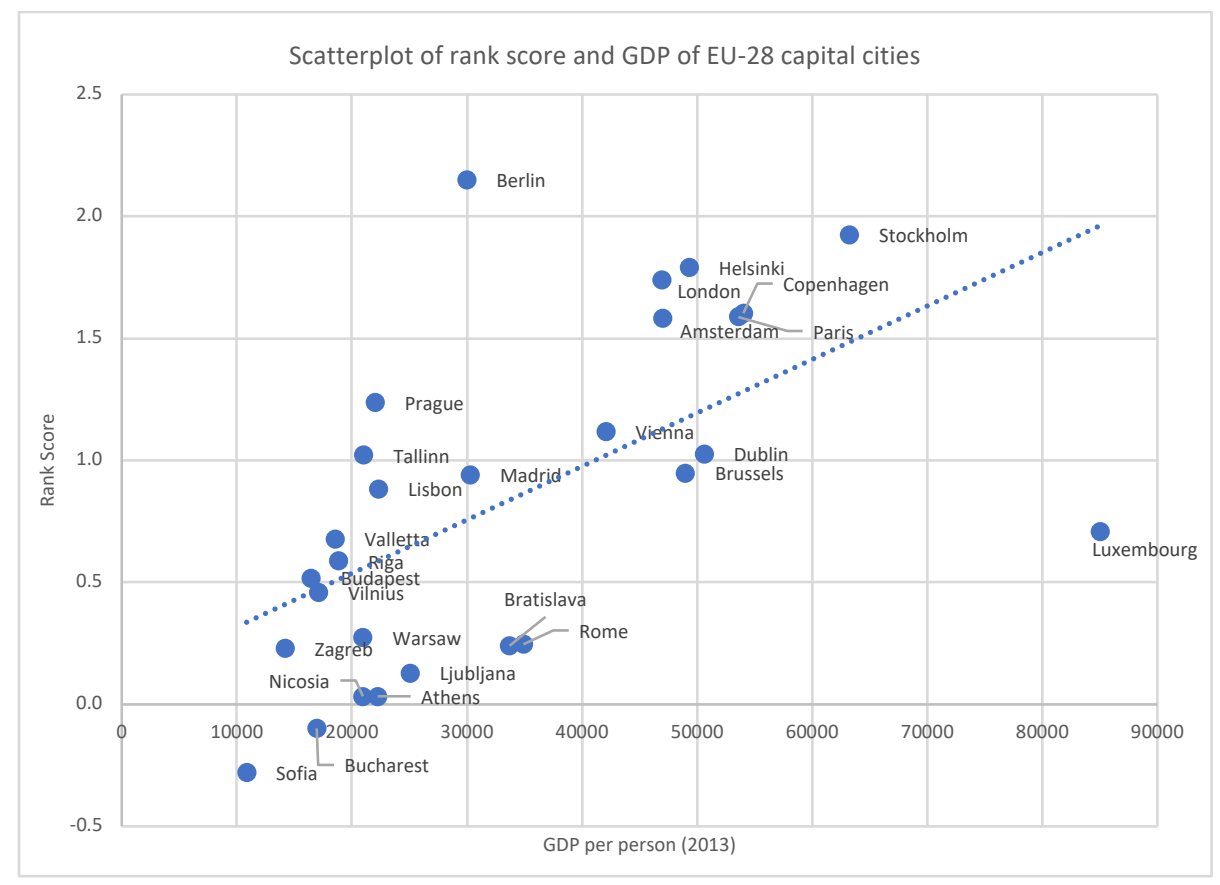

Figure 4-7:Scatterplot of the rank score and GDP of EU-28 capital cities

\subsubsection{Rank score comparison with size and population}

City's size and population can be either an advantage or a drawback in determining how smart and sustainable it is (Siemens, 2009). All other things being held constant, a city should be able to coordinate the activities of a million residents better than that of ten million residents (Mori \& Christodoulou, 2012). However, the city with ten million residents has a leverage resource-wise to pursue smart and sustainable policies and infrastructure (Munda, 2006). We found no statistically significant correlation between a city rank and its population and size. This is in line with findings by (Serbanica \& Constantin, 2017) who concluded that green cities can be equally small, medium or large. In fact, contrary to expectations, the number of registered cars in smaller cities are usually more than the number of registered cars in larger cities. This can be attributed to a more developed public transport system in larger cities, reducing the need to own private vehicles (Serbanica \& Constantin, 2017). 


\subsubsection{Further Discussion}

In terms of social development, Sofia and Bucharest, the 2 least ranked cities, are in countries with very high level of poverty when compared with the European average. Other cities like Budapest, Zagreb, Athens, Nicosia, Ljubjana have a "lower then European average" quality of healthcare systems, employment rates and amount of disposable incomes and are ranked very low. This shows the importance of the social systems in a city in enabling an inclusive society.

The environment also plays a huge role in determining the sustainability of cities. Our sensitivity analysis shows that a reduction of PM10 concentration in Sofia will significantly improve its ranking. In Sofia, the population-weighted concentration of PM10 exceeds the annual EU limit value of $40 \mu \mathrm{g} / \mathrm{m} 3$. Nicosia and Warsaw also have very high values of PM10 concentration. The other cities studies have values of PM10 well below the annual EU with northern European countries recording the lowest.

Citizen engagement is another relevant issue for a smart and sustainable city. Beyond government policies, the individual actions of citizens can collectively have more influence than policies in determining how smart and sustainable a city is (Berry \& Portney, 2013). Such actions include the cultivation of an energy saving culture in households, sorting of waste, the decision to commute using ride-sharing rather than private vehicle, amongst others (Fellows \& Pitfield, 2000; Poortinga, Steg, \& Vlek, 2004; Sharholy, Ahmad, Mahmood, \& Trivedi, 2008). A research project by Siemens (2009) showed a high correlation between citizen engagement and the green rank score of cities. According to this report, "about three-quarters of the existing technological changes that would help London to meet its long-term carbon reduction targets depended on the decisions of citizens or companies, not of governments" (Denig, 2011; Siemens, 2009). Citizens' actions and attitudes can be influenced through incentives and penalties that encourage a change in behaviour (Osbaldiston \& Schott, 2012). Education and public awareness also go a long way in arming the public with knowledge to make good and informed decisions that affect the ranking of a city (Tilbury, 1995).

\subsection{Validation}

To validate our study, we compared the ranking for Smart Sustainable cities in Europe with other related European urban ranking systems in Table 4-6. The Smart Sustainable Cities (SSC) ranking 
has eight cities in common with the European Soot-free city ranking in the top-ten list, seven common cities with the European Green city index ranking, four common cities with the European Quality of Life Index ranking and no common cities with the European medium-sized cities ranking. Using a Kendall's $\tau$ rank correlation test, we see that our ranking is strongly correlated with the European Soot-free city ranking and the European Green City Index but moderately correlated with the European Quality of Life Index. Although, we had a Kendall $\tau$ correlation coefficient of one (1.00) between our ranking and the European medium-sized cities ranking, this is because the two ranking systems had only 2 cities in common with similar ranks in both ranking systems. These results show that although our ranking correlates with other ranking systems of related philosophy, it still sufficiently differs because of the unique ranking attribute and methodological characteristics of our study.

Table 4-6: Top 10 cities in four European ranking systems and their correlation with Smart Sustainable Cities Ranking

\begin{tabular}{|l|l|l|l|l|}
\hline SSC Ranking & $\begin{array}{l}\text { European } \\
\text { Soot-free City } \\
\text { Ranking }\end{array}$ & $\begin{array}{l}\text { European } \\
\text { Green city } \\
\text { Index }\end{array}$ & $\begin{array}{l}\text { Europe Quality } \\
\text { of Life Index }\end{array}$ & $\begin{array}{l}\text { European } \\
\text { Smart Cities } \\
\text { Ranking }\end{array}$ \\
\hline Berlin & Zurich & Copenhagen & Zurich & Luxembourg \\
\hline Stockholm & Copenhagen & Stockholm & Frankfurt & Aarhus \\
\hline Helsinki & Vienna & Oslo & Munich & Turku \\
\hline London & Stockholm & Vienna & Edinburgh & Aalborg \\
\hline Copenhagen & Berlin & Amsterdam & Trondheim & Odense \\
\hline Paris & Helsinki & Zurich & Geneva & Tampere \\
\hline Amsterdam & London & Helsinki & Vienna & Oulu \\
\hline Prague & Paris & Berlin & Copenhagen & Eindhoven \\
\hline Vienna & Stuttgart & Brussels & Stockholm & Linz \\
\hline Dublin & Amsterdam & Paris & Berlin & Salzburg \\
\hline $\begin{array}{l}\text { Number of } \\
\text { cities }\end{array}$ & 23 & 30 & 58 & 70 \\
\hline $\begin{array}{l}\text { Common cities } \\
\text { with SSCR }\end{array}$ & 15 & 24 & 28 & 2 \\
\hline $\begin{array}{l}\text { Kendall's } \tau \\
\text { rank } \\
\text { correlation } \\
\text { with SSCR }\end{array}$ & 0.70 & 0.61 & 0.49 & 1.00 \\
\hline
\end{tabular}

Finally, it should be noted that this ranking is influenced by the set of final variables selected to characterize how smart and sustainable a city is and the year of the data used. However, as 
demonstrated by our methodology, the selected variables can be appropriately used as a representative sample of the indicators in the UNECE smart sustainable framework.

\subsection{Conclusions}

Cities can be viewed as the source of and the solution to many of today's economic, social, and environmental challenges. Because of this, the EU is promoting various initiatives to drive cities to be more sustainable, resource-efficient, and inclusive. In this article, we ranked European capital cities based on how smart and sustainable they are, using a selection of indicators from a framework proposed by UNECE-ITU. We did this by obtaining publicly available data, from Eurostat, on the indicators in the framework and systematically reducing the number of indicators using multivariate statistics. Using hierarchical clustering, we created five (5) homogenous groups of indicators, selected representative indicators for each group using variance as the selection criterion and then applied PCA to the selected indicators to obtain a composite index. The ranking is based on a composite index which conceals multiple subjective assessment under a veil of objectivity. Furthermore, we carried out a sensitivity analysis and validation study of our results. Relating our ranking of European capital cities with geographical and demographic parameters, we found that Nordic cities and cities in western Europe perform better in our ranking than cities in Eastern Europe. Using GDP per inhabitant as an indicator for wealth, we determined that wealthier cities perform better in our ranking. Finally, we detected no correlation between a city's rank score and its population and size.

Our method is an effort to simplify and summarize a very complex concept into a manageable form. It should be noted that PCA is completely non- parametric: any data set can be plugged in and an answer comes out, requiring no parameters to tweak and no regard for how the data were recorded. From one perspective, the fact that PCA is non-parametric can be considered as a positive feature because the answer is unique and independent of the user. From another perspective, the fact that PCA ignores the source of the data is also a weakness. However, we have taken steps to ensure the quality of our data to mitigate this.

Overall, this research has contributed to knowledge by using a multivariate data analysis approach to rank capital metro regions within the European Union using data from a single open database based on how smart and sustainable they are. This approach ensures that the cities being compared 
have a useful amount of homogeneity and uses the underlying structure of the dataset to weight and aggregate our data while guaranteeing the consistence, coherence and reproducibility of our results.

This ranking is meant to attract attention and induce competition amongst cities. By utilizing the method and result of this research, cities and their stakeholders will not only be able to objectively assess the extent to which they may be perceived as being smart and sustainable, but also be able to identify leverage points to improve their sustainability. 


\section{Chapter 5 - Conclusions}

\subsection{Summary of findings}

The overall goal of this dissertation is to assess cities based on how smart and sustainable they are. We aim to answer the following research questions:

- What is the relationship between smart cities performance and sustainable cities performance?

- What drives the adoption of the sharing economy to optimise the use of resources within cities

- How well do cities in Europe perform in terms of their smartness and sustainability?

The three papers in this dissertation analyse cities and citizens based on the innovative use of ICT to facilitate sustainable development.

The first paper explores the relationship between ICT and environmental sustainability at city level and found four groups of cities with similar ICT (smart) and $\mathrm{CO}_{2}$ (sustainable) characteristics, namely smart but not sustainable cities, not smart but sustainable cities, smart and sustainable cities and those on the path of being smart and sustainable. This shows the possibility of a European city to be smart and not sustainable and vice versa. Furthermore, we found that capital European cities tend to have a different smart-sustainable profile from its neighbouring cities within the same country.

The second paper evaluates the individual drivers of the use of technology to foster sustainability within cities using weighting and meta-analysis. This paper revealed that: (1) quantitative research on the drivers of the sharing economy is still in its infancy and has been restricted to the developed parts of the world, (2) the most quantitatively evaluated constructs of the sharing economy originate from TPB and TRA or are adapted from them, and (3) the 'best' predictors identified in the existing literature include attitude, subjective norm and perceived behavioural control on intention to share; and economic benefit and perceived risk on attitude. 
The third paper focuses on ranking European capital cities based on how smart and sustainable they are. Our results show that twelve (12) of the top fourteen (14) cities are in Western Europe while eleven (11) of the bottom fourteen (14) cities are in Eastern Europe. We also showed that the top performing cities are primarily located in Northern Europe. Finally, our ranking validation showed that even though our ranking correlates with other rankings of similar philosophy, it still sufficiently differs because of the unique ranking attributes and methodological characteristics of our study.

\subsection{Contributions}

This dissertation makes several contributions to the body of knowledge of both information systems and smart cities.

Firstly, we have been able to empirically clarify the relationship between smart city performance and sustainable city performance using city-level data. This was done using a new approach to study the relationship between ICT development and $\mathrm{CO}_{2}$ emission using cities in the EU as a case study. Furthermore, we have been able to shed light on the intra-country and intercity comparisons between the role the different components of ICT development play in urbanisation and environmental sustainability on a micro-level.

Secondly, we have been able to provide a concise and clearer understanding of the drivers of the use of technology through the sharing economy to foster sustainability in cities by citizens. This contribution not only lays a foundation for additional hypothesises which researchers can evaluate in future smart sustainable cities assessment studies but also provides interesting insights for city councils and governments pushing for a citizen adoption of sustainable practices within their administrative boundaries.

Thirdly, we have been able to rank capital cities in Europe based on how smart and sustainable they are. This dissertation provides a new approach to ranking cities that addresses the methodological gaps found in previous studies. This new approach ensures that the cities being compared have a useful amount of homogeneity and uses the underlying structure of the dataset to weigh and aggregate our data while guaranteeing the 
consistence, coherence and reproducibility of our results. It also identifies specific indicators which cities can leverage to improve their ranking.

\subsection{Impact}

Although, it is still very early to assess the full impact of our work, we are already seeing some interest in our work both within the research and larger community. We will be assessing the influence of the three papers in this dissertation using both journal and article level metrics. At the time of printing this dissertation, articles presented in this dissertation had been cited a total of 17 times in Scopus, 29 times in Google Scholar and downloaded over 7,000 times. This is interesting considering that the articles were only published in the year 2019. Chapter four (The Lisbon ranking for smart sustainable cities in Europe) has remained the most downloaded article (calculated over 90 days) from Sustainable Cities and Society since its publication in that journal. Furthermore, as of May/June 2019, chapter four had received enough citations to place it in the top $1 \%$ of the academic field of engineering based on a highly cited threshold for the field and publication year (Web of Science). These metrics are indicative of the amount of interest parts of this dissertation is drawing in the research community. Outside academia, articles in this dissertation have been mentioned a total of 52 times on Twitter, which indicates the amount of buzz and attention surrounding our research. All these are shown in Table 5-1. We do not have impact metrics on chapter three (Understanding the sharing economy and its implications on sustainability in smart cities) yet because it is still undergoing reviews in a top-tier journal.

Table 5-1: Journal and article level metrics (December 2019)

\begin{tabular}{|c|c|c|c|c|c|}
\hline & $\begin{array}{c}\text { Journal } \\
\text { level }\end{array}$ & \multicolumn{4}{|c|}{ Article level metric } \\
\hline Research articles & $\begin{array}{c}\text { Impact } \\
\text { factor } \\
\text { (Journal) }\end{array}$ & $\begin{array}{c}\text { Number } \\
\text { of } \\
\text { citations } \\
\text { (Scopus) }\end{array}$ & $\begin{array}{c}\text { Field- } \\
\text { Weighted } \\
\text { Citation } \\
\text { Impact } \\
\text { (Scopus) }\end{array}$ & $\begin{array}{c}\text { Number of } \\
\text { downloads } \\
\text { (ScienceDirect) }\end{array}$ & $\begin{array}{c}\text { Social } \\
\text { media } \\
\text { mentions } \\
\text { (Twitter) }\end{array}$ \\
\hline
\end{tabular}




\begin{tabular}{|l|c|c|c|c|c|}
\hline $\begin{array}{l}\text { Assessing the gap between } \\
\text { Technology and the Environmental } \\
\text { Sustainability of European Cities. }\end{array}$ & 3.232 & 2 & 1.69 & 2,000 & 29 \\
\hline $\begin{array}{l}\text { Understanding the sharing economy } \\
\text { and its implication on sustainability in } \\
\text { smart cities. }\end{array}$ & N/A N/A & N/A & N/A & N/A \\
\hline $\begin{array}{l}\text { The Lisbon ranking for smart } \\
\text { sustainable cities in Europe. }\end{array}$ & 4.624 & 15 & 16.79 & 5,878 & 23 \\
\hline
\end{tabular}

These metrics are also indicative of the potential impact of this dissertation on society. By drawing a connection between technology and environmental sustainability, it increases the awareness of individuals, businesses and governments about global environmental concerns and how technology can be used in transformative ways to address some of these concerns. Overall, this not only improves the world at present but also guarantees its future.

\subsection{Limitations and future research}

This dissertation characterised in detail, using multivariate statistics and meta-analysis, functional urban areas and citizens based on the mutual ties of smartness and sustainability. The first logical limitation derived from this approach is the amount of data we had access to. This limited the depth and width of our studies (Akande, Cabral, Gomes, et al., 2019). Consequently, the inclusion of more and new data and dimensions to evaluate cities within the broad concept of smartness and sustainability can be a viable future direction. For instance, (Pinto, Morales, Fedoruk, Kovaleva, \& Diemer, 2019) evaluated the sustainability of cities from a political dimension including variables such as law and justice, organization and governance and ethics and accountability. The inclusion of new or barely explored variables such as modern urban governance with exponential technologies (artificial intelligence, robotics, virtual and augmented technologies etc.) in primary studies will be interesting for future research on smart sustainable cities.

In the weighting and meta-analytic study in chapter 3, our data was limited to 22 articles based on our selection criteria. These 22 articles are not exhaustive, as there are other studies which were not included in our analysis because they are either qualitative, yet to be published, published in non-peer-reviewed mediums such as books or magazines, or published in languages other than 
English. Due to the relatively limited sample size, generalization based on our results should be done with caution. Furthermore, studies included in our analysis were assumed to be methodologically sound because they had been peer-reviewed. This should also be kept in mind when interpreting our results.

Cities that were evaluated in chapters 2 and 4 were limited to Europe because of our research focus and data availability. Hence, our results should be generalised with caution. However, it will be interesting to replicate our study for other cities in other parts of the developed and developing world. Furthermore, the studies in these chapters were cross-sectional and only captured a single point in time. Future studies can take a longitudinal approach to study how the relationship between the smartness and sustainability of cities has evolved over time. This approach will provide additional insights to the smart-sustainable relationship in cities and can be used to project how cities will evolve in the future.

Overall, the field of smart sustainable cities is still in its infancy, making it a fertile area for various theoretical, exploratory, empirical, analytical and institutional studies. We see our future work evolving around the use of exponential technologies to decrease GHG emission because of the scarcity of literature in this area. Specifically, we are interested in the role of blockchain in improving energy efficiency, because the transition to a sustainable future heavily requires a rethink of how we generate, transmit and distribute power. Renewable Energy Sources (RES) serve as a viable option in solving our environmental energy predicament (Mengelkamp et al., 2018). RES generate energy from sources that are naturally replenished and do not pollute the environment in the process of doing so (Bayram, Shakir, Abdallah, \& Qaraqe, 2014). Furthermore, RES reduces the need to transmit energy over long distances since they can be produced in close proximity to where they will be consumed. However, because RES depend on the forces of nature such as the wind and sun, there is usually uncertainty and fluctuation associated with their production (Bahrami \& Amini, 2017). Hence, to guarantee reliability, sustainability and local balance of the generation and consumption of power from RES, there is need to manage them within decentralized microgrids. Blockchains can serve as a viable information system to facilitate a peer-to-peer energy market within decentralized microgrids. It can enable two or more entities within the microgrid to trade locally produced renewable energy anonymously with each other based on "smart contracts" (Luu, Chu, Olickel, Saxena, \& Hobor, 2016) and settle such 
transactions using digital currencies (Mihaylov et al., 2014). This will be interesting to study because utilizing blockchain as an information system to manage peer-to-peer renewable energy trading addresses the three dimensions of sustainability by creating economic value, promoting environmental sustainability and fostering social inclusion. 


\section{References}

Abdi, H., \& Williams, L. J. (2010). Principal component analysis. Wiley Interdisciplinary Reviews: Computational Statistics, 2(4), 433-459. https://doi.org/10.1002/wics.101

Acedo, A., Painho, M., \& Casteleyn, S. (2017). Place and city: Operationalizing sense of place and social capital in the urban context. Transactions in GIS, 21(3), 503-520. https://doi.org/10.1111/tgis.12282

Aesaert, K., Voogt, J., Kuiper, E., \& van Braak, J. (2017). Accuracy and bias of ICT self-efficacy: An empirical study into students' over- and underestimation of their ICT competences. Computers in Human Behavior, 75(Supplement C), 92-102. https://doi.org/https://doi.org/10.1016/j.chb.2017.05.010

Ahvenniemi, H., Huovila, A., Pinto-Seppa, I., \& Airaksinen, M. (2017). What are the differences between sustainable and smart cities? Cities, 60, 234-245. https://doi.org/10.1016/j.cities.2016.09.009

Ajzen, I. (1985). From Intentions to Actions: A Theory of Planned Behavior. In J. Kuhl \& J. Beckmann (Eds.), Action Control: From Cognition to Behavior (pp. 11-39). Berlin, Heidelberg: Springer Berlin Heidelberg. https://doi.org/10.1007/978-3-642-69746-3_2 Ajzen, I. (2011). The theory of planned behaviour: Reactions and reflections. Psychology \& Health, 26(9), 1113-1127. https://doi.org/10.1080/08870446.2011.613995

Akande, A., Cabral, P., \& Casteleyn, S. (2019). Assessing the Gap between Technology and the Environmental Sustainability of European Cities. Information Systems Frontiers. https://doi.org/10.1007/s10796-019-09903-3

Akande, A., Cabral, P., Gomes, P., \& Casteleyn, S. (2018). The Lisbon Ranking for Smart Sustainable Cities in Europe. Sustainable Cities and Society. https://doi.org/10.1016/j.scs.2018.10.009

Akande, A., Cabral, P., Gomes, P., \& Casteleyn, S. (2019). The Lisbon ranking for smart sustainable cities in Europe. Sustainable Cities and Society, 44, 475-487. https://doi.org/https://doi.org/10.1016/j.scs.2018.10.009

Akande, A., Costa, A. C., Mateu, J., \& Henriques, R. (2017). Geospatial Analysis of Extreme Weather Events in Nigeria (1985-2015) Using Self-Organizing Maps, 2017. 
Aksoy, E., Gregor, M., Fons, J., Garzillo, C., Cugny-Seguin, M., Löhnertz, M., \& Schröder, C. (2016). City typologies of Europe: a tool to support urban sustainability studies and practices. WIT Transactions on Ecology and the Environment, 204(Sc), 199-210. https://doi.org/10.2495/SC160171

Al-Nasrawi, S., Adams, C., \& El-Zaart, A. (2015). A conceptual multidimensional model for assessing smart sustainable cities. Journal of Information Systems and Technology Management, 12(3), 541-558.

Amaro, S., Andreu, L., \& Huang, S. (2018). Millenials' intentions to book on Airbnb. Current Issues in Tourism, O(0), 1-15. https://doi.org/10.1080/13683500.2018.1448368

Amirkiaee, S. Y., \& Evangelopoulos, N. (2018). Why do people rideshare? An experimental study. Transportation Research Part F: Traffic Psychology and Behaviour, 55, 9-24. https://doi.org/10.1016/j.trf.2018.02.025

Andrés, L., \& Padilla, E. (2018). Driving factors of GHG emissions in the EU transport activity. Transport Policy, 61, 60-74. https://doi.org/https://doi.org/10.1016/j.tranpol.2017.10.008 Angeloni, S. (2016). Data on some socio-economic parameters explaining the movement of extra-EU asylum seekers in Europe. Data in Brief, 9, 966-969. https://doi.org/10.1016/j.dib.2016.11.017

Annaert, J.-L. (2004). ECFIN country focus A bright spot in the heart of Europe: what can we learn from the Luxembourg success story? Focus, 1(8), 1-9.

Annez, P. C., \& Buckley, R. M. (2008). Urbanization and Growth. Urbanization and growth: setting the context. https://doi.org/10.1596/978-0-8213-7573-0

Añón Higón, D., Gholami, R., \& Shirazi, F. (2017). ICT and environmental sustainability: A global perspective. Telematics and Informatics, 34(4), 85-95. https://doi.org/10.1016/j.tele.2017.01.001

Azadnia, M., Zahedi, S., \& Pourabedy, M. R. (2017). Analysis of the Impact of ICT on Sustainable Development using Sustainability Indicators. International Journal of Computer Applications, 169(6), 975-8887. Retrieved from https://pdfs.semanticscholar.org/d30f/f2717b122b2642e64e282fbfff526f56599e.pdf Bahrami, S., \& Amini, M. H. (2017). A Decentralized Framework for Real-Time Energy Trading in 
Distribution Networks with Load and Generation Uncertainty, 1-8. Retrieved from http://arxiv.org/abs/1705.02575

Balcan, M. M., \& Gupta, P. (2014). Robust hierarchical clustering. ArXiv Preprint ArXiv:1401.0247, 15, 35. https://doi.org/10.1109/IMSCCS.2006.167

Bannerjee, S., Bone, J., \& Finger, Y. (2016). European Digital City Index - Methodology Report. https://doi.org/978-1-84875-153-8

Baptista, G., \& Oliveira, T. (2016). A weight and a meta-analysis on mobile banking acceptance research. Computers in Human Behavior, 63, 480-489. https://doi.org/10.1016/j.chb.2016.05.074

Barbu, C. M., Florea, D. L., Ogarcă, R. F., \& Răzvan Barbu, M. C. (2018). From ownership to access: How the sharing economy is changing the consumer behavior. Amfiteatru Economic, 20(48), 373-387. https://doi.org/10.24818/EA/2018/48/373

Bardhi, F., \& Eckhardt, G. M. (2012). Access-Based Consumption: The Case of Car Sharing. Journal of Consumer Research, 39(4), 881-898. https://doi.org/10.1086/666376

Barnes, S. J., \& Mattsson, J. (2017). Understanding collaborative consumption: Test of a theoretical model. Technological Forecasting and Social Change, 118, 281-292. https://doi.org/10.1016/j.techfore.2017.02.029

Barosh, L., Friel, S., Engelhardt, K., \& Chan, L. (2014). The cost of a healthy and sustainable diet Who can afford it? Australian and New Zealand Journal of Public Health, 38(1), 7-12. https://doi.org/10.1111/1753-6405.12158

Bartlett, M. S. (1937). Properties of Sufficiency and Statistical Tests. Proceedings of the Royal Society of London. Series A, Mathematical and Physical Sciences, 160(901), 268-282. Retrieved from http://www.jstor.org/stable/96803

Bates, M. J. (1976). Rigorous Systematic Bibliography. RQ, 16(1), 7-26. Retrieved from http://www.jstor.org/stable/41354519

Batten, J. (2016). Sustainable Cities Index 2016. Arcadis Global. Retrieved from https://www.arcadis.com/media/0/6/6/\%7B06687980-3179-47AD-89FDF6AFA76EBB73\%7DSustainable Cities Index 2016 Global Web.pdf

Bayram, I. S., Shakir, M. Z., Abdallah, M., \& Qaraqe, K. (2014). A survey on energy trading in 
smart grid. In 2014 IEEE Global Conference on Signal and Information Processing (GlobalSIP) (pp. 258-262). https://doi.org/10.1109/GlobalSIP.2014.7032118

Becker-Leifhold, C. V. (2018). The role of values in collaborative fashion consumption - A critical investigation through the lenses of the theory of planned behavior. Journal of Cleaner Production, 199, 781-791. https://doi.org/10.1016/j.jclepro.2018.06.296

Belk, R. (2010). Sharing. Journal of Consumer Research, 36(5), 715-734. https://doi.org/10.1086/612649

Belk, R. (2014). You are what you can access: Sharing and collaborative consumption online. Journal of Business Research, 67(8), 1595-1600. https://doi.org/https://doi.org/10.1016/j.jbusres.2013.10.001

Berk, K. N., \& Carey, P. M. (2009). Data Analysis with Microsoft Excel: Updated for Office 2007 (3rd ed.). Boston, MA, USA: Duxbury Press.

Berkhout, F., \& Hertin, J. (2001). Impacts of information and communication technologies on environmental sustainability: Speculations and evidence. Report to the OECD, Brighton, 5.

Bernardi, M., \& Diamantini, D. (2018). Shaping the sharing city: An exploratory study on Seoul and Milan. Journal of Cleaner Production, 203, 30-42. https://doi.org/https://doi.org/10.1016/j.jclepro.2018.08.132

Berrini, M., \& Bono, L. (2007). Urban ecosystem europe. Europe. Rome. Retrieved from http://www.dexia.com/EN/journalist/press_releases/Documents/20080201_urban_ecosys tem_UK.pdf

Berrone, P., Ricart, J. E., Carraso, C., \& Ricart, R. (2016). IESE Cities in motion index 2016, 60. https://doi.org/10.15581/018.ST-471

Berry, J. M., \& Portney, K. E. (2013). Sustainability and interest group participation in city politics. Sustainability (Switzerland), 5(5), 2077-2097. https://doi.org/10.3390/su5052077

Bibri, S. E., \& Krogstie, J. (2017a). On the social shaping dimensions of smart sustainable cities: A study in science, technology, and society. Sustainable Cities and Society, 29, 219-246. https://doi.org/https://doi.org/10.1016/j.scs.2016.11.004

Bibri, S. E., \& Krogstie, J. (2017b). Smart sustainable cities of the future: An extensive interdisciplinary literature review. Sustainable Cities and Society, 31, 183-212. 
https://doi.org/10.1016/j.scs.2017.02.016

Bifulco, F., Tregua, M., Amitrano, C., \& D'Auria, A. (2016). ICT and sustainability in smart cities management. International Journal of Public Sector Management, 29(2), 132-147. https://doi.org/http://dx.doi.org/10.1108/IJPSM-07-2015-0132

Billón, M., Ezcurra, R., \& Lera-López, F. (2008). The Spatial Distribution of the Internet in the European Union: Does Geographical Proximity Matter? European Planning Studies, 16(1), 119-142. https://doi.org/10.1080/09654310701748009

Böcker, L., \& Meelen, T. (2017). Sharing for people, planet or profit? Analysing motivations for intended sharing economy participation. Environmental Innovation and Societal Transitions, 23, 28-39. https://doi.org/https://doi.org/10.1016/j.eist.2016.09.004

Bodansky, D. (2010). The Copenhagen Climate Change Conference: A Postmortem. American Journal of International Law, 104(2), 230-240. https://doi.org/10.5305/amerjintelaw.104.2.0230

Bojković, N., Petrović, M., \& Parezanović, T. (2018). Towards indicators outlining prospects to reduce car use with an application to European cities. Ecological Indicators, 84, 172-182. https://doi.org/https://doi.org/10.1016/j.ecolind.2017.08.061

Borenstein, M., Hedges, L. V., Higgins, J. P., \& Rothstein, H. R. (2009). Identifying and Quantifying Heterogeneity. In Introduction to Meta-Analysis (pp. 107-125). John Wiley \& Sons, Ltd. https://doi.org/10.1002/9780470743386.ch16

Box, G. E. P., \& Cox, D. R. (1964). An Analysis of Transformations. Journal of the Royal Statistical Society. Series B: Statistical Methodology, 26(2), 211-252. Retrieved from http://www.econ.illinois.edu/ econ508/Papers/boxcox64.pdf

Bruno, G., Esposito, E., Genovese, A., \& Gwebu, K. L. (2010). A Critical Analysis of Current Indexes for Digital Divide Measurement. The Information Society, 27(1), 16-28. https://doi.org/10.1080/01972243.2010.534364

Bunz, U., Curry, C., \& Voon, W. (2007). Perceived versus actual computer-email-web fluency. Computers in Human Behavior, 23(5), 2321-2344. https://doi.org/https://doi.org/10.1016/j.chb.2006.03.008

Burnham, J. F. (2006). Scopus database: a review. Biomedical Digital Libraries, 3, 1. 
https://doi.org/10.1186/1742-5581-3-1

Buttazzoni, M. (2008). The potential global CO 2 reductions from ICT use: Identifying and assessing the opportunities to reduce the first billion tonnes of $\mathrm{CO} 2$ emissions. Solna. Retrieved from https://www.wwf.se/source.php/1183710/identifying_the_1st_billion_tonnes_ict.pdf Cabral, A. L. B., Sousa, A. W., Mendes, F. A. R., \& de Carvalho, C. R. F. (2017). Phenotypes of asthma in low-income children and adolescents: cluster analysis. Jornal Brasileiro de Pneumologia, 43(1), 44-50. https://doi.org/10.1590/S1806-37562016000000039

Caprihan, A., Pearlson, G. D., \& Calhoun, V. D. (2008). Application of principal component analysis to distinguish patients with schizophrenia from healthy controls based on fractional anisotropy measurements. Neurolmage, 42(2), 675-682. https://doi.org/10.1016/j.neuroimage.2008.04.255

Castán, J. A., Martínez, S. I., Menchaca, J. L., \& Berrones, M. G. T. (2016). Improving Vehicular Mobility in Urban Traffic Using Ubiquitous Computing. Journal of Computer and Communications, 4(August), 57-62. https://doi.org/http://dx.doi.org/10.4236/jcc.2016.410006

Cerny, B. A., \& Kaiser, H. F. (1977). A Study Of A Measure Of Sampling Adequacy For FactorAnalytic Correlation Matrices. Multivariate Behavioral Research, 12(1), 43-47. https://doi.org/10.1207/s15327906mbr1201_3

Chen, C., Ding, Y., \& Liu, S. (2008). City Economical Function and Industrial Development: Case Study along the Railway Line in North Xinjiang in China. Journal of Urban Planning and Development, 134(4), 153-158. https://doi.org/10.1061/(ASCE)07339488(2008)134:4(153)

Chen, G., Wiedmann, T., Hadjikakou, M., \& Rowley, H. (2016). City carbon footprint networks. Energies, 9(8), 1-16. https://doi.org/10.3390/en9080602

Chen, H. K., Chou, H. W., \& Hung, S. C. (2018). Interrelationships between behaviour intention and its influential factors for consumers of motorcycle express cargo delivery service. Transportmetrica A: Transport Science, 0(0), 1-30. https://doi.org/10.1080/23249935.2018.1509401 
Cheng, M. (2016). Sharing economy: A review and agenda for future research. International Journal of Hospitality Management, 57, 60-70. https://doi.org/10.1016/j.ijhm.2016.06.003

Choi, C., \& Hoon Yi, M. (2009). The effect of the Internet on economic growth: Evidence from cross-country panel data. Economics Letters, 105(1), 39-41. https://doi.org/10.1016/j.econlet.2009.03.028

Chourabi, H., Nam, T., Walker, S., Gil-Garcia, J. R., Mellouli, S., Nahon, K., ... Scholl, H. J. (2011). Understanding smart cities: An integrative framework. Proceedings of the Annual Hawaii International Conference on System Sciences, 2289-2297. https://doi.org/10.1109/HICSS.2012.615

Çilan, Ç. A., Bolat, B. A., \& Coşkun, E. (2009). Analyzing digital divide within and between member and candidate countries of European Union. Government Information Quarterly, 26(1), 98-105. https://doi.org/https://doi.org/10.1016/j.giq.2007.11.002

Constantin, D. L. (1999). Environmental Preservation Strategy in the New Romania: Institutional and Behavioural Challenges. In S. C. Lonergan (Ed.), Environmental Change, Adaptation, and Security (pp. 317-333). Dordrecht: Springer Netherlands. https://doi.org/10.1007/978-94-011-4219-9_22

Cruz-Jesus, F., Oliveira, T., \& Bacao, F. (2012). Digital divide across the European Union. Information and Management, 49(6), 278-291. https://doi.org/10.1016/j.im.2012.09.003

Cruz-Jesus, F., Oliveira, T., Bacao, F., \& Irani, Z. (2017). Assessing the pattern between economic and digital development of countries. Information Systems Frontiers, 19(4), 835-854. https://doi.org/10.1007/s10796-016-9634-1

Cuervo, M. R. V., \& Menéndez, A. J. L. (2006). A multivariate framework for the analysis of the digital divide: Evidence for the European Union-15. Information \& Management, 43(6), 756-766. https://doi.org/https://doi.org/10.1016/j.im.2006.05.001

Currid, E. (2006). New York as a Global Creative Hub: A Competitive Analysis of Four Theories on World Cities. Economic Development Quarterly, 20(4), 330-350. https://doi.org/10.1177/0891242406292708

D'Auria, A., Tregua, M., \& Vallejo-Martos, M. C. (2018). Modern conceptions of cities as smart and sustainable and their commonalities. Sustainability (Switzerland), 10(8), 1-18. 
https://doi.org/10.3390/su10082642

David, D. (2017). Environment and urbanization. The International Encyclopedia of Geography, 24(1), 31-46. https://doi.org/10.1002/9781118786352.wbieg0623

Deakin, M., \& Reid, A. (2016). Smart cities: Under-gridding the sustainability of city-districts as energy efficient-low carbon zones. Journal of Cleaner Production. https://doi.org/10.1016/j.jclepro.2016.12.054

Debnath, A. K., Chin, H. C., Haque, M. M., \& Yuen, B. (2014). A methodological framework for benchmarking smart transport cities. Cities, 37, 47-56. https://doi.org/10.1016/j.cities.2013.11.004

Dedrick, J. (2010). Green IS: Concepts and issues for information systems research. Communications of the Association for Information Systems, 27(1), 173-184. Retrieved from https://www.scopus.com/inward/record.uri?eid=2-s2.077958113523\&partnerID=40\&md5=ed4ac9f968bef414d0ad0ce37b52ba73

Degbelo, A., Bhattacharya, D., Granell, C., \& Trilles, S. (2016). Toolkits for smarter cities: a brief assessment. In UCAmI 2016 (Ed.), UCAmI 2016 - 10th International Conference on Ubiquitous Computing \& Ambient Intelligence (pp. 431-436). Las Palmas, Gran Canaria, Spain: Springer International Publishing. https://doi.org/10.1007/978-3-319-48799-1 47

Degbelo, A., Granell Granell, C., Trilles Oliver, S., Bhattacharya, D., Casteleyn, S., \& Kray, C. (2016). Opening up Smart Cities: Citizen-Centric Challenges and Opportunities from GIScience. ISPRS International Journal of Geo-Information, 5(2), 16. https://doi.org/10.3390/ijgi5020016

Denig, S. (2011). Sustainable Urban Infrastructure: London edition - a view to 2025. London. Retrieved from https://w5.siemens.com/web/si/sl/corporate/portal/raziskave/Documents/sustainable_ur ban_infrastructure-study_london.pdf

Der, G., \& Everitt, B. (2010). A Handbook of Statistical Analyses using SAS. ... of the Royal Statistical Society: Series A (Statistics in ... (2nd Editio). Washington, D.C: Chapman \& Hall / CRC. https://doi.org/10.1111/j.1541-0420.2009.01343_9.x

Dongtotsang, D. T., \& Sagun, R. a. (2006). Mobile Telephony as an Enabler of Environmental 
Action in the Philippines. Policy. Manitoba.

Doyle, K., Sainsbury, K., Cleary, S., Parkinson, L., Vindigni, D., McGrath, I., \& Cruickshank, M. (2017). Happy to help/happy to be here: Identifying components of successful clinical placements for undergraduate nursing students. Nurse Education Today, 49, 27-32. https://doi.org/10.1016/j.nedt.2016.11.001

Dunn, T. J., Baguley, T., \& Brunsden, V. (2014). From alpha to omega: A practical solution to the pervasive problem of internal consistency estimation. British Journal of Psychology, 105(3), 399-412. https://doi.org/10.1111/bjop.12046

Duxbury, N., Hosagrahar, J., \& Pascual, J. (2016). Why must culture be at the heart of sustainable urban development? Retrieved from http://www.agenda21culture.net/sites/default/files/files/documents/en/culture_sd_cities _web.pdf

Dziuban, C. D., \& Shirkey, E. C. (1974). When is a correlation matrix appropriate for factor analysis. Some decision rules. Psychological Bulletin, 81(6), 358-361. https://doi.org/10.1037/h0036316

Edenhofer, O., Pichs Madruga, R., \& Sokona, Y. (2012). Renewable Energy Sources and Climate Change Mitigation (Special Report of the Intergovernmental Panel on Climate Change). Clim. Policy (Vol. 6). https://doi.org/10.5860/CHOICE.49-6309

Egbue, O., \& Long, S. (2012a). Barriers to widespread adoption of electric vehicles: An analysis of consumer attitudes and perceptions. Energy Policy, 48, 717-729. https://doi.org/https://doi.org/10.1016/j.enpol.2012.06.009

Egbue, O., \& Long, S. (2012b). Barriers to widespread adoption of electric vehicles: An analysis of consumer attitudes and perceptions. Energy Policy, 48, 717-729. https://doi.org/https://doi.org/10.1016/j.enpol.2012.06.009

Eichholtz, P., Kok, N., \& Quigley, J. M. (2010). Doing Well by Doing Good? Green Office Buildings. American Economic Review, 100(5), 2492-2509. https://doi.org/10.1257/aer.100.5.2492

Einav, L., Farronato, C., \& Levin, J. (2016). Peer-to-Peer Markets. Annual Review of Economics, 8(1), 615-635. https://doi.org/10.1146/annurev-economics-080315-015334 
Escamilla Solano, S., Plaza Casado, P., \& Flores Ureba, S. (2017). Smart Cities and Sustainable Development. A Case Study. In M. Peris-Ortiz, D. R. Bennett, \& D. Pérez-Bustamante Yábar (Eds.), Sustainable Smart Cities: Creating Spaces for Technological, Social and Business Development (pp. 65-77). Cham: Springer International Publishing. https://doi.org/10.1007/978-3-319-40895-8_5

Estevez, E., Lopes, N. V., \& Janowski, T. (2016). Smart Sustainable Cities. Reconnaissance Study, 330.

European Comission. (2016). Urban Europe: Statistics on Cities, Towns and Suburbs. https://doi.org/10.2785/91120

European Commission. (2009). ICT Impact on Greenhouse Gas Emissions in Industries, (01), 1165.

European Commission. (2010a). Communication from the Commission EUROPE 2020 A strategy for smart, sustainable and inclusive growth. Com(2010) 2020, Brussels(3 March), Commission of the European Communities. https://doi.org/10.1016/j.resconrec.2010.03.010

European Commission. (2010b). Making our cities attractive: How the EU contributes to improving the urban environment. Luxembourg. https://doi.org/10.2779/42720 European Commission. (2014a). Digital Agenda for Europe - Rebooting Europe's economy. European Commission, 8. https://doi.org/10.2775/41229

European Commission. (2014b). European Economy: Macroeconomic Imbalances Luxembourg 2014 (Vol. 3209). https://doi.org/10.2765/74234

European Commission. (2014c). The Urban Dimension of EU Policies - Key Features of an EU Urban Agenda, 12. Retrieved from http://ec.europa.eu/regional_policy/consultation/urb_agenda/index_en.cfm European Commission. (2016a). European Green Capital Award and European Green Leaf Award. Brussels. Retrieved from http://ec.europa.eu/environment/europeangreencapital/europeangreenleaf/ European Commission. (2016b). Sustainable development in the European Union. https://doi.org/10.1002/(SICI)1099-0976(199711)7:6<181::AID-EET134>3.0.CO;2-S 
European Commission. (2016c). The Martketplace of the European Innovation Partnership on Smart cities and Communities (EIP-SCC). Brussels. Retrieved from http://ec.europa.eu/eip/smartcities/files/operational-implementation-plan-oip-v2_en.pdf European Commission. (2017). Sustainable development in the European Union: MONITORING REPORT ON PROGRESS TOWARDS THE SDGS IN AN EU CONTEXT (Vol. 256). https://doi.org/10.1002/(SICI)1099-0976(199711)7:6<181::AID-EET134>3.0.CO;2-S

Eurostat. (2013). Territorial typologies for European cities and metropolitan regions. Luxembourg. https://doi.org/ISSN 2443-8219

Eurostat. (2016). Eurostat regional yearbook 2017 edition (2017th ed.). Luxembourg: Publications office of the European Union. https://doi.org/10.2785/257716

Eurostat. (2017). Final report of the quality of life indicators. Luxembourg: Publications office of the European Union. https://doi.org/10.2785/021270

Everitt, B., \& Hothorn, T. (2006). A handbook of statistical analyses using R. https://doi.org/10.1088/1751-8113/44/8/085201

Everitt, Brian, Landau, S., Leese, M., \& Stah, D. (2011). Cluster Analysis. (W. Shewhart \& S. Wilks, Eds.) (5th Editio). Chichester, UK: John Wiley \& Sons, Ltd. https://doi.org/10.1002/9780470977811

Feldmann, B. (2008). The Urban Audit - measuring the quality of life in European cities. Eurostat - Statistics in Focus, 82. Retrieved from http://epp.eurostat.ec.europa.eu/cache/ITY_OFFPUB/KS-SF-08-082/EN/KS-SF-08-082EN.PDF

Fellows, N. T., \& Pitfield, D. E. (2000). An economic and operational evaluation of urban carsharing. Transportation Research Part D: Transport and Environment, 5(1), 1-10. https://doi.org/https://doi.org/10.1016/S1361-9209(99)00016-4

Ferro, E., Helbig, N. C., \& Gil-Garcia, J. R. (2011). The role of IT literacy in defining digital divide policy needs. Government Information Quarterly, 28(1), 3-10. https://doi.org/https://doi.org/10.1016/j.giq.2010.05.007

Frenken, K., \& Schor, J. (2017). Putting the sharing economy into perspective. Environmental Innovation and Societal Transitions, 23, 3-10. https://doi.org/10.1016/j.eist.2017.01.003 
Friesen, C. E., Seliske, P., \& Papadopoulos, A. (2016). Using Principal Component Analysis to Identify Priority Neighbourhoods for Health Services Delivery by Ranking Socioeconomic Status. Online Journal of Public Health Informatics, 8(2), e192. https://doi.org/10.5210/ojphi.v8i2.6733

Gabrys, J. (2014). Programming Environments: Environmentality and Citizen Sensing in the Smart City. Environment and Planning D: Society and Space, 32(1), 30-48. https://doi.org/10.1068/d16812

García-Fuentes, M., Quijano, A., De Torre, C., García, R., Compere, P., Degard, C., \& Tomé, I. (2017). European Cities Characterization as Basis towards the Replication of a Smart and Sustainable Urban Regeneration Model. Energy Procedia, 111(September 2016), 836-845. https://doi.org/10.1016/j.egypro.2017.03.246

Garín-Muñoz, T., López, R., Pérez-Amaral, T., Herguera, I., \& Valarezo, A. (2018). Models for individual adoption of eCommerce, eBanking and eGovernment in Spain. Telecommunications Policy. https://doi.org/https://doi.org/10.1016/j.telpol.2018.01.002

Geissdoerfer, M., Savaget, P., Bocken, N. M. P., \& Hultink, E. J. (2017). The Circular Economy - A new sustainability paradigm? Journal of Cleaner Production, 143, 757-768. https://doi.org/https://doi.org/10.1016/j.jclepro.2016.12.048

Giampietro, M., \& Mayumi, K. (2018). Unraveling the Complexity of the Jevons Paradox: The Link Between Innovation, Efficiency, and Sustainability. Frontiers in Energy Research, 6, 26. https://doi.org/10.3389/fenrg.2018.00026

Giffinger, R., Fertner, C., Kramar, H., Kalasek, R., Pichler-Milanovic, N., \& Meijers, E. (2007). Ranking of European medium-sized cities. Vienna. Retrieved from http://www.smartcities.eu/download/smart_cities_final_report.pdf

Giffinger, R., Haindlmaier, G., \& Kramar, H. (2010). The role of rankings in growing city competition. Urban Research \& Practice, 3(3), 299-312. https://doi.org/10.1080/17535069.2010.524420

Gorla, N., Chiravuri, A., \& Chinta, R. (2017). Business-to-business e-commerce adoption: An empirical investigation of business factors. Information Systems Frontiers, 19(3), 645-667. https://doi.org/10.1007/s10796-015-9616-8 
Gouvea, R., Kapelianis, D., \& Kassicieh, S. (2017). Assessing the nexus of sustainability and information \& communications technology. Technological Forecasting and Social Change, (July), 0-1. https://doi.org/10.1016/j.techfore.2017.07.023

Grant, K. A., \& Chuang, S. (2012a). An aggregating approach to ranking cities for knowledgebased development. International Journal of Knowledge-Based Development, 3(1), 17. https://doi.org/10.1504/IJKBD.2012.045558

Grant, K. A., \& Chuang, S. (2012b). An aggregating approach to ranking cities for knowledgebased development. International Journal of Knowledge-Based Development, 3(1), 17. https://doi.org/10.1504/IJKBD.2012.045558

Groeneveld, R. A., \& Meeden, G. (1984). Measuring Skewness and Kurtosis. Journal of the Royal Statistical Society. Series D (The Statistician), 33(4), 391-399. Retrieved from http://www.jstor.org/stable/2987742

Gudmundsson, H. (2015). The European Green Capital Award . Its Role , Evaluation Criteria and Policy Implications. Toshi Keikaku, 64(2), 15. Retrieved from http://orbit.dtu.dk/files/110724430/313_Henrik_T2.pdf

Guo, H., \& Gao, S. (2017). Barriers to Adopting E-commerce in Chinese Rural Areas: A Case Study. In A. K. Kar, P. V. Ilavarasan, M. P. Gupta, Y. K. Dwivedi, M. Mäntymäki, M. Janssen, ... S. Al-Sharhan (Eds.), Digital Nations -- Smart Cities, Innovation, and Sustainability (pp. 71-82). Cham: Springer International Publishing.

Gutiérrez, J., García-Palomares, J. C., Romanillos, G., \& Salas-Olmedo, M. H. (2017). The eruption of Airbnb in tourist cities: Comparing spatial patterns of hotels and peer-to-peer accommodation in Barcelona. Tourism Management, 62, 278-291. https://doi.org/https://doi.org/10.1016/j.tourman.2017.05.003

Hagshenas, H., Vaziri, M., \& Gholamialam, A. (2013). Sustainable Urban Transport Assessment in Asian Cities. Current World Environment, 3(8), 221-230. Retrieved from https://www.adb.org/sites/default/files/publication/179577/sustainable-urban-transportasia-main-report-2006.pdf

Hair, J., Hult, T., Ringle, C. M., \& Sarstedt, M. (2014). A primer on partial least squares structural equation modeling (PLS-SEM) (1st ed.). Thousand Oaks, CA: SAGE Publications. 
Hak, T., van Rhee, H., \& Suurmond, R. (2016). How to Interpret Results of Meta-Analysis. SSRN Electronic Journal, (June), 1-21. https://doi.org/10.2139/ssrn.3241367

Hamari, J., Sjöklint, M., \& Ukkonen, A. (2016). The sharing economy: Why people participate in collaborative consumption. Journal of the Association for Information Science and Technology, 67(9), 2047-2059. https://doi.org/10.1002/asi.23552

Hamenda, A. (2018). an Integrated Model of Service Quality, Price Fairness, Ethical Practice and Customer Perceived Values for Customer Satisfaction of Sharing Economy Platform. International Journal of Business and Society, 19(3), 709-724.

Han, J., Meng, X., Zhou, X., Yi, B., Liu, M., \& Xiang, W.-N. (2016). A long-term analysis of urbanization process, landscape change, and carbon sources and sinks: A case study in China's Yangtze River Delta region. Journal of Cleaner Production, 141, 1040-1050. https://doi.org/10.1016/j.jclepro.2016.09.177

Hannachi, A., Jolliffe, I. T., Stephenson, D. B., \& Trendafilov, N. (2006). In search of simple structures in climate: Simplifying EOFS. International Journal of Climatology, 26(1), 7-28. https://doi.org/10.1002/joc.1243

Hardle, W. K., \& Simar, L. (2007). Applied Multivariate Statistical Analyses (2nd ed.). Berlin: Springer-Verlag. https://doi.org/10.1007/978-3-540-72244-1

Harzing, A.-W., \& Alakangas, S. (2016). Google Scholar, Scopus and the Web of Science: a longitudinal and cross-disciplinary comparison. Scientometrics, 106(2), 787-804. https://doi.org/10.1007/s11192-015-1798-9

Hawlitschek, F., Teubner, T., \& Gimpel, H. (2018). Consumer motives for peer-to-peer sharing. Journal of Cleaner Production, 204, 144-157. https://doi.org/10.1016/j.jclepro.2018.08.326

Hawlitschek, F., Teubner, T., \& Weinhardt, C. (2016). Trust in the Sharing Economy. Die Unternehmung, 70(1), 26-44. https://doi.org/10.5771/0042-059X-2016-1-26

Hedges, L. V., \& Vevea, J. L. (1998). Fixed- and Random-Effects Models in Meta-Analysis. Psychological Methods, 3(4), 486-504. https://doi.org/10.1037/1082-989X.3.4.486 Hellwig, K., Morhart, F., Girardin, F., \& Hauser, M. (2015). Exploring Different Types of Sharing: A Proposed Segmentation of the Market for "Sharing" Businesses. Psychology \& 
Marketing, 32(9), 891-906. https://doi.org/10.1002/mar.20825

Hernandez, B., Jimenez, J., \& Martín, M. J. (2009). Adoption vs acceptance of e-commerce: two different decisions. European Journal of Marketing, 43(9/10), 1232-1245. https://doi.org/10.1108/03090560910976465

Hirt, S., \& Stanilov, K. (2009). Twenty Years of Transition: The Evolution of Urban Planning in Eastern Europe and the Former Soviet Union, 1989-2009. Human Settlements Global Dialogue Series, No. 5. Retrieved from http://unhabitat.org/books/twenty-years-oftransition-the-evolution-of-urban-planning-in-eastern-europe-and-the-former-sovietunion-1989-2009/.

Höjer, M., \& Wangel, J. (2015). Smart Sustainable Cities: Definition and Challenges. In L. M. Hilty \& B. Aebischer (Eds.), ICT Innovations for Sustainability (pp. 333-349). Cham: Springer International Publishing.

Huaisui, Q., Shunquan, Y., Jiulin, S. U. N., \& Zehui, L. I. (2004). Relationships between energy consumption and climate change in China. Journal of Geographical Sciences, 1(994071000), 87-93. https://doi.org/10.1007/BF02873095

Huarng, K.-H., \& Yu, M.-F. (2018). Customer satisfaction and repurchase intention theory for the online sharing economy. Review of Managerial Science, (0123456789). https://doi.org/10.1007/s11846-018-0321-0

Hughes, S., Chu, E. K., \& Mason, S. G. (2018). Introduction. In S. Hughes, E. K. Chu, \& S. G. Mason (Eds.), Climate Change in Cities: Innovations in Multi-Level Governance (pp. 1-15). Cham: Springer International Publishing. https://doi.org/10.1007/978-3-319-65003-6_1 Humphreys, L. G., \& Montanelli, R. . (1975). An investigation of the parallel analysis criteria for determining the number of common factors. Multivariate Behavioral Research, 10(1), 193205.

Husson, F., Lê, S., \& Pagès, J. (2010a). Exploratory Multivariate Analysis by Example using R. Chapman \& Hall/CRC Computer Science \& Data Analysis (Vol. 40). https://doi.org/10.1080/02664763.2012.657409

Husson, F., Lê, S., \& Pagès, J. (2010b). Exploratory Multivariate Analysis by Example using R. Chapman \& Hall/CRC Computer Science \& Data Analysis (Vol. 40). 
https://doi.org/10.1080/02664763.2012.657409

Huyer, S., Hafkin, N., Ertl, H., \& Dryburgh, H. (2005). From the digital divide to digital opportunities: Measuring infostates for development. Women in the Information Society/. Geneva. Retrieved from http://www.itu.int/ITU-

D/ict/publications/dd/material/index_ict_opp.pdf

Hyvärinen, A. (2013). Independent Component Analysis of Images. In D. Jaeger \& R. Jung (Eds.), Encyclopedia of Computational Neuroscience (pp. 1-5). New York, NY: Springer New York. https://doi.org/10.1007/978-1-4614-7320-6_708-1

Ian, H., Kaliopa, D.-A., \& Natasa, P.-M. (2003). Transformation of cities in central and Eastern Europe: Towards globalization. United Nations University Press (1st ed.). Tokyo: United Nations University Press. Retrieved from https://chisineu.files.wordpress.com/2012/08/biblioteca_hamilton_transformation.pdf Ichikawa, H., Yamato, N., \& Dustan, P. (2017). Competitiveness of Global Cities from the Perspective of the Global Power City Index. Procedia Engineering, 198(September 2016), 736-742. https://doi.org/10.1016/j.proeng.2017.07.125

IPCC. (2014a). Climate Change 2014: Synthesis Report. Contribution of Working Groups I, II and III to the Fifth Assessment Report of the Intergovernmental Panel on Climate Change. Core Writing Team, R.K. Pachauri and L.A. Meyer. Geneva. https://doi.org/10.1017/CBO9781107415324.004

IPCC. (2014b). Climate Change 2014 Synthesis Report. Contribution of Working Groups I, II and III to the Fifth Assessment Report of the Intergovernmental Panel on Climate Change, 1112.

IPCC. (2018). Global Warming of $1.5^{\circ} \mathrm{C}$, an IPCC special report on the impacts of global warming of $1.5^{\circ} \mathrm{C}$ above pre-industrial levels and related global greenhouse gas emission pathways, in the context of strengthening the global response to the threat of climate change, Incheon. Retrieved from http://www.ipcc.ch/report/sr15/

Isnard, M., \& Sautory, O. (1994). Les macros SAS d' analyse des données. Institut National de la Statistique et des Études Économiques.

ISO. (2014a). ISO 37120:2014 Sustainable development of communities - Indicators for city 
services and quality of life. Geneva. Retrieved from

https://www.iso.org/standard/61885.html

ISO. (2014b). Sustainable Development of communities - Indicators for city services and quality of life. Geneva. Retrieved from https://www.acciona.com/sustainable-development/

ITU. (2005). WSIS Thematic Meeting on Multi-Stakeholder Partnerships for Bridging the Digital Divide.

ITU. (2008). ITU and Climate Change. International Telecommunication Union. https://doi.org/10.1017/CBO9780511803826

ITU. (2009). eEnvironment Toolkit and the e-Environment Readiness Index (EERI). Geneva. Retrieved from http://www.itu.int/ITU-D/cyb/app/docs/eEnvironment ToolkitFINAL.pdf ITU. (2014). Agreed definition of a smart sustainable city. Focus Group on Smart Sustainable Cities. Geneva.

ITU. (2017a). Measuring the Information Society Report 2017 - Volume 1. International Telecommunication Union (Vol. 1). https://doi.org/10.3359/oz0303157

ITU. (2017b). Yearbook of Statistics, Telecommunication/ICT Indicators 2006-2015 (42nd Editi). Geneva. https://doi.org/https://doi.org/http://handle.itu.int/11.1002/pub/80decce2-en Jacinto, C., \& Soares, C. G. (2008). The added value of the new ESAW/Eurostat variables in accident analysis in the mining and quarrying industry. Journal of Safety Research, 39(6), 631-644. https://doi.org/10.1016/j.jsr.2008.10.009

Jacobs, J. (2016). Cities and the Wealth of Nations. Knopf Doubleday Publishing Group. Retrieved from https://books.google.pt/books?id=sDG5DAAAQBAJ Janssen, N. A. H., Hoek, G., Simic-Lawson, M., Fischer, P., van Bree, L., ten Brink, H., ... Cassee, F. R. (2011). Black carbon as an additional indicator of the adverse health effects of airborne particles compared with PM10 and PM2.5. Environmental Health Perspectives, 119(12), 1691-1699. https://doi.org/10.1289/ehp.1003369

Jenks, M., \& Jones, C. (2008). Dimensions of the sustainable city. (M. Jenks \& C. Jones, Eds.) (Vol. 2). New York, NY, USA: Springer International Publishing. https://doi.org/10.1007/978-1-4020-8647-2

Jeyaraj, A., Rottman, J. W., \& Lacity, M. C. (2006). A review of the predictors, linkages, and 
biases in IT innovation adoption research. Journal of Information Technology, 21(1), 1-23. https://doi.org/10.1057/palgrave.jit.2000056

Johnson, R. E., Rosen, C. C., Chang, C.-H. (Daisy), Djurdjevic, E., \& Taing, M. U. (2012).

Recommendations for improving the construct clarity of higher-order multidimensional constructs. Human Resource Management Review, 22(2), 62-72.

https://doi.org/10.1016/j.hrmr.2011.11.006

Jolliffe, I.T. (2002). Principal Component Analyses (2nd ed.). New York: Springer-Verlag New York. https://doi.org/10.1007/b98835

Jolliffe, Ian T., \& Cadima, J. (2016). Principal component analysis: a review and recent developments. Philosophical Transactions of the Royal Society A: Mathematical, Physical and Engineering Sciences, 374(2065), 20150202. https://doi.org/10.1098/rsta.2015.0202

Joseph, N., Kar, A. K., \& Ilavarasan, P. V. (2017). A Model for Prioritization and Prediction of Impact of Digital Literacy Training Programmes and Validation. In A. K. Kar, P. V. Ilavarasan, M. P. Gupta, Y. K. Dwivedi, M. Mäntymäki, M. Janssen, ... S. Al-Sharhan (Eds.), Digital Nations -- Smart Cities, Innovation, and Sustainability (pp. 227-238). Cham: Springer International Publishing.

Kahn, M. E. (2006). Green Cities: Urban Growth and the Environment. https://doi.org/10.1111/j.1467-9787.2006.00531_8.x

Kaiser, H. F. (1960). The Application of Electronic Computers to Factor Analysis. Educational and Psychological Measurement, 20(1), 141-151. https://doi.org/10.1177/001316446002000116

Kalsoom, Q. (2018). Attitude Change to Sustainable Development. In W. Leal Filho (Ed.), Encyclopedia of Sustainability in Higher Education (pp. 1-7). Cham: Springer International Publishing. https://doi.org/10.1007/978-3-319-63951-2_160-1

Kar, A., llavarasan, P. V., Gupta, M. ., Dwivedi, Y., Mäntymäki, M., Janssen, M., ... Al-Sharhan, S. (2017). Digital Nations - Smart Cities, Innovation, and Sustainability 16th IFIP WG 6.11 Conference on e-Business, e-Services, and e-Society, I3E 2017, Delhi, India, November 2123, 2017, Proceedings. (A. Kumar Kar, M. Janssen, V. Ilavarasan, A. Simintiras, M. P. Gupta, S. Al-Sharhan, ... M. Mäntymäki, Eds.) (1st ed., Vol. 10595). Springer International 
Publishing. https://doi.org/10.1007/978-3-319-68557-1

Karvalics, L. Z. (2005). The Information (Society) Race. In J. Berleur \& C. Avgerou (Eds.), Perspectives and Policies on ICT in Society: An IFIP TC9 (Computers and Society) Handbook (pp. 99-117). Boston, MA: Springer US. https://doi.org/10.1007/0-387-25588-5_8

Kim, D. J., \& Hwang, Y. (2012). A study of mobile internet user's service quality perceptions from a user's utilitarian and hedonic value tendency perspectives. Information Systems Frontiers, 14(2), 409-421. https://doi.org/10.1007/s10796-010-9267-8

Kim, Y. G., Woo, E., \& Nam, J. (2018). Sharing economy perspective on an integrative framework of the NAM and TPB. International Journal of Hospitality Management, 72(February), 109-117. https://doi.org/10.1016/j.ijhm.2018.01.008

Koch, I. (2013). Analysis of Multivariate and High-Dimensional Data. Cambridge University Press. https://doi.org/10.1017/СBO9781139025805

Koh, J., \& Kim, Y.-G. (2003). Sense of virtual community: A conceptual framework and empirical validation. International Journal of Electronic Commerce, 8(2), 75-94. https://doi.org/10.1080/10864415.2003.11044295

Kotsiantis, S. B., Kanellopoulos, D., \& Pintelas, P. E. (2006). Data preprocessing for supervised learning. International Journal of Computer Science, 1(2), 111-117. https://doi.org/10.1080/02331931003692557

Kouser, K., Lavanya, P. G., Rangarajan, L., \& Acharya Kshitish, K. (2016). Effective Feature Selection for Classification of Promoter Sequences. Plos One, 11(12), 1-20. https://doi.org/10.1371/journal.pone.0167165

KPMG. (2010a). City typology as the basis for policy. City. Retrieved from http://www.kpmg.com/Global/en/IssuesAndInsights/ArticlesPublications/Documents/City -typology-as-the-basis-for-policy.pdf

KPMG. (2010b). City typology as the basis for policy. City.

Kramers, A, Wangel, J., \& Höjer, M. (2016). Governing the smart sustainable city: The case of the Stockholm Royal Seaport. Proceedings of ICT for Sustainability 2016, 46, 99-108. Kramers, Anna, Höjer, M., Lövehagen, N., \& Wangel, J. (2014). Smart sustainable cities Exploring ICT solutions for reduced energy use in cities. Environmental Modelling \& 
Software, 56, 52-62. https://doi.org/https://doi.org/10.1016/j.envsoft.2013.12.019 Kucharczyk, H., Kucharczyk, M., Stanislawek, K., \& Fedor, P. (2012). Application of PCA in Taxonomy Research. Principal Component Analysis - Multidisciplinary Applications. https://doi.org/10.5772/711

Kumar, G., Mehra, H., Seth, A. R., Radhakrishnan, P., Hemavathi, N., \& Sudha, S. (2014). An hybrid clustering algorithm for optimal clusters in Wireless sensor networks. In Electrical, Electronics and Computer Science (SCEECS), 2014 IEEE Students' Conference on (pp. 1-6). https://doi.org/10.1109/SCEECS.2014.6804442

Lang, C. (2018). Perceived risks and enjoyment of access-based consumption: identifying barriers and motivations to fashion renting. Fashion and Textiles, 5(1). https://doi.org/10.1186/s40691-018-0139-z

Lang, C., \& Joyner Armstrong, C. M. (2018). Collaborative consumption: The influence of fashion leadership, need for uniqueness, and materialism on female consumers' adoption of clothing renting and swapping. Sustainable Production and Consumption, 13(November), 37-47. https://doi.org/10.1016/j.spc.2017.11.005

Langley, P., \& Leyshon, A. (2017). Platform capitalism: The intermediation and capitalization of digital economic circulation. Finance and Society, 3(1), 11-31. https://doi.org/10.2218/finsoc.v3i1.1936

Lê, S., Josse, J., \& Husson, F. (2008). FactoMineR: An R Package for Multivariate Analysis. J. of Statistical Software, 25(1), 1-18. https://doi.org/10.1016/j.envint.2008.06.007

Lee, Z. W. Y., Chan, T. K. H., Balaji, M. S., \& Chong, A. Y.-L. (2018). Why people participate in the sharing economy: an empirical investigation of Uber. Internet Research, 28(3), 829-850. https://doi.org/10.1108/IntR-01-2017-0037

Leisch, F. (2006). A toolbox for K-centroids cluster analysis. Computational Statistics \& Data Analysis, 51(2), 526-544. https://doi.org/https://doi.org/10.1016/j.csda.2005.10.006

Li, X., \& Yeh, a. G. O. (1998). Principal component analysis of stacked multi-temporal images for the monitoring of rapid urban expansion in the Pearl River Delta. International Journal of Remote Sensing, 19(8), 1501-1518. https://doi.org/10.1080/014311698215315

Liao, T. L., Huang, C. J., \& Wu, C. Y. (2012). Chapter 5 - Empirical Study: Do fund managers herd 
to counter investor sentiment? Principal Component Analysis - Multidisciplinary Applications, (2000). Retrieved from http://cdn.intechopen.com/pdfs/30006/InTechEmpirical_study_do_fund_managers_herd_to_counter_investor_sentiment_pdf Lindblom, A., Lindblom, T., \& Wechtler, H. (2018). Collaborative consumption as C2C trading: Analyzing the effects of materialism and price consciousness. Journal of Retailing and Consumer Services, 44(February), 244-252. https://doi.org/10.1016/j.jretconser.2018.07.016

Lindström, B., \& Eriksson, B. (1993). Quality of life among children in the Nordic countries. Quality of Life Research, 2(1), 23-32. https://doi.org/10.1007/BF00642886

Little, A. W., \& Green, A. (2009). Successful globalisation, education and sustainable development. International Journal of Educational Development, 29(2), 166-174. https://doi.org/https://doi.org/10.1016/j.ijedudev.2008.09.011

Liu, Y., \& Yang, Y. (2018). Empirical examination of users' adoption of the sharing economy in China using an expanded technology acceptance model. Sustainability (Switzerland), 10(4). https://doi.org/10.3390/su10041262

Luu, L., Chu, D.-H., Olickel, H., Saxena, P., \& Hobor, A. (2016). Making Smart Contracts Smarter. Proceedings of the 2016 ACM SIGSAC Conference on Computer and Communications Security - CCS'16, 254-269. https://doi.org/10.1145/2976749.2978309

Malone, D. (2014). Bitcoin Mining and its Energy Footprint. IET Conference Proceedings, 280285(5). Retrieved from http://digitallibrary.theiet.org/content/conferences/10.1049/cp.2014.0699

Mardani, A., Streimikiene, D., Zavadskas, E. K., Cavallaro, F., Nilashi, M., Jusoh, A., \& Zare, H. (2017). Application of Structural Equation Modeling (SEM) to solve environmental sustainability problems: A comprehensive review and meta-analysis. Sustainability (Switzerland), 9(10). https://doi.org/10.3390/su9101814

Maresova, P., \& Klimova, B. (2017). Selected Aspects in Searching for Health Information on the Internet Among Generation Y. In A. K. Ka, P. V. Ilavarasa, M. P. Gupta, Y. K. Dwivedi, M. Mäntymäki, M. Jansse, ... S. Al-Sharha (Eds.), 16th Conference on e-Business, e-Services and e-Society (I3E) (Vol. LNCS-10595, pp. 221-226). Delhi, India: Springer International 
Publishing. https://doi.org/10.1007/978-3-319-68557-1_20

Marsal-Llacuna, M. L., Colomer-Llinàs, J., \& Meléndez-Frigola, J. (2015). Lessons in urban monitoring taken from sustainable and livable cities to better address the Smart Cities initiative. Technological Forecasting and Social Change, 90(PB), 611-622. https://doi.org/10.1016/j.techfore.2014.01.012

Mayer, A. L. (2008). Strengths and weaknesses of common sustainability indices for multidimensional systems. Environment International, 34(2), 277-291. https://doi.org/https://doi.org/10.1016/j.envint.2007.09.004

Mazzella, F., Sundararajan, A., Butt d’Espous, V., \& Mohlmann, M. (2016). How Digital Trust Powers the Sharing Economy: The Digitization of Trust. IESE Insight, 30(3), 24-31. https://doi.org/10.15581/002.ART-2887

McDonnell, M. J., \& MacGregor-Fors, I. (2016). The ecological future of cities. Science, 352(6288), 936-938. https://doi.org/10.1126/science.aaf3630

McManus, P. (2012). Measuring Urban Sustainability: the potential and pitfalls of city rankings. Australian Geographer, 43(4), 411-424. https://doi.org/10.1080/00049182.2012.731301

Meijering, J. V., Kern, K., \& Tobi, H. (2014). Identifying the methodological characteristics of European green city rankings. Ecological Indicators, 43, 132-142. https://doi.org/10.1016/j.ecolind.2014.02.026

Melville, N. P. (2010). Information Systems Innovation for Environmental Sustainability. MIS Quarterly, 34(1), 1-21. Retrieved from http://www.jstor.org/stable/20721412

Mengelkamp, E., Gärttner, J., Rock, K., Kessler, S., Orsini, L., \& Weinhardt, C. (2018). Designing microgrid energy markets: A case study: The Brooklyn Microgrid. Applied Energy, 210, 870-880. https://doi.org/10.1016/j.apenergy.2017.06.054

Mercer. (2018). 2018 Quality of Living rankings.

Metsalu, T., \& Vilo, J. (2015). ClustVis: a web tool for visualizing clustering of multivariate data using Principal Component Analysis and heatmap. Nucleic Acids Research, 43(W1), W566W570. Retrieved from http://dx.doi.org/10.1093/nar/gkv468

Mihaylov, M., Jurado, S., Avellana, N., Moffaert, K. Van, Abril, I. M. de, \& Nowé, A. (2014). NRGcoin: Virtual currency for trading of renewable energy in smart grids. In 11th 
International Conference on the European Energy Market (EEM14) (pp. 1-6).

https://doi.org/10.1109/EEM.2014.6861213

Mikalef, P., Pappas, I. O., Krogstie, J., \& Giannakos, M. (2017). Big data analytics capabilities: a systematic literature review and research agenda. Information Systems and E-Business Management. https://doi.org/10.1007/s10257-017-0362-y

Mingay, S., \& Pamlin, D. (2008). Assessment of global low-carbon and environmental leadership in the ICT sector. Report G00161337. Retrieved from http://scholar.google.com/scholar?hl=en\&btnG=Search\&q=intitle:Assessment+of+Global+ Low-

+Carbon+and+Environmental+Leadership+in+the+ICT+Sector\#0\%5Cnhttp://scholar.google .com/scholar?hl=en\&btnG=Search\&q=intitle:Assessment+of+global+lowcarbon+and+environmen

Mittendorf, C. (2018). Collaborative consumption: the role of familiarity and trust among Millennials. Journal of Consumer Marketing, 35(4), 377-391. https://doi.org/10.1108/JCM12-2016-2040

Moher, D., Liberati, A., Tetzlaff, J., Altman, D., \& and the PRISMA Group. (2009). Preferred reporting items for systematic reviews and meta-analyses: The prisma statement. Annals of Internal Medicine, 151(4), 264-269. https://doi.org/10.7326/0003-4819-151-4200908180-00135

Mori, K., \& Christodoulou, A. (2012). Review of sustainability indices and indicators: Towards a new City Sustainability Index (CSI). Environmental Impact Assessment Review, 32(1), 94106. https://doi.org/https://doi.org/10.1016/j.eiar.2011.06.001

Mori Memorial Foundation. (2016). Global Power City Index 2016. Institute for Urban Strategies, 74(4), A28-A29. https://doi.org/10.1002/ana.24042

Morse, S., \& Fraser, E. D. G. (2005). Making 'dirty' nations look clean? The nation state and the problem of selecting and weighting indices as tools for measuring progress towards sustainability. Geoforum, 36(5), 625-640. https://doi.org/https://doi.org/10.1016/j.geoforum.2004.10.005

Munda, G. (2004). Social multi-criteria evaluation: Methodological foundations and operational 
consequences. European Journal of Operational Research, 158(3), 662-677. https://doi.org/https://doi.org/10.1016/S0377-2217(03)00369-2

Munda, G. (2006). Social multi-criteria evaluation for urban sustainability policies. Land Use Policy, 23(1), 86-94. https://doi.org/10.1016/j.landusepol.2004.08.012

Mungai, W. (2005). Using ICTs for Poverty Reduction and Environmental Protection in Kenya The "M-vironment" Approach U. International Institute for Sustaibable Development. Retrieved from http://www.ictregulationtoolkit.org/en/Document.2922.pdf

Mustafa, S. Z., \& Kar, A. K. (2017). Evaluating Multi-dimensional Risk for Digital Services in Smart Cities. In A. K. Kar, P. V. llavarasan, M. P. Gupta, Y. K. Dwivedi, M. Mäntymäki, M. Janssen, ... S. Al-Sharhan (Eds.), Digital Nations -- Smart Cities, Innovation, and Sustainability (pp. 23-32). Cham: Springer International Publishing.

Nam, T., \& Pardo, T. A. (2011). Conceptualizing Smart City with Dimensions of Technology, People, and Institutions. In Proceedings of the 12th Annual International Digital Government Research Conference: Digital Government Innovation in Challenging Times (pp. 282-291). New York, NY, USA: ACM. https://doi.org/10.1145/2037556.2037602

Naranjo-Zolotov, M., Oliveira, T., \& Casteleyn, S. (2019). Citizens' intention to use and recommend e-participation: Drawing upon UTAUT and citizen empowerment. Information Technology \& People, 32(2), 364-386. https://doi.org/10.1108/ITP-08-2017-0257

Naranjo Zolotov, M., Oliveira, T., \& Casteleyn, S. (2018). E-participation adoption models research in the last 17 years: A weight and meta-analytical review. Computers in Human Behavior, 81, 350-365. https://doi.org/10.1016/j.chb.2017.12.031

Nasrawi, S. A. Al, Adams, C., \& El-Zaart, A. (2016). A Conceptual Multidimensional Model for Assessing Smart Sustainable Cities. Journal of Information Systems and Technology Management, 12(3), 541-558. https://doi.org/10.4301/S1807-17752015000300003

Neves, L., Krajewski, J., Jung, P., \& Bockemuehl, M. (2012). SMARTer 2020: The role of ICT in driving a sustainable future. Technical report, A Report by The Climate Group on Behalf of the Global e-Sustainability Initiative. Global ESustainability Initiative (GeSI), 1-243. https://doi.org/10.1111/j.2006.0906-7590.04873.x

Numbeo. (2016). Europe: Quality of Life Index 2015. Retrieved July 28, 2018, from 
https://www.numbeo.com/quality-of-life/region_rankings.jsp?title=2015\&region=150 OECD. (2005). OECD Guide to Measuring the Information Society 2011. Society. https://doi.org/10.1787/9789264113541-en

OECD. (2008). Handbook on Constructing Composite Indicators: Methodology and User Guide (Eds). Paris: European Commission Joint Research Center. https://doi.org/10.1787/9789264043466-en

OECD. (2009). Measuring the Relationship between ICT and the Environment. Geneva. https://doi.org/10.1787/221687775423

Oliveira, A., Cabral, A. J. R., Fraga O. Martins, M., Cabral, P., Mendes, J. M., \& Carreira, M. (2017). Poor housing and stroke mortality in population over 64 years old at the parish level, in mainland Portugal. GeoJournal, 82(4), 665-682. https://doi.org/10.1007/s10708016-9712-4

Oliveira, T., Faria, M., Thomas, M. A., \& Popovič, A. (2014). Extending the understanding of mobile banking adoption: When UTAUT meets TTF and ITM. International Journal of Information Management, 34(5), 689-703.

https://doi.org/https://doi.org/10.1016/j.ijinfomgt.2014.06.004

Omucheni, D. L., Kaduki, K. A., Bulimo, W. D., \& Angeyo, H. K. (2014). Application of principal component analysis to multispectral-multimodal optical image analysis for malaria diagnostics. Malaria Journal, 13(485), 1-11. https://doi.org/10.1186/1475-2875-13-485

Oni, O., \& Papazafeiropoulou, A. (2014). Diverse views on IT innovation diffusion among SMEs: Influencing factors of broadband adoption. Information Systems Frontiers, 16(4), 729-747. https://doi.org/10.1007/s10796-012-9384-7

Ono, H., \& Zavodny, M. (2007). Digital inequality: A five country comparison using microdata. Social Science Research, 36(3), 1135-1155. https://doi.org/https://doi.org/10.1016/j.ssresearch.2006.09.001

Organisation for Economic Co-Operation and Development, \& China Development Research Foundation. (2010). Trends in Urbanisation and Urban Policies in OECD Countries : What Lessons for China ?, 219. https://doi.org/10.1787/9789264092259-en

Osbaldiston, R., \& Schott, J. P. (2012). Environmental Sustainability and Behavioral Science: 
Meta-Analysis of Proenvironmental Behavior Experiments. Environment and Behavior, 44(2), 257-299. https://doi.org/10.1177/0013916511402673

Ospina, A. V., \& Heeks, R. (2010). Unveiling the Links between ICTs \& Climate Change in Developing Countries : A Scoping Study. Canada Internation Development Research Center. Manchester. Retrieved from http://www.niccd.org/ScopingStudy.pdf

Owusu, P. A., \& Asumadu-Sarkodie, S. (2016). A review of renewable energy sources, sustainability issues and climate change mitigation. Cogent Engineering, 3(1). https://doi.org/10.1080/23311916.2016.1167990

Oyedele, A., \& Simpson, P. (2018). Emerging adulthood, sharing utilities and intention to use sharing services. Journal of Services Marketing, 32(2), 161-174. https://doi.org/10.1108/JSM-09-2016-0344

Pappas, I., Mikalef, P., Giannakos, M., \& Krogstie, J. (2018). Big Data and Business Analytics Ecosystems : Paving the way towards digital transformation and sustainable societies. Information Systems and E-Business Management, (August), 14. https://doi.org/10.1007/s10257-018-0377-z

Phillis, Y. A., Kouikoglou, V. S., \& Verdugo, C. (2017a). Urban sustainability assessment and ranking of cities. Computers, Environment and Urban Systems, 64, 254-265. https://doi.org/10.1016/j.compenvurbsys.2017.03.002

Phillis, Y. A., Kouikoglou, V. S., \& Verdugo, C. (2017b). Urban sustainability assessment and ranking of cities. Computers, Environment and Urban Systems, 64, 254-265. https://doi.org/10.1016/j.compenvurbsys.2017.03.002

Pinto, J. T. M., Morales, M. E., Fedoruk, M., Kovaleva, M., \& Diemer, A. (2019). Servitization in support of sustainable cities: What are steel's contributions and challenges? Sustainability (Switzerland), 11(3). https://doi.org/10.3390/su11030855

Policy, S. for E. (2018). Indicators for sustainable cities. In-depth Report 12, 2015(12), 24. https://doi.org/10.2779/121865

Poortinga, W., Steg, L., \& Vlek, C. (2004). Values, Environmental Concern, and Environmental Behavior: A Study into Household Energy Use. Environment and Behavior, 36(1), 70-93. https://doi.org/10.1177/0013916503251466 
Prieger, J. E. (2003). The Supply Side of the Digital Divide: Is There Equal Availability in the Broadband Internet Access Market? Economic Inquiry, 41(2), 346-363. https://doi.org/10.1093/ei/cbg013

Privitera, R., Palermo, V., Martinico, F., Fichera, A., \& Rosa, D. La. (2018). Towards lower carbon cities: urban morphology contribution in climate change adaptation strategies. European Planning Studies, 26(4), 812-837. https://doi.org/10.1080/09654313.2018.1426735

PwC. (2016). Cities of Opportunity. Retrieved from http://cpi.unhabitat.org/publications Rana, N. P., Luthra, S., Mangla, S. K., Islam, R., Roderick, S., \& Dwivedi, Y. K. (2018). Barriers to the Development of Smart Cities in Indian Context. Information Systems Frontiers. https://doi.org/10.1007/s10796-018-9873-4

Reh, W., Fellermann, A., \& Duprez, L. (2013). Soot-free Cities: A European City Ranking. Brussels. Retrieved from http://www.sootfreecities.eu/sootfreecities.eu/public/download/cityranking-background.pdf

Riffat, S., Powell, R., \& Aydin, D. (2016). Future cities and environmental sustainability. Future Cities and Environment, 2(1), 1. https://doi.org/10.1186/s40984-016-0014-2

Rivera, M B, Eriksson, E., \& Wangel, J. (2015). ICT practices in smart sustainable cities-in the intersection of technological solutions and practices of everyday life. 29th International Conference on Informatics for Environmental Protection (Envirolnfo 2015), Third International Conference on ICT for Sustainability (ICT4S 2015), Atlantis Press, 317-324.

Rivera, M Börjesson, Eriksson, E., \& Wangel, J. (2015). ICT practices in smart sustainable cities: In the intersection of technological solutions and practices of everyday life. ACSR: Advances in Computer Science Research, (January), 317-324. https://doi.org/10.1111/j.1472-4642.2008.00521.x

Roaf, J., Atoyan, R., Joshi, B., \& Krogulski, K. (2014). 25 Years of Transition: post-communist Europe and the IMF. Retrieved from https://www.imf.org/external/pubs/ft/reo/2014/eur/eng/pdf/erei_sr_102414.pdf

Roos, D., \& Hahn, R. (2017a). Does shared consumption affect consumers' values, attitudes, and norms? A panel study. Journal of Business Research, 77(April), 113-123.

https://doi.org/10.1016/j.jbusres.2017.04.011 
Roos, D., \& Hahn, R. (2017b). Does shared consumption affect consumers' values, attitudes, and norms? A panel study. Journal of Business Research, 77(November 2016), 113-123. https://doi.org/10.1016/j.jbusres.2017.04.011

Rossy de Brito, S., Socorro da Silva, A., Carvalho da Mata, E., Vijaykumar, N. L., Alex Jorge da Rocha, C., Abreu Monteiro, M., ... Francês, C. R. L. (2018). An approach to evaluate largescale ICT training interventions. Information Systems Frontiers, 20(4), 883-899. https://doi.org/10.1007/s10796-016-9705-3

Royo, S., \& Yetano, A. (2015). “Crowdsourcing” as a tool for e-participation: two experiences regarding CO2 emissions at municipal level. Electronic Commerce Research, 15(3), 323348. https://doi.org/10.1007/s10660-015-9183-6

Saisana, M., \& Saltelli, A. (2011). Rankings and ratings: Instructions for use. Hague Journal on the Rule of Law, 3(2), 247-268. https://doi.org/10.1017/S1876404511200058

Salah, E. A. M., Turki, A. M., \& Al-Othman, E. M. (2012). Assessment of Water Quality of Euphrates River Using Cluster Analysis. Journal of Environmental Protection, 3(December), 1629-1633. https://doi.org/10.4236/jep.2012.312180

Scariano, S. M. (2013). An Introductory Application of Principal Components to Cricket Data, 21(3), 83-103.

Serbanica, C., \& Constantin, D. L. (2017). Sustainable cities in central and eastern European countries. Moving towards smart specialization. Habitat International, 68, 55-63. https://doi.org/10.1016/j.habitatint.2017.03.005

Serrano, A., Garcia-Guzman, J., Xydopoulos, G., \& Tarhini, A. (2018). Analysis of Barriers to the Deployment of Health Information Systems: a Stakeholder Perspective. Information Systems Frontiers, 1-20. https://doi.org/10.1007/s10796-018-9869-0

Shareef, M. A., Kumar, V., Kumar, U., \& Dwivedi, Y. K. (2011). E-Government Adoption Model (GAM): Differing service maturity levels. Government Information Quarterly, 28(1), 17-35. https://doi.org/10.1016/j.giq.2010.05.006

Sharholy, M., Ahmad, K., Mahmood, G., \& Trivedi, R. C. (2008). Municipal solid waste management in Indian cities - A review. Waste Management, 28(2), 459-467. https://doi.org/https://doi.org/10.1016/j.wasman.2007.02.008 
Sharma, S. (1996). Applied Multivariate Techniques. New York, NY, USA: John Wiley \& Sons, Inc.

Sheng, N., \& Tang, U. W. (2016). The first official city ranking by air quality in China - A review and analysis. Cities, 51, 139-149. https://doi.org/10.1016/j.cities.2015.08.012

Siemens. (2009). European Green City Index: Assessing the environmental impact of Europe's major cities. Munich: Siemens AG. Retrieved from http://scholar.google.com/scholar?hl=en\&btnG=Search\&q=intitle:European+Green+City+l ndex\#0

Skjelvik, J. M., Erlandsen, A. M., \& Haavardsholm, O. (2017). Environmental impacts and potential of the sharing economy. Rosendahls. https://doi.org/http://dx.doi.org/10.6027/TN2017-554

Slob, A., \& van Lieshout, M. (2002). The contribution of Information and Communication Technoliges to the transition towards a climate- neutral society. In M. T. J. Kok, W. J. V. Vermeulen, A. P. C. Faaij, \& D. de Jager (Eds.), Global Warming and Social Innovation: the challenge of a Climate Neutral Society (pp. 143-159). London: Earthscan Publications Ltd. https://doi.org/10.4324/9781849771450

Spicer, J. (2005). Making Sense of Multivariate Data Analysis: An Intuitive Approach (6th Editio). California: SAGE Publications Inc. Retrieved from http://site.ebrary.com/id/10387851

Sung, E., Kim, H., \& Lee, D. (2018). Why do people consume and provide sharing economy accommodation?-A sustainability perspective. Sustainability (Switzerland), 10(6). https://doi.org/10.3390/su10062072

Sustainable Development Commission. (2010). Smarter Moves. How information communications technology can promote sustainable mobility. Challenges. Geneva. Retrieved from https://research-repository.standrews.ac.uk/bitstream/handle/10023/2223/sdc-2009-smartermoves.pdf?sequence=1\&isAllowed=y

Sutherland, W., \& Jarrahi, M. H. (2018). The sharing economy and digital platforms: A review and research agenda. International Journal of Information Management, 43(February), 328-341. https://doi.org/10.1016/j.ijinfomgt.2018.07.004

Suurmond, R., van Rhee, H., \& Hak, T. (2017). Introduction, comparison, and validation of Meta- 
Essentials: A free and simple tool for meta-analysis. Research Synthesis Methods, 8(4), 537-553. https://doi.org/10.1002/jrsm.1260

Szopik-Depczyńska, K., Cheba, K., Bąk, I., Stajniak, M., Simboli, A., \& Ioppolo, G. (2018). The study of relationship in a hierarchical structure of EU sustainable development indicators. Ecological Indicators, 90(December 2017), 120-131. https://doi.org/10.1016/j.ecolind.2018.03.002

Takano, T., Nakamura, K., \& Watanabe, M. (2002). Urban residential environments and senior citizens' longevity in megacity areas: the importance of walkable green spaces. Journal of Epidemiology and Community Health, 56(12), 913 LP - 918. Retrieved from http://jech.bmj.com/content/56/12/913.abstract

Talò, C., Mannarini, T., \& Rochira, A. (2014). Sense of Community and Community Participation: A Meta-Analytic Review. Social Indicators Research, 117(1), 1-28. https://doi.org/10.1007/s11205-013-0347-2

Taylor, Z. (2016). "Lies, Damned Lies and Statistics" A Crititcal Examination of City Ranking Studies. Toronto. Retrieved from https://www.google.com/url?sa=t\&rct=j\&q=\&esrc=s\&source=web\&cd=1\&cad=rja\&uact=8 \&ved=2ahUKEwiqsebB0_7dAhVILBoKHVBeDbgQFjAAegQIBBAB\&url=https\%3A\%2F\%2Fww w.researchgate.net\%2Fpublication\%2F303444233_\%27Lies_Damned_Lies_and_Statistics\% 27_A_Critical_Examination_

Teo, T. S. H., Kim, S. L., \& Jiang, L. (2018). E-Learning Implementation in South Korea: Integrating Effectiveness and Legitimacy Perspectives. Information Systems Frontiers. https://doi.org/10.1007/s10796-018-9874-3

The Economist Intelligence Unit. (2016). Best cities ranking and report A special report from the Economist Intelligence Unit. The Economist. Retrieved from http://pages.eiu.com/rs/eiu2/images/EIU_BestCities.pdf

Tilbury, D. (1995). Environmental Education for Sustainability: defining the new focus of environmental education in the 1990s. Environmental Education Research, 1(2), 195-212. https://doi.org/10.1080/1350462950010206

Toni, M., Renzi, M. F., \& Mattia, G. (2016). Understanding the link between collaborative 
economy and sustainable behaviour: An empirical investigation. Journal of Cleaner Production, 172, 4467-4477. https://doi.org/10.1016/j.jclepro.2017.11.110

Trenz, M., Frey, A., \& Veit, D. (2018). Disentangling the facets of sharing: A categorization of what we know and don't know about the Sharing Economy. Internet Research, 28(4), 888925. https://doi.org/10.1108/IntR-11-2017-0441

Tu, K.-J., \& Lin, L.-T. (2008). Evaluative structure of perceived residential environment quality in high-density and mixed-use urban settings: An exploratory study on Taipei City. Landscape and Urban Planning, 87(3), 157-171. https://doi.org/http://dx.doi.org/10.1016/j.landurbplan.2008.05.009

UN-HABITAT. (2011). Global Report on Human Settlements 2011. Cities and Climate Change. https://doi.org/10.1787/9789264091375-en

UN-HABITAT. (2015). The city prosperity initiative: 2015 global city report. Nairobi. Retrieved from http://unhabitat.org/wp-content/uploads/2016/02-old/CPI_2015 Global City Report.compressed.pdf

UNECE. (2015a). Key performance indicators for smart sustainable cities to assess the achievement of sustainable development goals (Vol. 1603). https://doi.org/ITU-T L.1603 UNECE. (2015b). The UNECE-ITU Smart Sustainable Cities Indicators. Geneva. Retrieved from http://www.unece.org/fileadmin/DAM/hlm/projects/SMART_CITIES/ECE_HBP_2015_4.pdf UNESCO. (2018). Handbook on Measuring Equity in Education. https://doi.org/10.1016/S07338619(03)00096-3

United Nations. (2014). World Urbanization Prospects: The 2014 Revision, Highlights (ST/ESA/SER.A/352). New York, United States of America. https://doi.org/10.4054/DemRes.2005.12.9

Van Dijk, J. A. G. M. (2009). The Digital Divide in Europe. The Routledge Handbook of Internet Politics.

van Leeuwen, C. J., Frijns, J., van Wezel, A., \& van de Ven, F. H. M. (2012). City Blueprints: 24 Indicators to Assess the Sustainability of the Urban Water Cycle. Water Resources Management, 26(8), 2177-2197. https://doi.org/10.1007/s11269-012-0009-1

Venkatesh, A. (2008). Digital home technologies and transformation of households. Information 
Systems Frontiers, 10(4), 391-395. https://doi.org/10.1007/s10796-008-9097-0

Venkatesh, V., Thong, J., \& Xu, X. (2012). Consumer acceptance and use of information technology: Extending the unified theory of acceptance and use of technology. MIS Quarterly, 36(1), 157-178.

Vicente, M. R., \& López, A. J. (2011). Assessing the regional digital divide across the European Union-27. Telecommunications Policy, 35(3), 220-237. https://doi.org/https://doi.org/10.1016/j.telpol.2010.12.013

Vidal, R., Ma, Y., \& Sastry, S. S. (2016). Principal Component Analysis. In Generalized Principal Component Analysis (pp. 25-62). New York, NY: Springer New York. https://doi.org/10.1007/978-0-387-87811-9_2

Vinod Kumar, T. M., \& Dahiya, B. (2017). Smart Economy in Smart Cities. In T. M. Vinod Kumar (Ed.), Smart Economy in Smart Cities: International Collaborative Research: Ottawa, St.Louis, Stuttgart, Bologna, Cape Town, Nairobi, Dakar, Lagos, New Delhi, Varanasi, Vijayawada, Kozhikode, Hong Kong (pp. 3-76). Singapore: Springer Singapore. https://doi.org/10.1007/978-981-10-1610-3_1

von Clausewitz, C. (2009). The Science of Behavior and the Image of Man. New York, NY, USA: Routledge.

Wang, C. (Renee), \& Jeong, M. (2018). What makes you choose Airbnb again? An examination of users' perceptions toward the website and their stay. International Journal of Hospitality Management, 74(September 2017), 162-170. https://doi.org/10.1016/j.ijhm.2018.04.006

Watson, R. T., Boudreau, M.-C., \& Chen, A. J. (2010). Information Systems and Environmentally Sustainable Development: Energy Informatics and New Directions for the IS Community. MIS Quarterly, 34(1), 23-38. Retrieved from http://www.jstor.org/stable/20721413

Webb, J., Hawkey, D., \& Tingey, M. (2016). Governing cities for sustainable energy: The UK case. Cities, 54, 28-35. https://doi.org/10.1016/j.cities.2015.10.014

Wei, Y., Huang, C., Li, J., \& Xie, L. (2016). An evaluation model for urban carrying capacity: A case study of China's mega-cities. Habitat International, 53, 87-96. https://doi.org/10.1016/j.habitatint.2015.10.025 
Weng, Q., Liu, H., Liang, B., \& Lu, D. (2008). The spatial variations of urban land surface temperatures: Pertinent factors, zoning effect, and seasonal variability. IEEE Journal of Selected Topics in Applied Earth Observations and Remote Sensing, 1(2). https://doi.org/10.1109/JSTARS.2008.917869

Wheeler, S. M., \& Timothy, B. (2014). The sustainable urban development reader (Third Edit). London, New York: Routledge.

Willard, T., \& Halder, M. (2003). The information society and sustainable development: exploring the linkages. Sustainable Development. Retrieved from http://scholar.google.com/scholar?hl=en\&btnG=Search\&q=intitle:The+Information+Societ $\mathrm{y}+$ and+Sustainable+Development+Exploring+the+Linkages\#0

Witten, I. H., Frank, E., Hall, M. A., \& Pal, C. J. (2016). Data Mining: Practical Machine Learning Tools and Techniques. Elsevier Science. Retrieved from https://books.google.pt/books?id=1SylCgAAQBAJ

Wold, S., Esbensen, K., \& Geladi, P. (1987). Principal component analysis. Chemometrics and Intelligent Laboratory Systems, 2(1-3), 37-52. https://doi.org/10.1016/01697439(87)80084-9

Wolfe, D., \& Bramwell, A. (2016). Innovation, creativity and governance: Social dynamics of economic performance in city-regions. Innovation, 18(4), 449-461. https://doi.org/10.1080/14479338.2016.1265054

Wong, C. (2002). Developing Indicators to Inform Local Economic Development in England. Urban Studies, 39(10), 1833-1863. https://doi.org/10.1080/0042098022000002984

Wood, J. “Andy." (2008). Methodology for Dealing With Duplicate Study Effects in a MetaAnalysis. Organizational Research Methods, 11(1), 79-95. https://doi.org/10.1177/1094428106296638

World Bank. (2007). Growth and CO2 Emissions How Do Different Countries Fare? World Bank, (October), 1-50. Retrieved from http://siteresources.worldbank.org/INTCC/2145741192124923600/21511758/CO2DecompositionfinalOct2007.pdf

World Bank Group. (2016). Digital Adoption Index (DAI): Measuring the Global Spread of Digital Technologies. Retrieved from 
http://pubdocs.worldbank.org/en/587221475074960682/WDR16-BP-DAI-

methodology.pdf

Wu, J., Zeng, M., \& Xie, K. L. (2017). Chinese travelers' behavioral intentions toward roomsharing platforms: The influence of motivations, perceived trust, and past experience. International Journal of Contemporary Hospitality Management, 29(10), 2688-2707. https://doi.org/10.1108/IJCHM-08-2016-0481

Wu, S. J., \& Raghupathi, W. (2018). The Strategic Association Between Information and Communication Technologies and Sustainability: A Country-Level Study. In I. R. M. Association (Ed.), Sustainable Development: Concepts, Methodologies, Tools, and Applications (pp. 694-719). Hershey, PA, USA: IGI Global. https://doi.org/10.4018/978-15225-3817-2.ch032

Wu, X., \& Zhi, Q. (2016). Impact of Shared Economy on Urban Sustainability: From the Perspective of Social, Economic, and Environmental Sustainability. Energy Procedia, 104, 191-196. https://doi.org/https://doi.org/10.1016/j.egypro.2016.12.033

Xiao, S., Lu, Z., \& Xu, L. (2017). Multivariate sensitivity analysis based on the direction of eigen space through principal component analysis. Reliability Engineering and System Safety, 165(March), 1-10. https://doi.org/10.1016/j.ress.2017.03.011

Yang, S., Song, Y., Chen, S., \& Xia, X. (2017). Why are customers loyal in sharing-economy services? A relational benefits perspective. Journal of Services Marketing, 31(1), 48-62. https://doi.org/10.1108/JSM-01-2016-0042

Yi, L., \& Thomas, H. R. (2007). A review of research on the environmental impact of e-business and ICT. Environment International, 33(6), 841-849. https://doi.org/https://doi.org/10.1016/j.envint.2007.03.015

Zare, M., Pahl, C., Rahnama, H., Nilashi, M., Mardani, A., Ibrahim, O., \& Ahmadi, H. (2016). Multi-criteria decision making approach in E-learning: A systematic review and classification. Applied Soft Computing, 45, 108-128. https://doi.org/https://doi.org/10.1016/j.asoc.2016.04.020

Zhang, X., \& Venkatesh, V. (2017). A nomological network of knowledge management system use: Antecedents and consequences. MIS Quarterly, 41(4), 1275-1306. 
Zhou, Z., Zhang, S., Wang, C., Zuo, J., He, Q., \& Rameezdeen, R. (2016). Achieving energy efficient buildings via retrofitting of existing buildings: a case study. Journal of Cleaner Production, 112(Part 5), 3605-3615.

https://doi.org/https://doi.org/10.1016/j.jclepro.2015.09.046 


\section{Appendix}

\subsection{Appendix A}

$\mathrm{R}^{2}$ is a measure of the similarity (or dissimilarity) of groups in a cluster. It is given by the formula below:

$$
R^{2}=1-\frac{\sum_{g=1}^{G} \sum_{i c g} \sum_{k=1}^{P}\left(x_{i k}-\bar{x}_{g k}\right)^{2}}{\sum_{g=1}^{G} \sum_{i c g} \sum_{k=1}^{P}\left(x_{i k}-\bar{x}_{k}\right)^{2}}
$$

\subsection{Appendix B}

Procedure to obtain the score of each city from a PCA with 6 selected variables

Let $\mathrm{Si}$ be the final score attributed to each city i $(\mathrm{I}=1,2,3, \ldots \ldots ., 129)$

$$
S_{i}=\sum_{k=1}^{2} \alpha_{k} \gamma_{i}^{k}
$$

Eq. (B.1)

with

$$
\alpha_{k}=\frac{\lambda_{k}}{\sum_{k=1}^{2} \lambda_{k}}
$$

Eq. (B.2)

where $\lambda \mathrm{k}$ is the k-eigenvalue of the variance and covariance matrix $V=\frac{1}{129} \sum_{i=1}^{129} \underline{x}_{i}{ }^{t} \underline{x}_{i}$ with xi being the 6dimensional vector describing city i after data normalization. So, $\sum_{k=1}^{2} \lambda_{k}$ is the total inertia explained by the first two axes.

Also, $\gamma_{i}^{k}$ is the coordinate of city i on axis $\mathrm{k}$ generated by the unit eigenvector $\mu \mathrm{k}$ given by: 


$$
\gamma_{i}^{k}=<\underline{x}_{i}, \underline{\mu}_{k}>={ }^{t} \underline{x}_{i} \underline{\mu}_{k}
$$

Eq. (B.3)

So,

$$
\gamma_{i}^{k}=\sum_{j=1}^{6} x_{i}^{j} \mu_{k}^{j}
$$

Eq. (B.4)

and

$$
S_{i}=\sum_{k=1}^{2} \alpha_{k}\left(\sum_{j=1}^{6} x_{i}^{j} \mu_{k}^{j}\right)
$$

Eq. (B.5)

$$
S_{i}=\sum_{j=1}^{6} x_{i}^{j}\left(\sum_{k=1}^{2} \alpha_{k} \mu_{k}^{j}\right)
$$

Eq. (B.6)

where $\sum_{k=1}^{2} \alpha_{k} \mu_{k}^{j}$ is the factor score associated with variable $\mathrm{j}$. 


\subsection{APPENDIX C}

\begin{tabular}{|c|c|c|c|c|c|c|c|c|c|c|c|}
\hline$\#$ & City & Country & Code & ICT Index & Cluster & $\#$ & City & Country & Code & ICT Index & Cluster \\
\hline 1 & Salzburg & Austria & $\mathrm{SZG}$ & 1.857 & 1 & 35 & Marseille & France & MRS & 1.604 & 1 \\
\hline 2 & Graz & Austria & GRA & 1.793 & 1 & 36 & Nice & France & $\mathrm{NCE}$ & 1.777 & 1 \\
\hline 3 & Linz & Austria & LNZ & 1.756 & 1 & 37 & Grenoble & France & GNB & 1.885 & 1 \\
\hline 4 & Vienna & Austria & VIE & 1.767 & 1 & 38 & Lyon & France & LYS & 1.807 & 1 \\
\hline 5 & Brussels & Belgium & BRU & 2.345 & 3 & 39 & Saint-Étienne & France & SXE & 1.650 & 1 \\
\hline 6 & Gent & Belgium & GNT & 2.213 & 3 & 40 & Berlin & Germany & BER & 1.939 & 4 \\
\hline 7 & Antwerp & Belgium & ANR & 2.223 & 3 & 41 & Bochum & Germany & $\mathrm{BOC}$ & 2.080 & 1 \\
\hline 8 & Leuven & Belgium & LVN & 2.458 & 3 & 42 & Bonn & Germany & $\mathrm{BNN}$ & 1.931 & 1 \\
\hline 9 & Liège & Belgium & LGG & 2.227 & 3 & 43 & Bremen & Germany & BRE & 2.019 & 4 \\
\hline 10 & Sofia & Bulgaria & SOF & 0.499 & 2 & 44 & Cologne & Germany & CGN & 2.058 & 4 \\
\hline 11 & Dubrovnik & Croatia & DUK & 0.731 & 2 & 45 & Dortmund & Germany & DTM & 2.119 & 1 \\
\hline 12 & Zagreb & Croatia & ZAG & 1.043 & 2 & 46 & Dresden & Germany & DRS & 1.768 & 1 \\
\hline 13 & Nicosia & Cyprus & NIC & 1.333 & 2 & 47 & Duisburg & Germany & DSG & 2.057 & 1 \\
\hline 14 & Prague & Czech Republic & PRG & 1.774 & 4 & 48 & Düsseldorf & Germany & DUS & 2.087 & 1 \\
\hline 15 & Brno & Czech Republic & BRQ & 1.764 & 1 & 49 & Essen & Germany & ESS & 2.129 & 1 \\
\hline 16 & Copenhagen & Denmark & $\mathrm{CPH}$ & 2.963 & 3 & 50 & Frankfurt & Germany & FRA & 2.077 & 1 \\
\hline 17 & Odense & Denmark & ODE & 3.203 & 3 & 51 & Hamburg & Germany & HAM & 2.050 & 4 \\
\hline 18 & Tallinn & Estonia & TLL & 2.138 & 1 & 52 & Hannover & Germany & HAJ & 2.052 & 1 \\
\hline
\end{tabular}




\begin{tabular}{|c|c|c|c|c|c|c|c|c|c|c|c|}
\hline 19 & Helsinki & Finland & HEL & 2.623 & 3 & 53 & Karlsruhe & Germany & KAR & 2.053 & 1 \\
\hline 20 & Strasbourg & France & SXB & 1.820 & 1 & 54 & Kiel & Germany & KEL & 2.047 & 1 \\
\hline 21 & Bordeaux & France & BOD & 1.978 & 1 & 55 & Leipzig & Germany & LEJ & 2.095 & 1 \\
\hline 22 & Dijon & France & DIJ & 2.089 & 1 & 56 & Heidelberg & Germany & HDB & 1.823 & 1 \\
\hline 23 & Rennes & France & RNS & 1.691 & 1 & 57 & Munich & Germany & MUC & 2.054 & 4 \\
\hline 24 & Reims & France & RHE & 1.832 & 1 & 58 & Nuremberg & Germany & NUE & 1.974 & 1 \\
\hline 25 & Le Havre & France & LEH & 1.869 & 1 & 59 & Stuttgart & Germany & STR & 2.112 & 4 \\
\hline 26 & Rouen & France & RNE & 1.613 & 1 & 60 & Wuppertal & Germany & WUP & 2.120 & 1 \\
\hline 27 & Paris & France & PAR & 1.825 & 4 & 61 & Aachen & Germany & AAH & 2.131 & 1 \\
\hline 28 & Montpellier & France & MPL & 1.319 & 2 & 62 & Athens & Greece & $\overline{\text { ATH }}$ & 1.051 & 4 \\
\hline 29 & Limoges & France & LIG & 1.887 & 1 & 63 & Thessaloniki & Greece & SKG & 0.979 & 2 \\
\hline 30 & Metz & France & MZM & 1.837 & 1 & 64 & Budapest & Hungary & BUD & 1.377 & 2 \\
\hline 31 & Toulouse & France & TLS & 1.907 & 1 & 65 & Dublin & Ireland & DUB & 1.844 & 1 \\
\hline 32 & Lille & France & LIL & 1.385 & 2 & 66 & Bologna & Italy & BLQ & 0.928 & 2 \\
\hline 33 & Nantes & France & NTE & 1.645 & 1 & 67 & Florence & Italy & FLR & 0.873 & 2 \\
\hline 34 & Cannes & France & CEQ & 1.744 & 1 & 68 & Milan & Italy & MIL & 0.907 & 2 \\
\hline \# & City & Country & Code & ICT Index & Cluster & \# & City & Country & Code & ICT Index & Cluster \\
\hline 69 & Modena & Italy & MOD & 0.972 & 2 & 104 & Granada & Spain & GRX & 1.945 & 1 \\
\hline 70 & Napoli & Italy & NAP & 0.747 & 2 & 105 & Madrid & Spain & MAD & 1.914 & 4 \\
\hline 71 & Padova & Italy & PAD & 0.937 & 2 & 106 & Málaga & Spain & MAL & 1.807 & 1 \\
\hline 72 & Parma & Italy & PMF & 0.921 & 2 & 107 & Pamplona & Spain & PNA & 2.018 & 1 \\
\hline 73 & Rome & Italy & ROM & 0.820 & 2 & 108 & Seville & Spain & $\begin{array}{l}\text { SVQ } \\
\end{array}$ & 1.841 & 1 \\
\hline
\end{tabular}




\begin{tabular}{|c|c|c|c|c|c|c|c|c|c|c|c|}
\hline 74 & Torino & Italy & TRN & 0.900 & 2 & 109 & Valencia & Spain & VLC & 1.985 & 1 \\
\hline 75 & Trieste & Italy & TRS & 1.028 & 2 & 110 & Gothenburg & Sweden & GOT & 2.583 & 3 \\
\hline 76 & Venice & Italy & VCE & 0.746 & 2 & 111 & Malmö & Sweden & MMA & 2.577 & 3 \\
\hline 77 & Verona & Italy & VBS & 0.944 & 2 & 112 & Stockholm & Sweden & STO & 3.065 & 3 \\
\hline 78 & Riga & Latvia & RIX & 1.525 & 1 & 113 & Bath \& NE Somerset & United Kingdom & BES & 2.552 & 3 \\
\hline 79 & Vilnius & Lithuania & VNO & 1.682 & 1 & 114 & Belfast & United Kingdom & BFS & 2.583 & 3 \\
\hline 80 & Luxembourg & Luxembourg & LUX & 2.280 & 3 & 115 & Bristol & United Kingdom & BRS & 2.522 & 3 \\
\hline 81 & Valletta & Malta & MLA & 1.019 & 2 & 116 & Cardiff & United Kingdom & CWL & 1.980 & 1 \\
\hline 82 & Amsterdam & Netherlands & AMS & 2.582 & 3 & 117 & Coventry & United Kingdom & CVT & 1.980 & 3 \\
\hline 83 & Eindhoven & Netherlands & EIN & 2.645 & 3 & 118 & Edinburgh & United Kingdom & EDI & 2.529 & 3 \\
\hline 84 & Rotterdam & Netherlands & RTM & 2.679 & 3 & 119 & Glasgow & United Kingdom & GLA & 2.429 & 3 \\
\hline 85 & The Hague & Netherlands & HAG & 2.688 & 3 & 120 & Kingston-upon-Hull & United Kingdom & KIN & 2.503 & 3 \\
\hline 86 & Utrecht & Netherlands & UTC & 2.313 & 3 & 121 & Leeds & United Kingdom & LBA & 2.270 & 3 \\
\hline 87 & Gdansk & Poland & GDN & 1.059 & 2 & 122 & Liverpool & United Kingdom & LPL & 2.012 & 1 \\
\hline 88 & Katowice & Poland & KTW & 1.037 & 2 & 123 & London & United Kingdom & LON & 2.970 & 4 \\
\hline 89 & Kraków & Poland & KRK & 1.179 & 2 & 124 & Manchester & United Kingdom & MAN & 2.047 & 1 \\
\hline 90 & Warsaw & Poland & WAW & 0.966 & 2 & 125 & $\begin{array}{l}\text { Newcastle-upon- } \\
\text { Tyne }\end{array}$ & United Kingdom & NCL & 2.477 & 3 \\
\hline 91 & Wroclaw & Poland & WRO & 1.416 & 2 & 126 & Nottingham & United Kingdom & NQT & 2.438 & 3 \\
\hline 92 & Lisbon & Portugal & LIS & 1.308 & 2 & 127 & Sheffield & United Kingdom & SZD & 2.132 & 1 \\
\hline 93 & Oporto & Portugal & OPO & 1.087 & 2 & 128 & Southampton & United Kingdom & SOU & 2.437 & 3 \\
\hline 94 & Guimaraes & Portugal & GMS & 1.391 & 2 & 129 & Birmingham & United Kingdom & BHX & 2.377 & 3 \\
\hline 95 & Bucharest & Romania & BUH & 0.407 & 2 & & & & & & \\
\hline
\end{tabular}




\begin{tabular}{|l|l|l|l|l|l|l|l|l|l|l|}
\hline 96 & Timisoara & Romania & TSR & 0.230 & 2 & & & & & \\
\hline 97 & Bratislava & Slovakia & BTS & 1.393 & 2 & & & & & \\
\hline 98 & Kosice & Slovakia & KSC & 1.048 & 2 & & & & & \\
\hline 99 & Ljubljana & Slovenia & LJU & 1.551 & 1 & & & & & \\
\hline 100 & $\begin{array}{l}\text { Santa Cruz } \\
\text { de Tenerife }\end{array}$ & Spain & TCI & 2.114 & 1 & & & & & \\
\hline 101 & Barcelona & Spain & BCN & 1.933 & 1 & & & & & \\
\hline 102 & Bilbao & Spain & BIO & 1.866 & 1 & & & & & \\
\hline 103 & Gijón & Spain & GIJ & 1.965 & 1 & & & & & \\
\hline
\end{tabular}




\subsection{APPENDIX D}

options center;

$\%$ let Dataset= WORK.SAS CLUSTER ANALYSIS;

$\%$ let Variables $=\mathrm{CO} 2$ s ICT_s;

$\%$ let Algorithm=ward;

$\%$ let NClus=4;

$\%$ let ID=Cities;

Title 'Hierarchical Cluster Analysis';

Data CA Input Table;

Set \&Dataset;

Run;

PROC CLUSTER SIMPLE NOEIGEN RMSSTD RSQUARE NOTIE NONORM /*STANDARD*/ METHOD=\&Algorithm OUT $=$ HCA Tree \&Algorithm;

ID \&ID;

VAR \&Variables;

Run;

PROC TREE DATA=HCA Tree \&Algorithm OUT=HCA \&Algorithm NCLUSTERs=\&NCLUS;

ID \&ID;

COPY \&Variables;

RUN;

/* Hierarchical Cluster Analysis */

PROC SORT;

BY CLUSTER;

PROC PRINT;

BY CLUSTER;

VAR \&ID \&Variables;

Run;

Proc means data=HCA_\&Algorithm mean nway;

Var \&Variables;

by cluster;

output out=Initial_Seeds (LABEL="Initial Seeds") mean=;

RUN;

/* Initial Seeds Extraction */

Data CA_Input_Table;

Set \&Dataset;

Run;

Title 'Kmeans - Initial Seeds from \&Algorithm';

Data Initial_Seeds ;

SET Initial_Seeds ;

RUN;

Data kMeans_Input_Table;

Set \&Dataset;

RUN;

Proc Fastclus SEED=Initial_Seeds MAXCLUSTERS=\&NCLUS OUT=KMeans_Results MAXITER=50 REPLACE=NONE; ID \&ID;

Var \&Variables;

PROC SORT;

BY CLUSTER;

PROC PRINT;

BY CLUSTER;

VAR \&ID \&Variables;

Run;

Proc means data=KMeans Results N MEAN MEDIAN MODE MIN MAX STD VAR NWAY P10 P90;

Var \&Variables;

by cluster;

output out=KMeans_Statistics mean=;

RUN;

/*K-MEANS FROM HIERARCHICAL INITIAL SEEDS */ 


\subsection{Appendix E}

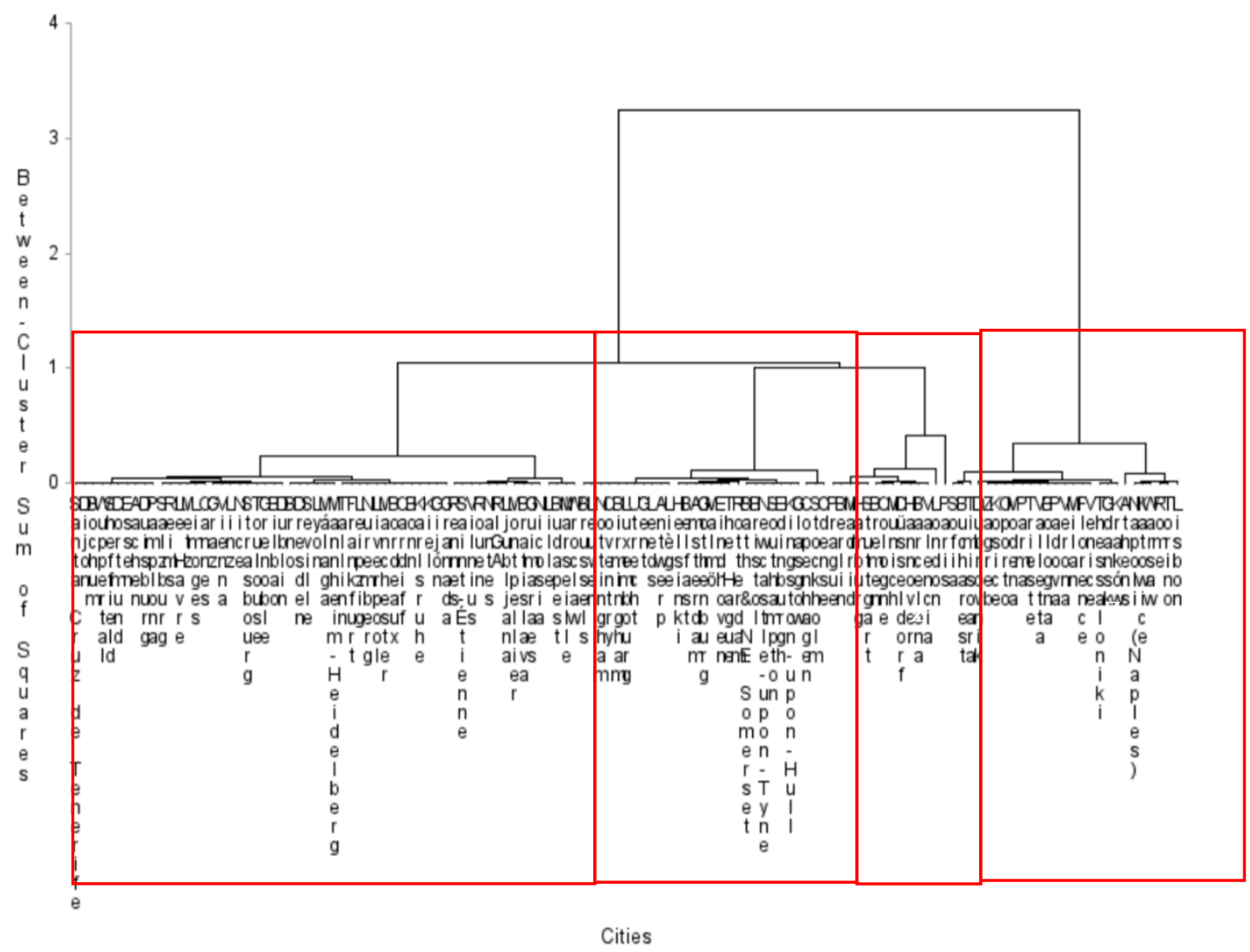

\subsection{APPENDIX}

\begin{tabular}{|c|c|c|}
\hline Literature & Original variable name & New variable name \\
\hline $\begin{array}{l}\text { (Amirkiaee \& Evangelopoulos, } \\
\text { 2018) }\end{array}$ & Attitude towards ridesharing & Attitude \\
\hline (Y. G. Kim et al., 2018) & Attitude towards behavior & \\
\hline (Lindblom et al., 2018) & Collaborative consumption attitude & \\
\hline
\end{tabular}




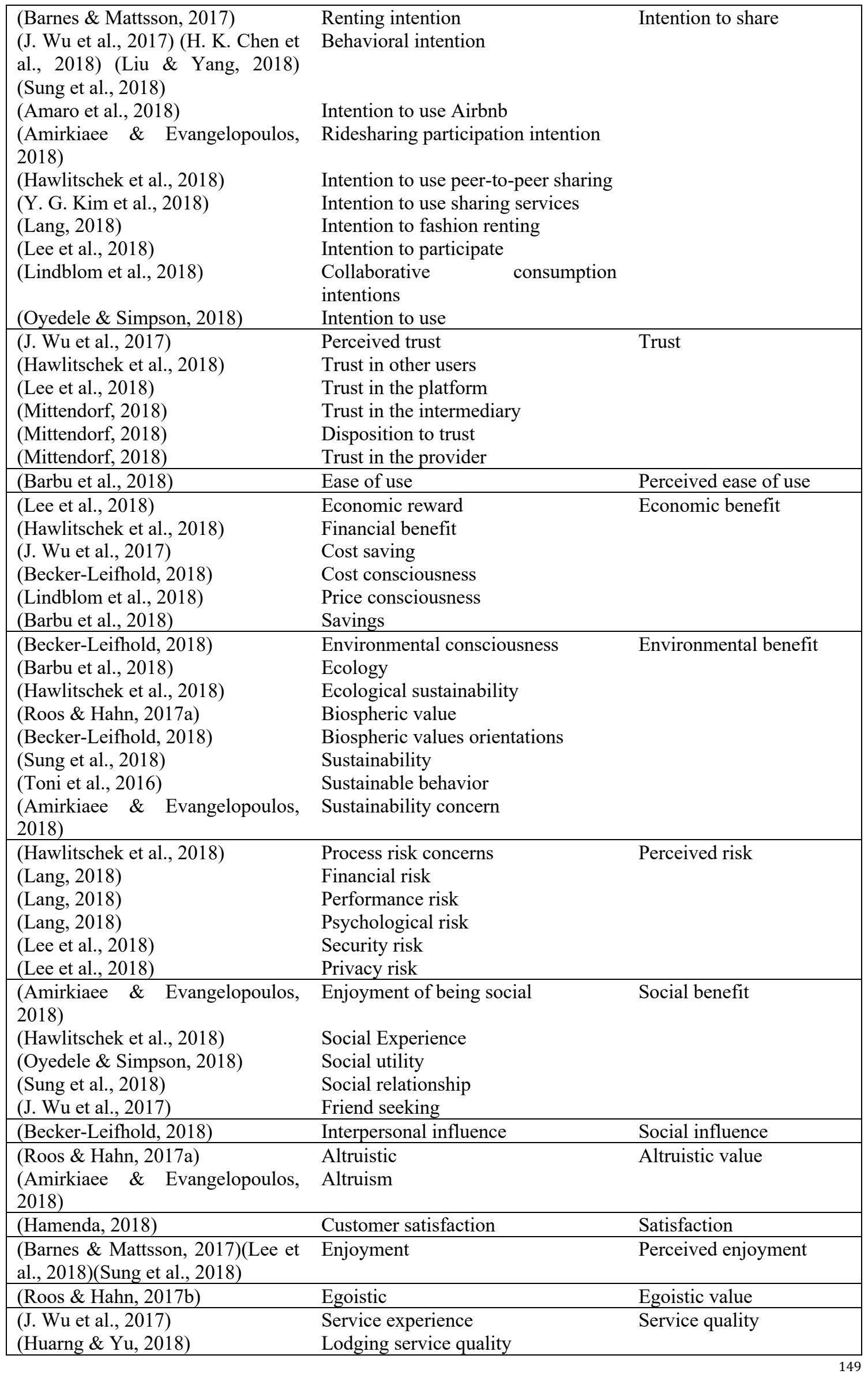




\subsection{APPENDIX A}

\begin{tabular}{|c|c|c|c|c|c|}
\hline Indicator & & Topic & $\begin{array}{l}\text { Thematic } \\
\text { Area }\end{array}$ & Interpretation & Description of role \\
\hline $\begin{array}{l}\text { Household level of } \\
\text { internet access (\%) }\end{array}$ & V1 & Infrastructure & Economy & $\begin{array}{l}\text { Number of households with internet } \\
\frac{\text { access }}{\text { Total number of households }} * 100\end{array}$ & $\begin{array}{l}\text { The internet plays } \\
\text { a positive role in } \\
\text { the economic } \\
\text { growth of a city } \\
\text { which is a key } \\
\text { determinant of } \\
\text { how smart and } \\
\text { sustainable a city } \\
\text { is (Choi \& Hoon } \\
\text { Yi, 2009). Data on } \\
\text { this indicator is } \\
\text { widely available } \\
\text { with relative long } \\
\text { time series. }\end{array}$ \\
\hline $\begin{array}{l}\text { Total Research and } \\
\text { Development } \\
\text { (R\&D) } \\
\text { appropriations } \\
\text { (Euro per } \\
\text { inhabitant) }\end{array}$ & V2 & Innovation & Economy & $\frac{\text { Total R\&D appropriations }}{\text { Total population of the city }}$ & $\begin{array}{l}\text { The amount of } \\
\text { money being } \\
\text { funnelled into } \\
\text { research and } \\
\text { development is a } \\
\text { key indicator of } \\
\text { commercial and } \\
\text { technological }\end{array}$ \\
\hline
\end{tabular}




\begin{tabular}{|c|c|c|c|c|c|}
\hline & & & & & innovation. \\
\hline $\begin{array}{l}\text { Patent applications } \\
\text { to the European } \\
\text { Patent Office (EPO) } \\
\text { per million of active } \\
\text { population }\end{array}$ & V3 & Innovation & Economy & $\frac{\text { Number of new patent application }}{\text { One millionth of the city's total population }}$ & $\begin{array}{l}\text { This indicator } \\
\text { shows how active } \\
\text { the research } \\
\text { community is. } \\
\text { Research spurs } \\
\text { innovation which } \\
\text { has a positive } \\
\text { effect on the } \\
\text { economy }\end{array}$ \\
\hline $\begin{array}{l}\text { Persons employed } \\
\text { between the ages of } \\
20 \text { and } 64(\%)\end{array}$ & V4 & Employment & Economy & $\begin{array}{l}\text { Number of persons between } 20 \text { and } 64 \\
\text { years of age emplyed } \\
\frac{\text { Total number of population between }}{20 \text { and } 64 \text { years of age }}\end{array}$ & $\begin{array}{l}\text { This indicator } \\
\text { shows how } \\
\text { engaged the } \\
\text { economically } \\
\text { active population } \\
\text { of a city is. It also } \\
\text { reflects the } \\
\text { economic health of } \\
\text { the city and how } \\
\text { successful its } \\
\text { economic policy is } \\
\text { (ISO, 2014b). }\end{array}$ \\
\hline $\begin{array}{l}\text { E-commerce, } \\
\text { Customer Relation } \\
\text { Management } \\
(\mathrm{CRM}) \text {, and secure } \\
\text { transactions }(\%)\end{array}$ & V5 & ICT / Trade & Economy & $\begin{array}{l}\text { Enterprises that receive orders via } \\
\frac{\text { computer mediated networks }}{\text { Total number of enterprises }} * 100\end{array}$ & $\begin{array}{l}\text { This is variable } \\
\text { indicates the } \\
\text { volume of "smart- } \\
\text { trade" occurring in } \\
\text { a city which in } \\
\text { turn helps to shape } \\
\text { the economy of }\end{array}$ \\
\hline
\end{tabular}




\begin{tabular}{|c|c|c|c|c|c|}
\hline & & & & & that city. \\
\hline $\begin{array}{l}\text { Share of journeys to } \\
\text { work by public } \\
\text { transport (rail, } \\
\text { metro, bus, tram) } \\
(\%)\end{array}$ & V6 & Infrastructure & Economy & 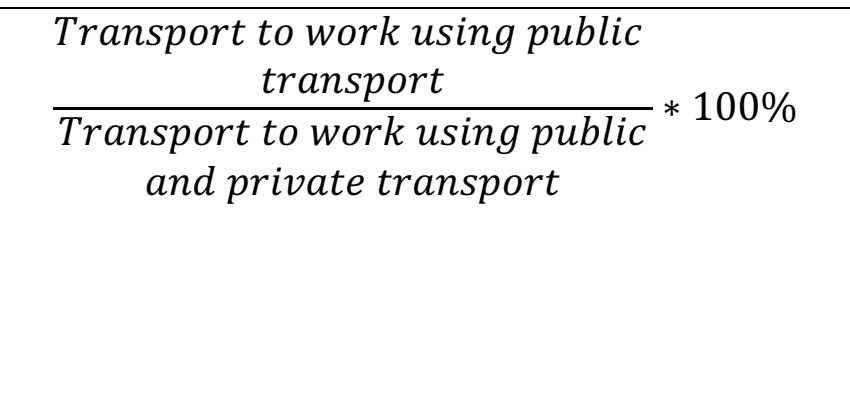 & $\begin{array}{l}\text { This indicator } \\
\text { reflects how strong } \\
\text { the sharing } \\
\text { economy is and } \\
\text { shows of how } \\
\text { diverse the } \\
\text { transportation } \\
\text { system in a city is. }\end{array}$ \\
\hline $\begin{array}{l}\text { Length of bicycle } \\
\text { network (dedicated } \\
\text { cycle paths and } \\
\text { lanes) }(\mathrm{km})\end{array}$ & V7 & Infrastructure & Economy & $\sum$ Length of dedicated bicylce paths & $\begin{array}{l}\text { Extensive bicycle } \\
\text { paths help to } \\
\text { reduce traffic } \\
\text { congestion and } \\
\text { contributes to } \\
\text { better quality } \\
\text { within cities. } \\
\text { Economic benefits } \\
\text { include reduced } \\
\text { health care costs } \\
\text { and reduced } \\
\text { expenditure on } \\
\text { fossil fuel (ISO, } \\
\text { 2014b). }\end{array}$ \\
\hline $\begin{array}{l}\text { Number of days } \\
\text { particulate matter } \\
\text { PM10 } \\
\text { concentrations } \\
\text { exceed } 50 \mu \mathrm{g} / \mathrm{m}^{3}\end{array}$ & V8 & Air quality & Environment & $\sum \begin{array}{c}\text { Days where PM10 concentration exceeds } \\
50 \mu \mathrm{g} / \mathrm{m} 3\end{array}$ & $\begin{array}{l}\text { This is a measure } \\
\text { of the long-term } \\
\text { exposure to PM10. } \\
\text { High particle } \\
\text { levels exposure } \\
\text { has been linked }\end{array}$ \\
\hline
\end{tabular}




\begin{tabular}{|c|c|c|c|c|c|}
\hline & & & & & $\begin{array}{l}\text { with the } \\
\text { development of } \\
\text { chronic bronchitis } \\
\text { and premature } \\
\text { deaths in babies. } \\
\text { Beyond } \\
\text { environmental } \\
\text { implications, this } \\
\text { indicator also has } \\
\text { economic impact } \\
\text { on businesses as it } \\
\text { reduces foreign } \\
\text { investment. }\end{array}$ \\
\hline $\begin{array}{l}\text { Annual average } \\
\text { concentration } \\
\text { of } \mathrm{NO}_{2}\left(\mu \mathrm{g} / \mathrm{m}^{3}\right)\end{array}$ & V9 & Air quality & Environment & $\frac{\text { NO2 Daily Concentration }}{365}$ & $\begin{array}{l}\text { Nitrogen Dioxide } \\
\left(\mathrm{NO}_{2}\right) \text { is a key } \\
\text { indicator of air } \\
\text { quality with } \\
\text { significant } \\
\text { implication on } \\
\text { human health and } \\
\text { the environment. } \\
\text { Specifically, it } \\
\text { contributes to the } \\
\text { formation of acidic } \\
\text { rain which } \\
\text { adversely affects } \\
\text { biodiversity and } \\
\text { the formation of } \\
\text { photochemical }\end{array}$ \\
\hline
\end{tabular}




\begin{tabular}{|c|c|c|c|c|c|}
\hline & & & & & $\begin{array}{l}\text { smog which leads } \\
\text { to various } \\
\text { respiratory } \\
\text { diseases (ISO, } \\
2014 b \text { ). }\end{array}$ \\
\hline $\begin{array}{l}\text { Greenhouse gas } \\
\text { (GHG) emissions } \\
\text { from transport } \\
\text { (million tonnes) }\end{array}$ & V10 & Air quality & Environment & $\sum \begin{array}{c}G H G(\text { equivalent carbon dioxide units) } \\
\text { generated over a year by transport } \\
\text { activites within a city }\end{array}$ & $\begin{array}{l}\text { GHG are gases in } \\
\text { the atmosphere } \\
\text { that trap heat that } \\
\text { would otherwise } \\
\text { escape back into } \\
\text { space. Hence, } \\
\text { they contribute to } \\
\text { the warming of our } \\
\text { planet and is a key } \\
\text { climate change } \\
\text { indicator. Only } \\
\text { three gases are } \\
\text { relevant in the } \\
\text { context of } \\
\text { transport (Carbon } \\
\text { dioxide, methane } \\
\text { and nitrous oxide) } \\
\text { and these have } \\
\text { been aggregated } \\
\text { according to their } \\
\text { global warming } \\
\text { potentials (ISO, } \\
\text { 2014b). }\end{array}$ \\
\hline
\end{tabular}




\begin{tabular}{|c|c|c|c|c|c|}
\hline $\begin{array}{l}\text { Annual average } \\
\text { concentration of } \\
\text { PM10 }\left(\mu \mathrm{g} / \mathrm{m}^{3}\right)\end{array}$ & V11 & Air quality & Environment & $\begin{array}{c}\text { Total mass of collected particles } \\
>2.5 \mu \mathrm{m} \text { and } \leq 10 \mu \mathrm{m} \\
\text { Volume of air sampled }\end{array}$ & $\begin{array}{l}\text { PM10 is primarily } \\
\text { created by } \\
\text { incomplete } \\
\text { combustion, } \\
\text { automobile } \\
\text { emission, dust and } \\
\text { cooking. PM10 is } \\
\text { a health concern } \\
\text { because they can } \\
\text { be inhaled into the } \\
\text { respiratory system } \\
\text { leading to various } \\
\text { heart and lung } \\
\text { diseases (ISO, } \\
2014 \mathrm{~b} \text {; Janssen et } \\
\text { al., 2011). }\end{array}$ \\
\hline $\begin{array}{l}\text { Share of the urban } \\
\text { waste water load (in } \\
\text { population } \\
\text { equivalents) treated } \\
\text { according to the } \\
\text { applicable standard } \\
(\%)\end{array}$ & V12 & Water & Environment & $\begin{array}{l}\text { Perentage of city's waste water } \\
\text { receiving treatment } \\
\text { Total amount of waste water } \\
\text { and collected produced } \\
\text { in the city }\end{array}$ & $\begin{array}{l}\text { This indicates how } \\
\text { well water is } \\
\text { managed in a city. } \\
\text { Properly managed } \\
\text { and treated water } \\
\text { system helps to } \\
\text { reduce the number } \\
\text { of water-borne } \\
\text { disease, improving } \\
\text { community health. } \\
\text { Treating waste } \\
\text { water to the point } \\
\text { of reuse is also }\end{array}$ \\
\hline
\end{tabular}




\begin{tabular}{|c|c|c|c|c|c|}
\hline & & & & & $\begin{array}{l}\text { good for the } \\
\text { environment (ISO, } \\
\text { 2014b). }\end{array}$ \\
\hline $\begin{array}{l}\text { Proportion of } \\
\text { population living in } \\
\text { households } \\
\text { considering that } \\
\text { they suffer from } \\
\text { noise }(\%)\end{array}$ & V13 & Noise & Environment & $\begin{array}{l}\text { Population who declare that } \\
\frac{\text { they are affected by noise }}{\text { Total population }}\end{array}$ & $\begin{array}{l}\text { Prolonged } \\
\text { exposure to noise } \\
\text { can lead to } \\
\text { physical and } \\
\text { mental health } \\
\text { problems. It is also } \\
\text { a good indicator } \\
\text { for environmental } \\
\text { comfort. }\end{array}$ \\
\hline $\begin{array}{l}\text { Share of solid waste } \\
\text { recycled }(\%)\end{array}$ & V14 & $\begin{array}{l}\text { Environmental } \\
\text { quality }\end{array}$ & Environment & $\begin{array}{l}\text { Total amount of recycled city's } \\
\frac{\text { solid waste }}{\text { Total amount of generated city's }} * 100 \% \\
\text { solid waste }\end{array}$ & $\begin{array}{l}\text { City's often } \\
\text { generate more } \\
\text { waste than they } \\
\text { recycle. Solid } \\
\text { waste has several } \\
\text { implications on the } \\
\text { environment, } \\
\text { public health and } \\
\text { the local economy. } \\
\text { However, its } \\
\text { proper } \\
\text { management } \\
\text { presents an } \\
\text { opportunity to the } \\
\text { circular economy, } \\
\text { generating } \\
\text { recycling micro- }\end{array}$ \\
\hline
\end{tabular}




\begin{tabular}{|c|c|c|c|c|c|}
\hline & & & & & $\begin{array}{l}\text { economies and } \\
\text { feeding into the } \\
\text { alternative energy } \\
\text { stream (ISO, } \\
\text { 2014b). }\end{array}$ \\
\hline $\begin{array}{l}\text { This city is a clean } \\
\text { city: strongly agree } \\
(\%)\end{array}$ & V15 & $\begin{array}{l}\text { Environmental } \\
\text { quality }\end{array}$ & Environment & 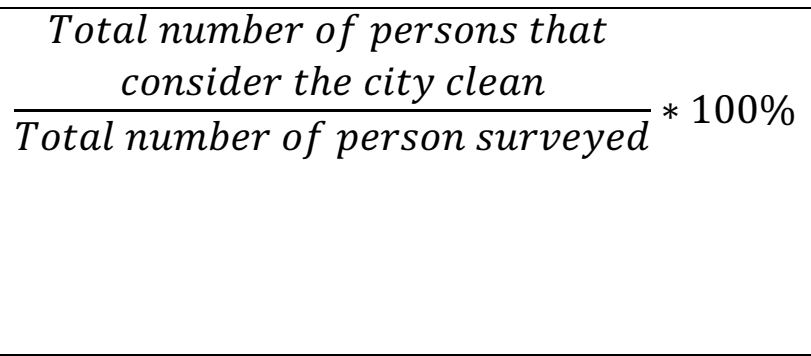 & $\begin{array}{l}\text { This is obtained as } \\
\text { a result of a } \\
\text { perception survey. } \\
\text { The cleanliness of } \\
\text { a city improves the } \\
\text { quality of life of } \\
\text { citizens. }\end{array}$ \\
\hline $\begin{array}{l}\text { Share of land } \\
\text { dedicated to green } \\
\text { urban areas, sports, } \\
\text { and leisure facilities } \\
(\%)\end{array}$ & V16 & $\begin{array}{l}\text { Environmental } \\
\text { quality }\end{array}$ & Environment & 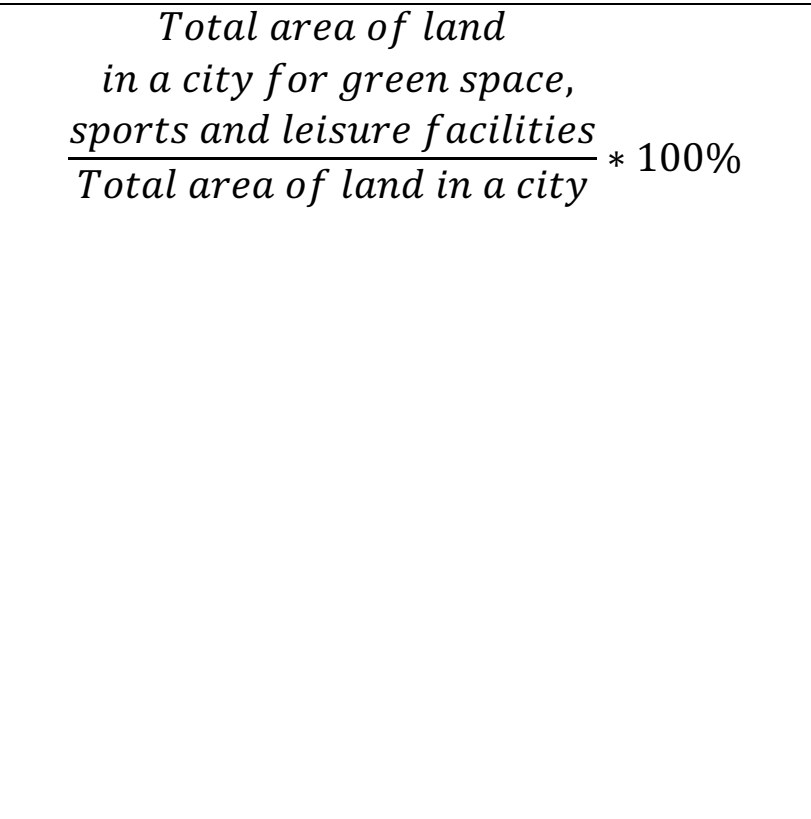 & $\begin{array}{l}\text { Green spaces, } \\
\text { sports and leisure } \\
\text { facilities play } \\
\text { important roles in } \\
\text { the environment } \\
\text { and the social } \\
\text { fabric of a city. } \\
\text { Green spaces help } \\
\text { to capture } \\
\text { atmospheric } \\
\text { pollutants. Sports } \\
\text { and leisure } \\
\text { facilities serve as } \\
\text { recreational } \\
\text { facilities } \\
\text { improving the } \\
\text { quality of life of }\end{array}$ \\
\hline
\end{tabular}




\begin{tabular}{|c|c|c|c|c|c|}
\hline & & & & & $\begin{array}{l}\text { citizens (ISO, } \\
\text { 2014b). }\end{array}$ \\
\hline $\begin{array}{l}\text { Protected terrestrial } \\
\text { area }(\%)\end{array}$ & V17 & Biodiversity & Environment & 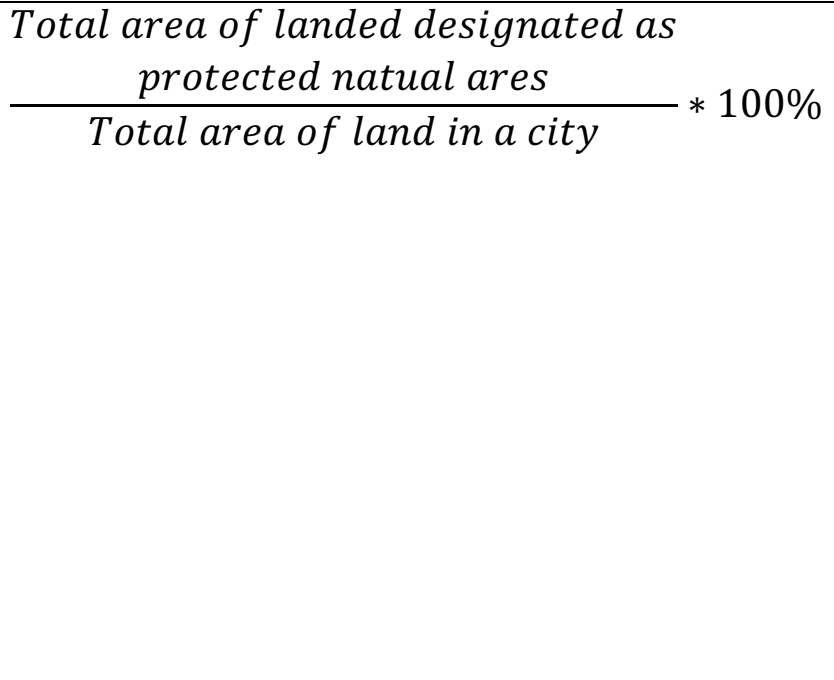 & $\begin{array}{l}\text { This indicator is } \\
\text { important because } \\
\text { urbanization } \\
\text { negatively affects } \\
\text { biodiversity } \\
\text { through urban } \\
\text { sprawl and the } \\
\text { spread of non- } \\
\text { native species } \\
\text { (ISO, 2014b). This } \\
\text { in turn threatens } \\
\text { the ecological } \\
\text { balance of our } \\
\text { planet }\end{array}$ \\
\hline $\begin{array}{l}\text { Share of renewable } \\
\text { energy in gross } \\
\text { final energy } \\
\text { consumption }(\%)\end{array}$ & V18 & Energy & Environment & $\begin{array}{l}\text { Total consumption of electricity } \\
\text { generated from renewable sources } \\
\text { Total energy consumption }\end{array}$ & $\begin{array}{l}\text { Sustainable urban } \\
\text { development } \\
\text { requires a shift } \\
\text { from fossil-based } \\
\text { energy sources to } \\
\text { renewable energy } \\
\text { sources. Hence, } \\
\text { this indicator is } \\
\text { important for } \\
\text { environmental } \\
\text { protection. }\end{array}$ \\
\hline
\end{tabular}




\begin{tabular}{|c|c|c|c|c|c|}
\hline $\begin{array}{l}\text { Electricity } \\
\text { generated from } \\
\text { renewable sources } \\
(\%)\end{array}$ & V19 & Energy & Environment & 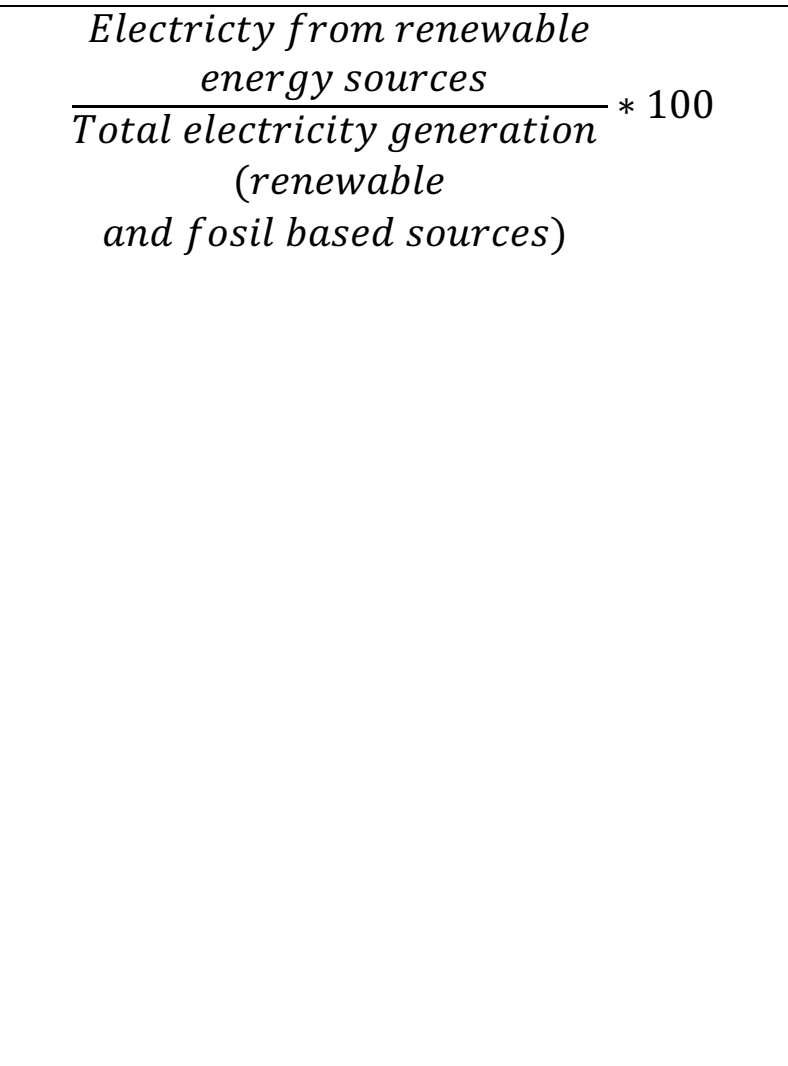 & $\begin{array}{l}\text { Electricity } \\
\text { produced from } \\
\text { renewable energy } \\
\text { sources comprises } \\
\text { the electricity } \\
\text { generation from } \\
\text { hydro plants, } \\
\text { wind, solar, } \\
\text { geothermal and } \\
\text { biomass/wastes. It } \\
\text { indicates growth in } \\
\text { the use of } \\
\text { sustainable energy } \\
\text { sources. It is a core } \\
\text { UNEP (United } \\
\text { Nations } \\
\text { Environment } \\
\text { Programme) } \\
\text { indicator and } \\
\text { considered to be } \\
\text { reliable (OECD, } \\
\text { 2009). }\end{array}$ \\
\hline $\begin{array}{l}\text { Persons aged } 25-64 \\
\text { with ISCED level } 5 \text {, } \\
6,7 \text {, or } 8 \text { as the } \\
\text { highest level of } \\
\text { education }(\%)\end{array}$ & V20 & Education & $\begin{array}{l}\text { Society and } \\
\text { Culture }\end{array}$ & $\begin{array}{l}\text { Number of persons aged } 25-64 \\
\text { with ISCED level } \\
\frac{5,6,7 \text { or } 8 \text { as the highest education }}{\text { Total number of persons }} * 100 \\
\text { aged } 25-64\end{array}$ & $\begin{array}{l}\text { Wide spread } \\
\text { education is an } \\
\text { important } \\
\text { component of } \\
\text { sustainable human } \\
\text { development } \\
\text { (UNESCO, 2018). }\end{array}$ \\
\hline
\end{tabular}




\begin{tabular}{|c|c|c|c|c|c|}
\hline & & & & & $\begin{array}{l}\text { This indicator } \\
\text { measures the } \\
\text { pervasiveness of } \\
\text { tertiary education } \\
\text { among the citizens } \\
\text { in cities }\end{array}$ \\
\hline $\begin{array}{l}\text { Share of students in } \\
\text { higher education in } \\
\text { the total population } \\
\text { (per } 1000 \text { persons) } \\
(\%)\end{array}$ & V21 & Education & $\begin{array}{l}\text { Society and } \\
\text { Culture }\end{array}$ & $\begin{array}{l}\text { Number of citizens holding higher } \\
\text { education degrees } \\
\text { one } 1000 \text { th of the city's } \\
\text { total population }\end{array}$ & $\begin{array}{l}\text { Education is one } \\
\text { of the main } \\
\text { opportunities for } \\
\text { social class } \\
\text { mobility. Hence, it } \\
\text { is a primary } \\
\text { indicator for } \\
\text { economic } \\
\text { development and } \\
\text { quality of life } \\
\text { (ISO, 2014b). }\end{array}$ \\
\hline $\begin{array}{l}\text { Infant mortality rate } \\
\text { (per } 1000 \text { live } \\
\text { births) }\end{array}$ & V22 & Health & $\begin{array}{l}\text { Society and } \\
\text { Culture }\end{array}$ & $\begin{array}{c}\text { Number of infants that die } \\
\text { before the age of } 5 \text { in a year } \\
\text { Every } 1000 \text { live births in same year }\end{array}$ & $\begin{array}{l}\text { Infant mortality } \\
\text { rate is a leading } \\
\text { indicator of the } \\
\text { level of child } \\
\text { health and the } \\
\text { socioeconomic } \\
\text { development of a } \\
\text { city (United } \\
\text { Nations, 2014). }\end{array}$ \\
\hline $\begin{array}{l}\text { Share of total } \\
\text { deaths per year }(\%)\end{array}$ & V23 & Health & $\begin{array}{l}\text { Society and } \\
\text { Culture }\end{array}$ & $\begin{array}{l}\text { Number of deaths from } \\
\frac{\text { medical cause }}{\text { Total number of deaths }} * 100\end{array}$ & $\begin{array}{l}\text { This is a primary } \\
\text { indicator of the } \\
\text { state of health care }\end{array}$ \\
\hline
\end{tabular}




\begin{tabular}{|c|c|c|c|c|c|}
\hline & & & & & in a city \\
\hline $\begin{array}{l}\text { Index of the number } \\
\text { of serious accidents } \\
\text { at work per } 100,000 \\
\text { persons in } \\
\text { employment }\end{array}$ & V24 & Safety & $\begin{array}{l}\text { Society and } \\
\text { Culture }\end{array}$ & $\begin{array}{l}\text { Number of persons involved } \\
\frac{\text { in accidents }}{\text { Number of persons in employment }} * 100 \%\end{array}$ & $\begin{array}{l}\text { This is a primary } \\
\text { indicator of health } \\
\text { and safety at work. } \\
\text { The data refers to } \\
\text { accidents at work } \\
\text { resulting in more } \\
\text { than } 3 \text { days' } \\
\text { absence from } \\
\text { work. }\end{array}$ \\
\hline $\begin{array}{l}\text { share of murders } \\
\text { and violent deaths } \\
(\%)\end{array}$ & V25 & Safety & $\begin{array}{l}\text { Society and } \\
\text { Culture }\end{array}$ & $\begin{array}{l}\text { Number of reported murders } \\
\frac{\text { and violent deaths }}{\text { Total number of persons in city }}\end{array}$ & $\begin{array}{l}\text { This is an indicator } \\
\text { for the number of } \\
\text { crimes in a city } \\
\text { which can affect } \\
\text { the feeling of } \\
\text { safety by citizens } \\
\text { (ISO, 2014b). }\end{array}$ \\
\hline $\begin{array}{l}\text { Children accessing } \\
\text { inappropriate web- } \\
\text { sites }(\%)\end{array}$ & V26 & Safety & $\begin{array}{l}\text { Society and } \\
\text { Culture }\end{array}$ & $\begin{array}{l}\text { Number of children accessing } \\
\frac{\text { inappropriate websites }}{\text { Total number of children }} * 100\end{array}$ & $\begin{array}{l}\text { This is an indicator } \\
\text { of the safety of } \\
\text { children in the } \\
\text { information age. } \\
\text { Accessing } \\
\text { inappropriate sites } \\
\text { can lead to } \\
\text { unlawful and } \\
\text { dangerous } \\
\text { behaviours which } \\
\text { can cause a } \\
\text { breakdown in the }\end{array}$ \\
\hline
\end{tabular}




\begin{tabular}{|c|c|c|c|c|c|}
\hline & & & & & society. \\
\hline $\begin{array}{l}\text { Severe housing } \\
\text { deprivation rate by } \\
\text { tenure status }(\%)\end{array}$ & V27 & Housing & $\begin{array}{l}\text { Society and } \\
\text { Culture }\end{array}$ & $\begin{array}{l}\text { Number of houses that exist } \\
\frac{\text { without registered titles }}{\text { Total number of households }} * 100\end{array}$ & $\begin{array}{l}\text { This is an } \\
\text { important indicator } \\
\text { for housing } \\
\text { security for city } \\
\text { residents. This can } \\
\text { also serve as a } \\
\text { secondary } \\
\text { indicator for } \\
\text { identifying formal } \\
\text { parts of the city } \\
\text { from the less } \\
\text { formal parts (ISO, } \\
\text { 2014b). }\end{array}$ \\
\hline $\begin{array}{l}\text { Number of public } \\
\text { libraries (all } \\
\text { distribution points) }\end{array}$ & V28 & Culture & $\begin{array}{l}\text { Society and } \\
\text { Culture }\end{array}$ & A count of the number of public libraries in a city & $\begin{array}{l}\text { This indicates the } \\
\text { amount of public } \\
\text { access to } \\
\text { information. } \\
\text { Libraries also } \\
\text { serve as a neutral } \\
\text { space for } \\
\text { community } \\
\text { engagement and } \\
\text { recreational } \\
\text { activity. Hence } \\
\text { they are very } \\
\text { important for } \\
\text { social inclusion } \\
\text { and development. }\end{array}$ \\
\hline
\end{tabular}




\begin{tabular}{|c|c|c|c|c|c|}
\hline Number of theatres & V29 & Culture & $\begin{array}{l}\text { Society and } \\
\text { Culture }\end{array}$ & A count of the number of theatres in a city & $\begin{array}{l}\text { Theatres are very } \\
\text { important to the } \\
\text { social and cultural } \\
\text { fabric of any city. } \\
\text { This is because the } \\
\text { participation of } \\
\text { people in local } \\
\text { cultural activates } \\
\text { improves their } \\
\text { quality of life } \\
\text { (Duxbury, } \\
\text { Hosagrahar, \& } \\
\text { Pascual, 2016). }\end{array}$ \\
\hline $\begin{array}{l}\text { Gender pay gap in } \\
\text { unadjusted form } \\
(\%)\end{array}$ & V30 & Inclusion & $\begin{array}{l}\text { Society and } \\
\text { Culture }\end{array}$ & 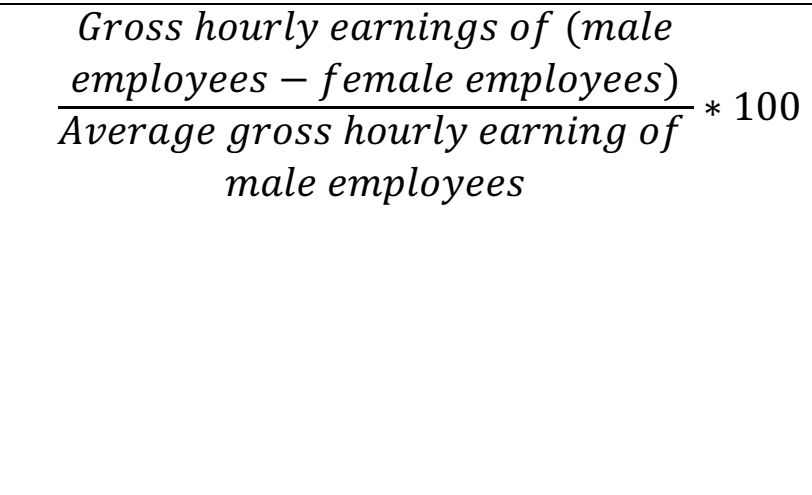 & $\begin{array}{l}\text { This indicator is } \\
\text { key to the United } \\
\text { Nations } 5^{\text {th }} \\
\text { Sustainable } \\
\text { Development } \\
\text { Goals (SDG) - } \\
\text { Achieve gender } \\
\text { equality and } \\
\text { empower all } \\
\text { women and girls. }\end{array}$ \\
\hline $\begin{array}{l}\text { Voter turnout in } \\
\text { national and EU } \\
\text { parliamentary } \\
\text { elections }(\%)\end{array}$ & V31 & Inclusion & $\begin{array}{l}\text { Society and } \\
\text { Culture }\end{array}$ & $\begin{array}{l}\text { Number of persons that voted in } \\
\frac{\text { national and EU elections }}{\text { City population eligible to vote }}\end{array} * 100$ & $\begin{array}{l}\text { The electorate } \\
\text { turn-out at } \\
\text { elections is an } \\
\text { indicator of the } \\
\text { public } \\
\text { participation and }\end{array}$ \\
\hline
\end{tabular}




\begin{tabular}{|c|c|c|c|c|c|}
\hline & & & & & $\begin{array}{l}\text { interest in policy } \\
\text { formulation and } \\
\text { community } \\
\text { development (ISO, } \\
\text { 2014b). }\end{array}$ \\
\hline $\begin{array}{l}\text { Gini coefficient of } \\
\text { equivalized } \\
\text { disposable income } \\
(\%)\end{array}$ & V32 & Inclusion & $\begin{array}{l}\text { Society and } \\
\text { Culture }\end{array}$ & $\begin{array}{l}\text { "This is calculated by plotting the cumulative } \\
\text { income share on the vertical axis against the } \\
\text { distribution of the population on the horizontal } \\
\text { axis, thus obtaining a so-called Lorenz curve. } \\
\text { The Gini coefficient is then calculated as the area } \\
\text { under the curve divided by the area under the } \\
\text { Lorenz curve of an equal distribution of income" } \\
\text { (Feldmann, 2008) }\end{array}$ & $\begin{array}{l}\text { This is an indicator } \\
\text { of income equality } \\
\text { distribution within } \\
\text { a city. This is } \\
\text { related to societal } \\
\text { sustainability as } \\
\text { income inequality } \\
\text { leads to a rise in } \\
\text { social vices such } \\
\text { as robbery, } \\
\text { homicide and } \\
\text { imprisonment } \\
\text { (Little \& Green, } \\
\text { 2009). }\end{array}$ \\
\hline
\end{tabular}




\subsection{APPENDIX B}

Procedure to obtain the score of each capital city from a Principal Component Analysis with previous 15 selected variables

Let $S_{i}$ be the final score attributed to each city $i(I=1,2,3, \ldots \ldots, 28)$

$$
S_{i}=\sum_{k=1}^{4} \alpha_{k} \gamma_{i}^{k}
$$

with

$$
\alpha_{k}=\frac{\lambda_{k}}{\sum_{k=1}^{4} \lambda_{k}}
$$

Eq. (B.2)

where $\lambda_{\mathrm{k}}$ is the k-eigenvalue of the variance and covariance matrix $V=\frac{1}{28} \sum_{i=1}^{28} \underline{x}_{i}{ }^{t} \underline{x}_{i}$ with $\underline{x}_{i}$ being the 15 -dimensional vector describing city i after data normalization. So, $\sum_{k=1}^{4} \lambda_{k}$ is the total inertia explained by the first four axes.

Also, $\gamma_{i}^{k}$ is the coordinate of city $\mathrm{i}$ on axis $\mathrm{k}$ generated by the unit eigenvector $\underline{\mu}_{\mathrm{k}}$ given by:

$$
\gamma_{i}^{k}=<\underline{x}_{i}, \underline{\mu}_{k}>={ }^{t} \underline{x}_{i} \underline{\mu}_{k}
$$

So,

$$
\gamma_{i}^{k}=\sum_{j=1}^{15} x_{i}^{j} \mu_{k}^{j}
$$

and

$$
\begin{aligned}
& S_{i}=\sum_{k=1}^{4} \alpha_{k}\left(\sum_{j=1}^{15} x_{i}^{j} \mu_{k}^{j}\right) \\
& S_{i}=\sum_{j=1}^{15} x_{i}^{j}\left(\sum_{k=1}^{4} \alpha_{k} \mu_{k}^{j}\right)
\end{aligned}
$$

Eq. (B.6)

where $\sum_{k=1}^{4} \alpha_{k} \mu_{k}^{j}$ is the factor score associated with variable $\mathrm{j}$. 


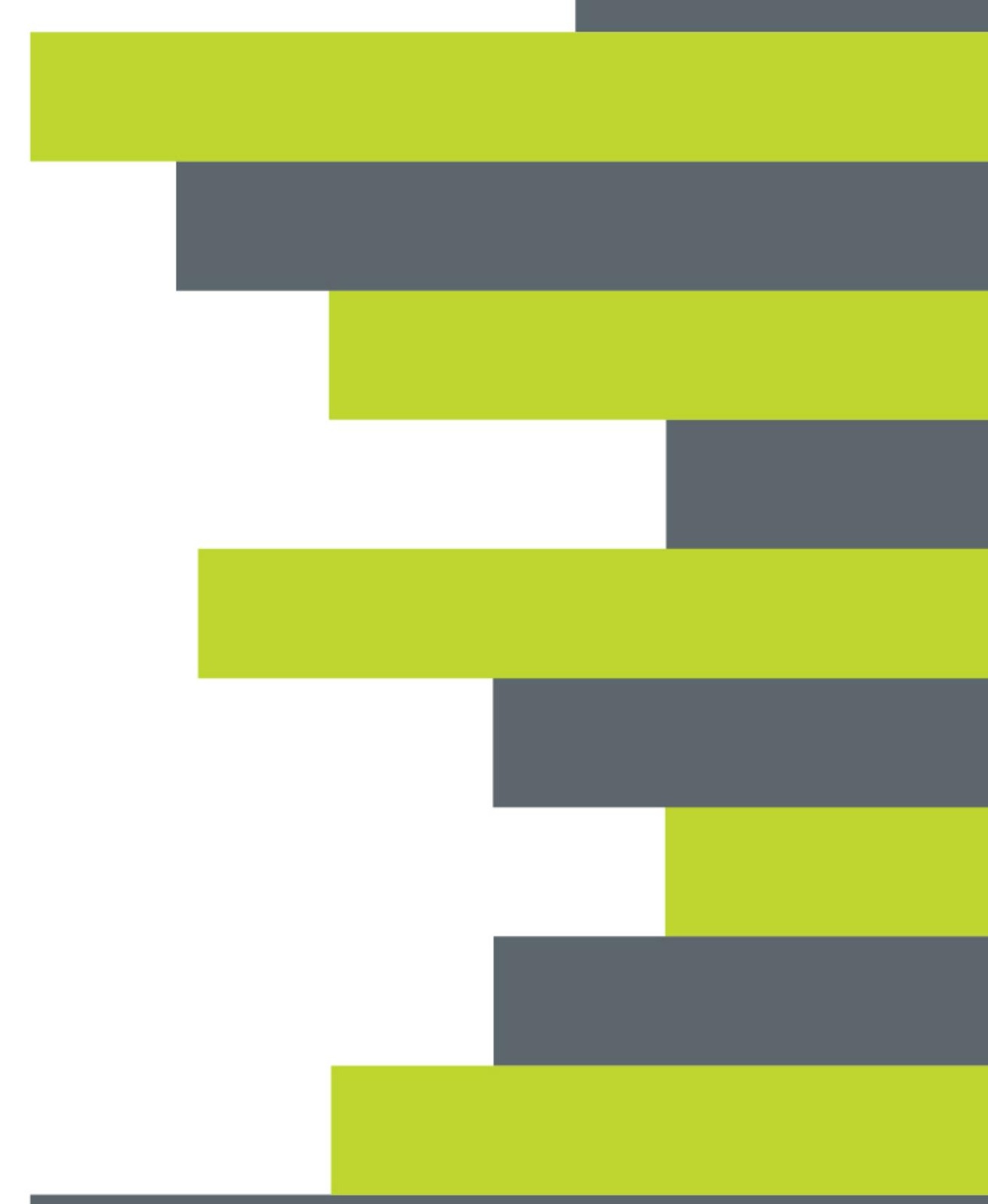

\section{Geo-c}

Joint Doctorate in Geoinformatics: Enabling Open Cities
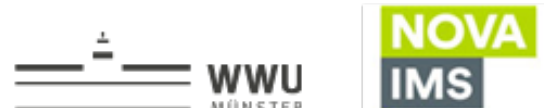
